\title{
Access to Services, Quality of Care, and Family Impact for Caregivers of Children with Autism Spectrum Disorders: A National Perspective Using 2009-2010 Children with Special Health Care Needs (CSHCN) Survey
}

Rini Vohra

West Virginia University

Follow this and additional works at: https://researchrepository.wvu.edu/etd

\author{
Recommended Citation \\ Vohra, Rini, "Access to Services, Quality of Care, and Family Impact for Caregivers of Children with Autism \\ Spectrum Disorders: A National Perspective Using 2009-2010 Children with Special Health Care Needs \\ (CSHCN) Survey" (2013). Graduate Theses, Dissertations, and Problem Reports. 191. \\ https://researchrepository.wvu.edu/etd/191
}

This Thesis is protected by copyright and/or related rights. It has been brought to you by the The Research Repository @ WVU with permission from the rights-holder(s). You are free to use this Thesis in any way that is permitted by the copyright and related rights legislation that applies to your use. For other uses you must obtain permission from the rights-holder(s) directly, unless additional rights are indicated by a Creative Commons license in the record and/ or on the work itself. This Thesis has been accepted for inclusion in WVU Graduate Theses, Dissertations, and Problem Reports collection by an authorized administrator of The Research Repository @ WVU. For more information, please contact researchrepository@mail.wvu.edu. 
Access to Services, Quality of Care, and Family Impact for Caregivers of Children with Autism Spectrum Disorders: A National Perspective Using 2009-2010 Children with Special Health Care Needs (CSHCN) Survey

\author{
Rini Vohra, B.Pharm \\ Thesis submitted to School of Pharmacy at \\ West Virginia University in partial fulfillment of requirements for the degree of \\ Master of Science \\ In \\ Pharmaceutical Sciences
}

Suresh Madhavan, Ph.D., Committee Chair

Usha Sambamoorthi, Ph.D.

Claire StPeter, Ph.D.

Department of Pharmaceutical Systems and Policy

Morgantown, West Virginia

2013

Keywords: Autism, ASD, Access to Services, Quality of Care, Family Burden

CopyRight Rini Vohra 2013 


\section{ABSTRACT \\ Access to Services, Quality of Care, and Family Impact for Caregivers of Children with Autism Spectrum Disorders: A National Perspective Using 2009-2010 Children with Special Health Care Needs (CSHCN) Survey}

\section{Rini Vohra}

\section{PURPOSE}

The main objective of the study was to examine health care disparities for children with autism spectrum disorders utilizing two studies.

Study 1: To examine the caregiver perceived access to services, quality of care, and family impact for children with Autism Spectrum Disorders (ASD), as compared to caregivers of children with other developmental disabilities (DD) and mental health conditions (MHC).

Study 2: To examine the impact of state health policies (Medicaid Income Eligibility and Autism Mandate) and Workforce (Child to Pediatrician Ratio and Number of Special Education Teachers) on perceived access to services and family impact for caregivers of children with ASD.

\section{METHOD}

Study Design: Cross-sectional survey

Data: National Survey of Children with Special Health Care Needs 2009-2010, a nationally representative data for US civilian non-institutionalized population with children aged 0-17 years.

Outcome Measures: Access to care was measured as: difficulty using services, difficulty getting referrals, lack of usual source of care, and inadequate insurance coverage. Quality of care was assessed as problems reported with: care coordination, lack of shared decision making, and no routine screening. Family impact was measured via: financial, employment, and time related burden.

\section{Study 1}

Study sample: All the children in the age group of 3-17 years with a caregiver reported current diagnosis of ASD, DD without ASD, MHC without ASD, or DD \& MHC without ASD were identified $(\mathrm{N}=18,702)$.

Methods: A cross sectional study was conducted using the 2009-2010 National Survey of Children with Special Health Care Needs $(\mathrm{N}=18,702)$. Chi-square analyses and logistic regressions were performed to examine the likelihood of reporting problems with access to services, quality of care, and family impact and compared across ASD, DD (cerebral palsy, down syndrome, developmental delay, or mental retardation), MHC (attention deficit hyperactivity disorder, anxiety, behavioral/conduct problems, or depression) and DD \& MHC (those who had both DD and MHC) group, after adjusting for socio-demographics, number of special children in 
the household, child's functional ability, and presence of a physical condition. All analyses were adjusted for complex survey design.

Results: Access to Services: ASD caregivers were significantly more likely to have difficulty using services as compared to DD, MHC, and DD \& MHC caregivers. ASD caregivers were more likely to report inadequate insurance coverage as compared to MHC, and DD but not DD \& MHC caregivers. Quality of care: ASD caregivers were more likely to report lack of shared decision making, as compared to DD, MHC, and DD \& MHC caregivers. ASD caregivers were also more dissatisfied with care coordination as compared to DD, MHC and DD \& MHC caregivers. Family Impact: ASD caregivers were more likely to have financial burden as compared to DD and MHC, but not DD \& MHC caregivers. ASD caregivers were also found to be more likely to have employment burden, as compared to DD, MHC, and DD \& MHC caregivers. Time-related burden was also significantly different between the four groups, where ASD caregivers were more likely to have time-related burden as compared to MHC, and DD \& MHC caregivers.

Conclusion: ASD caregivers differ significantly in their report of difficulty using services, adequacy of insurance coverage, shared decision making, care coordination, and family impact as compared to DD and MHC caregivers.

\section{Study 2}

Study sample: All the children in the age group of 3-17 years with a caregiver reported current diagnosis of ASD were identified $(\mathrm{N}=3,025)$.

Methods: Data on caregivers of children with ASD was drawn from 2009-2010 National Survey for Children with Special Health Care Needs $(\mathrm{N}=3,025)$ with a representative sample from each state. Two state health policy (Medicaid Income Eligibility \& autism mandate as a proxy measure of states' autism health care initiative) and two state health care workforce (Child to Pediatrician Ratio \& Special Education Teachers per 1,000 Special Education Students) estimates were taken from publicly available sources. Multilevel regressions were used to model the associations between state contextual characteristics and dependent outcome measures, controlling for state median household income, percentage of children in poverty, percentage of children with developmental disorders, child, and caregiver level characteristics.

Results: The caregivers of children with ASD reported difficulty using services $(54.5 \%)$, difficulty getting referrals $(27.7 \%)$, lack of source of care $(18.2 \%)$, inadequate insurance coverage $(31.2 \%)$, financial burden $(54 \%)$, time-related burden $(39.5 \%)$, and employment burden $(35 \%)$. The study had mixed findings from multilevel regression: In general, Medicaid income eligibility threshold of $\leq 100 \%$ FPL was associated with lower likelihood of difficulty getting referrals, reporting lack of source of care, and inadequate insurance coverage. Having an autism mandate in the state was associated with greater odds of reporting difficulty using services, lack of source of care, inadequate insurance coverage, but lower likelihood of reporting financial burden. For the state health care workforce, increase in child to pediatrician ratio was associated with increased likelihood of reporting problems with all measures of access. Increase in special education teachers per 1,000 special education students was associated with lower odds of reporting difficulty using services, time -related and employment burden. 
Conclusion: State Medicaid income eligibility, autism mandate, and state health care workforce are significant predictors of caregiver reported problems with access and impact of the condition on the family. In general, lower Medicaid income eligibility, no autism mandate, greater proportion of pediatricians and special education teachers in a state was associated with lower likelihood of reporting problems with accessing services and adverse family impact. However, due to the mixed nature of the results from this study, caution is warranted in the interpretation and extrapolation of these findings and further studies are required to establish a robust relationship between state contextual characteristics and outcome measures used in the study.

\section{FINAL CONCLUSIONS/IMPLICATIONS}

Issues reported by caregivers of children with ASD exist at both individual and state contextual level. The first study indicated that caregivers of ASD may feel that their child has greater health care needs which are not met with the care been provided through standard developmental disability clinics/centers and greater number of special services' centers focused solely on autism are needed for this group of children, a concern that has been raised by Centers for Medicaid and Medicare as well; and 2) The impact of the condition on the family is significantly different for children with ASD as compared to children with other DDs and MHCs. Even though, the financial burden for ASD caregivers does not significantly differ for caregivers of children with both DD and MHC, time spent in taking care of the child and leaving a job due to child's condition are critical issues for ASD caregivers, which need to be addressed by respite care programs. Our findings have implications for health care providers who are suggested to address the concerns of ASD caregivers and try to communicate better with them. In addition, state policy makers are also needed to address problems in access and quality of care reported by caregivers of children with ASD. Our second study highlighted the role of state level factors that may impact access to services and family burden perceived by the caregivers of children with ASD. It was shown that state contextual characteristics play a significant role in determining the caregiver reported access to services and family impact for children with ASD, above and beyond the child and caregiver characteristics. Even though the study findings were mixed, in general, they indicated that implementation of state health policies may not be sufficient in cases where strength of health care workforce is low.

Collectively this research highlights that accessing services and receiving quality care is still an issue for caregivers of children with ASD, which needs to be addressed by forming ASD centered specialty clinics and health care centers. Also, health care providers should not only focus on treating symptoms of the child with the condition, but also allow parents/caregivers to be equal proponents of their child's health care. State policy makers should also stress on patient centered care and consider building infrastructure such as patient centered medical homes which are designed to provide care from multiple professionals under one roof. 


\section{ACKNOWLEDGEMENTS}

The author of this manuscript would like to thank Dr. Suresh Madhavan, committee chair and advisor, for his constant support and help for the completion of this thesis. Special thanks to Dr. Usha Sambamoorthi and Dr. Claire StPeter for their time and participation as members on my committee. 


\section{TABLE OF CONTENTS}

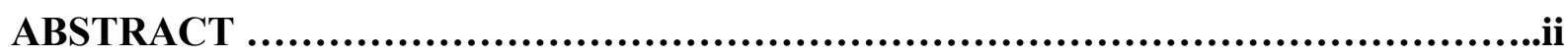

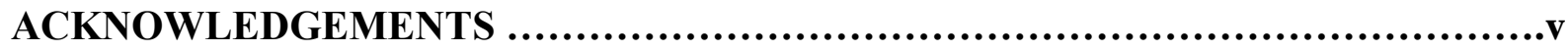

TABLE OF CONTENTS ................................................................vi

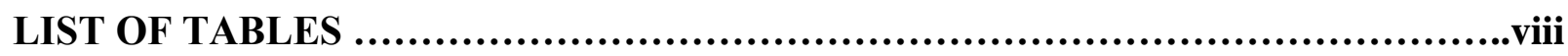

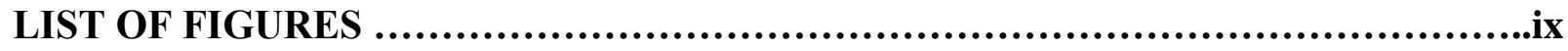

CHAPTER 1 - BACKGROUND \& INTRODUCTION ................................1-2

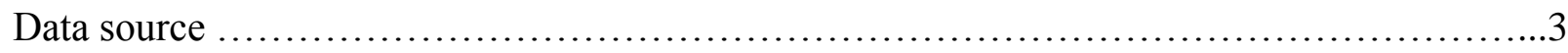

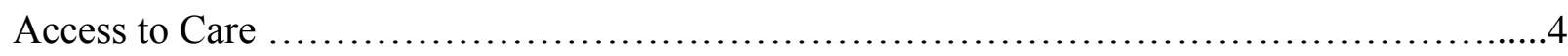

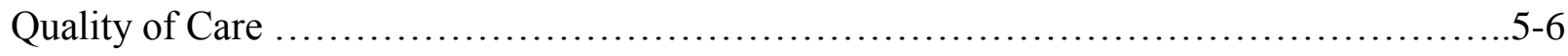

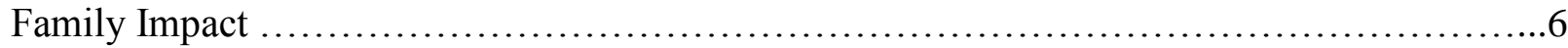

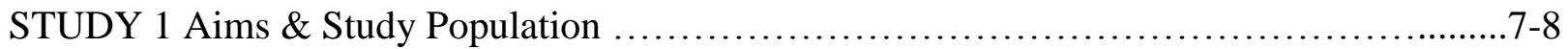

STUDY 1 Significance \& Hypotheses........................................................ 8 -10

STUDY 2 Aims \& Study Population .....................................................

STUDY 2 Significance \& Hypotheses .................................................11-12

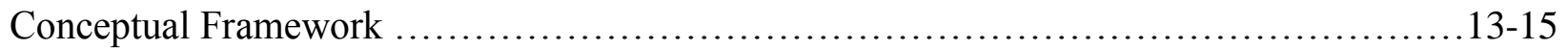

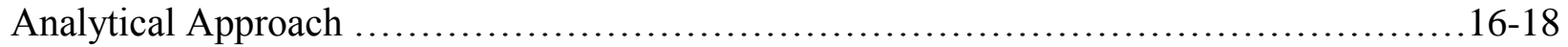

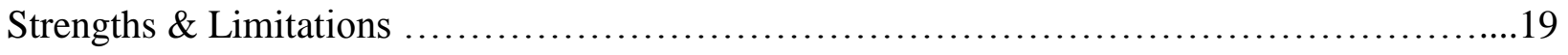

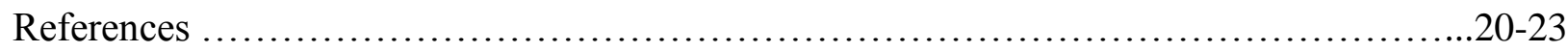

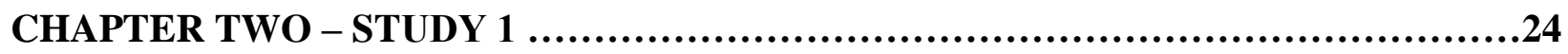

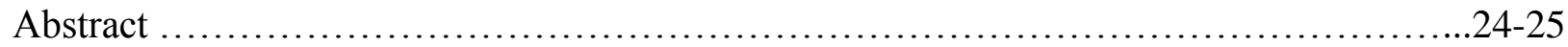

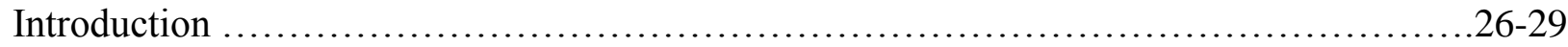

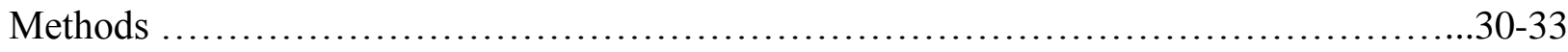

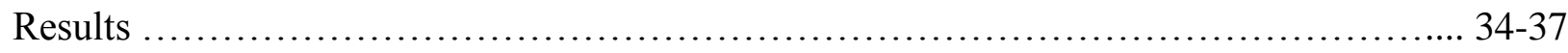

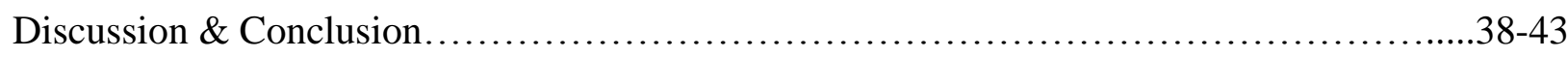

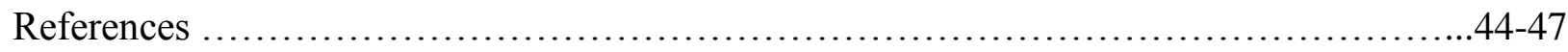

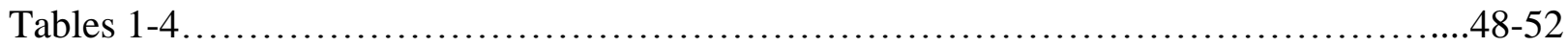




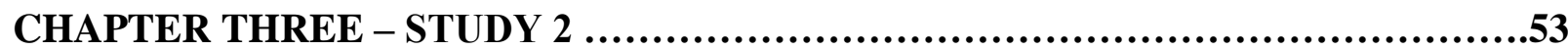

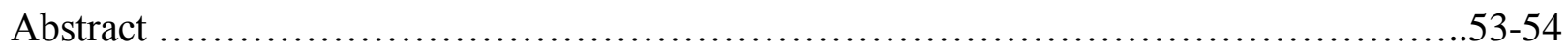

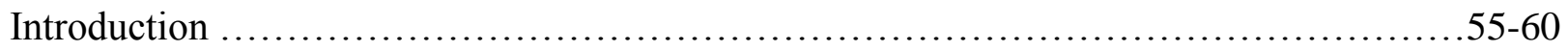

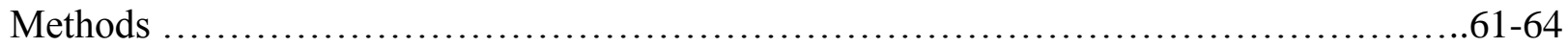

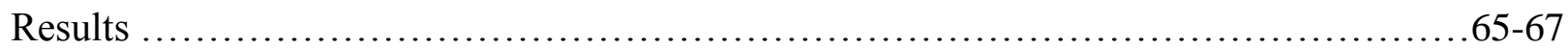

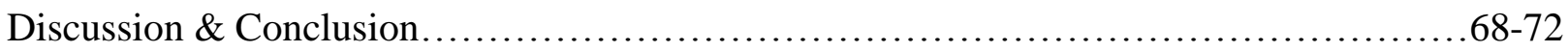

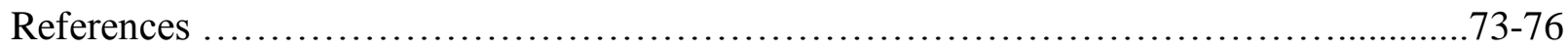

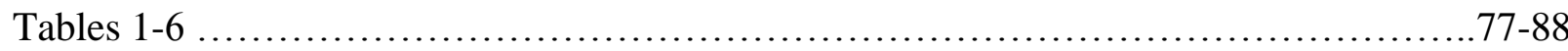

CHAPTER FOUR - EXECUTIVE SUMMARY ............................................

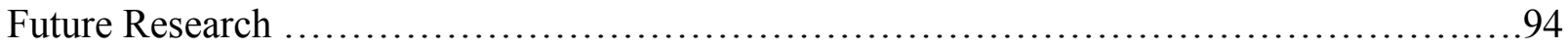

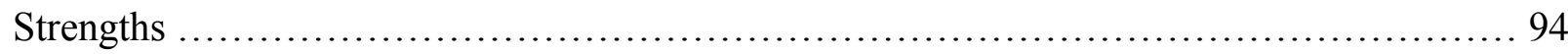

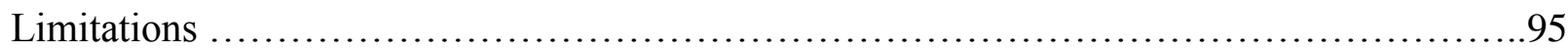

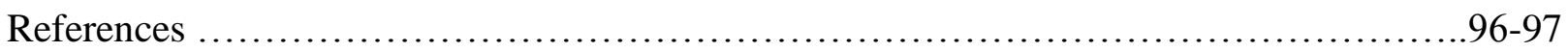




\section{LIST OF TABLES}

STUDY 1_Table 1. Description of Study Sample $(\mathbf{N}=18,702)$ by Type of Special Condition. 48-49

STUDY 1_Table 2. Access to Services, Quality of Care, \& Family Impact measures by type of Special Condition .50

STUDY 1_Table 3. Unadjusted Odds Ratios and 95\% Confidence Intervals from Logistic Regressions on Measures of Access to Services, Quality of Care, and Family

Impact. .51

STUDY 1_Table 4. Adjusted Odds Ratios and 95\% Confidence Intervals from Logistic Regressions on Measures of Access to Services, Quality of Care, and Family Impact. .52

STUDY 2_Table 1. Child, Family and State Characteristics for Children with ASD. Using NS-CSHCN 2009 - 2010 Survey $(N=3,025)$. .77-78

STUDY 2_Table 2. Unadjusted Percentages of Caregivers of Children with ASD who reported problems with Access to Services and Family Impact by State. Using NS-CSHCN 2009- 2010 Survey $(N=3,025)$ 79-80

STUDY 2_Table 3. Multilevel Logistic Regressions of Impact of State Health Policies on Problems with Access to Care Reported By Caregivers of Children with Autism in 50 States and DC. 81-82

STUDY 2_Table 4. Multilevel Logistic Regressions of Impact of State Health Policies on Family Impact Reported By Caregivers of Children with Autism in 50 States and DC .83-84

STUDY 2_Table 5. Multilevel Logistic Regressions of Impact of State Healthcare Workforce on Problems with Access to Services Reported By Caregivers of Children with Autism in 50 States and DC. .85-86

STUDY 2_Table 6. Multilevel Logistic Regressions of Impact of State Healthcare Workforce on Family Impact Reported By Caregivers of Children with Autism in 50 States and DC .87-88 


\section{LIST OF FIGURES}

FIGURE 1. Conceptual Framework based on modified Donabedian Model for quality of care...........................................................................................14

FIGURE 2. Conceptual Framework based on modified Donabedian Model for quality of care including state contextual characteristics.......................................15 


\section{CHAPTER ONE}

\section{BACKGROUND AND INTRODUCTION}

Autism Spectrum Disorders (ASD) are a group of developmental disabilities associated with impaired functioning skills and restricted, repetitive, and stereotyped patterns of behavior (American Psychiatric Association 2000). Prevalence of Autism Spectrum Disorders (ASD) has increased considerably over the past few decades in the Unites States (Autism and Developmental Disabilities Monitoring Network Surveillance Year 2008 Principal Investigators \& Centers for Disease Control and Prevention, 2012) as well as in other countries (Lazoff, Zhong, Piperni, \& Fombonne, 2010). According to the Morbidity and Mortality Weekly Report for the year 2008, every 1 in 88 children aged 8 years at 14 network sites in Unites states were affected by this spectrum of conditions (Autism and Developmental Disabilities Monitoring Network Surveillance Year 2008 Principal Investigators \& Centers for Disease Control and Prevention, 2012).

Children with ASD experience multiple challenging behaviors (Jang, Dixon, Tarbox, \& Granpeesheh, 2011; Matson, Wilkins, \& Macken, 2009; G. H. Murphy et al., 2005) and intellectual disabilities (Kraijer, 1999; Morgan et al., 2002) which hamper their communicating, social, and learning capabilities (Harris \& Handleman, 1990; Kanner, 1943; Tonge \& Brereton, 2011). It has also been observed that children with ASD require greater physician and specialist services as compared to the general population (Boulet, Boyle, \& Schieve, 2009; Liptak, Stuart, \& Auinger, 2006). However, provision and quality of required health care services required for children with ASD are found to be non-commensurate with the needs of this group. Caregivers of children with ASD have reported unmet needs (Brown et al., 2011; Siklos \& Kerns, 2006), 
issues with access to care (Krauss, Gulley, Sciegaj, \& Wells, 2003; Ruble, Heflinger, Renfrew, \& Saunders, 2005), and dissatisfaction with quality and quantity of the health care and community based services provided in the different sectors of the care system (Liptak, Orlando, Yingling, Theurer-Kaufman et al., 2006a; Montes, Halterman, \& Magyar, 2009; Spann, Kohler, \& Soenksen, 2003). Consequently, unmet needs along with a child's disability characteristics, as well as greater requirement of the health care services lead to an adverse impact on the caregiver health related quality of life (Johnson, Frenn, Feetham, \& Simpson, 2011; Khanna et al., 2011) and burden on the entire family (Kogan et al., 2008a).

Even though ASD is a public health concern with a reported annual average increase of 57\% (Centers for Disease Control and Prevention (CDC), 2012d), disparities in provision of good quality and cost effective health care services have persisted for a long period of time in the United States (Liptak, Orlando, Yingling, Theurer-Kaufman et al., 2006b; Montes, Halterman, \& Magyar, 2009; Ruble, Heflinger, Renfrew, \& Saunders, 2005). This research aimed to identify the gaps in the health care system due to which families of children with ASD feel that their child's needs are not adequately addressed by the offered health services, as well as examine the predictors of such disparities. This research focused on issues related to access to care, quality of care, and impact of the child's condition on family for caregivers of children with ASD via two studies. The goal of the first study was to examine disparities in perceived access to care, quality of care, and impact of the child's condition on family for caregivers of children with ASD as compared to caregivers of children with other developmental disabilities and other mental health conditions. The goal of the second study was to examine disparities in perceived access to care and impact of the child's condition on the family for caregivers of children with ASD across 50 states and Washington DC (US). 


\section{Data Source}

This research utilized 2009-2010 National Survey of Children with Special Health Care Needs (NS-CSHCN) which is primarily sponsored by United States Department of Health and Human Services (DHHS), Health Resources and Services Administration (HRSA), and Maternal and Child Health Bureau (MCHB). Additional sources of funding are provided by DHHS, Centers for Disease Control and Prevention (CDC), National Center on Birth Defects and Developmental Disabilities (NCBDDD), and Lucile Packard foundation for Children's Health (LPFCH). The survey for children with special health care needs was first collected in 2001, then for the year 2005-2006 and now the latest one for the year 2009-2010. The survey is conducted by CDC's National Center of Health Statistics (NCHS) and State and Local Area Integrated Telephone Survey (SLAITS) (CDC, NCHS) program.

The 2009-2010 NS-CSHCN is a cross-sectional telephone survey of households in 50 states and District of Columbia with at least one resident child 0-17 years of age at the time of the interview. The survey is conducted using a list assisted random digit dialing (RDD) sample of landline telephone and independent RDD sample of cellphone numbers from a period of July 7, 2009- March 2,2011 (CDC, NCHS). The data collection is constituted in 3 main files: screener file (that consists a list of questions to screen out the households which have children with special health care needs), household file ( that consists a list of questions on family and child demographic information), and interview file (that consists of information only for respondents that qualify for having a child with special health care needs in the household and covers information, health and functional status of the child, a list of physical, mental and behavioral conditions, "access to care" and unmet needs, types of services needed and used, 
"quality of care" perceived by the respondents, transition to adulthood, and impact of the child's needs on the family). The survey questions are answered by a parent/guardian/person that is primarily responsible for taking care of the child with special health care need.

\section{Access to care}

WHO (1978) underlines accessibility as one of the most important principles of primary health care and mentions:

"Accessibility implies the continuing and organized supply of care that is geographically, financially, culturally, and functionally within easy reach of the whole community. The care has to be appropriate and adequate in content and in amount to satisfy the needs of people and it has to be provided by methods acceptable to them." (p. 58)

Defining "Access to health care" has been a major concern for researchers and policy makers. According to Aday and Andersen, access is defined as not only by the availability of resources or the ability to obtain it but also actual utilization of services (Aday and Anderson, 1981, 1984). This concept of access is supported by Donabedian (1972) and the Institute of Medicine definition of health care access as the timely utilization of health services for achieving best possible health (IOM, 1998). In this study, a similar approach was taken towards defining access to care and the relevant concepts which are utilized to develop a precise definition of access. With respect to children with ASD, four primary aspects were included in defining access- Difficulty using services, no usual source of care (USOC), difficulty getting referrals and adequacy of health insurance coverage. This definition of access also conveniently incorporates 
four of the five dimensions of access: availability (Difficulty getting referrals, no USOC), accessibility (Difficulty getting referrals, no USOC, difficulty using services), accommodation (Difficulty using services), and affordability (Difficulty using services, adequacy of health insurance coverage) (Penchansky and Thomas, 1981). Acceptability $\left(5^{\text {th }}\right.$ dimension $)$ includes patient's extent of comfort with immutable characteristics (age, sex, and ethnicity) of the provider. This dimension was considered as less relevant to the current study as compared to the other four dimensions and was not included in the study.

\section{Quality of care}

The Institute of Medicine (IOM) has defined quality as "the degree to which health care services for individuals and populations increase the likelihood of desired outcomes and are consistent with current professional knowledge"(Institute of Medicine, 1990). IOM has outlined six core performance indicators as specific aims to improve quality of health care in the United States (National Research Council, 2001): Safety, Efficiency, Timeliness, Patient-Centeredness, Equity, and Effectiveness. These quality performance characteristics have also been adopted for developing a national strategy for quality improvement in health care (Department of Health and Human Services, March 2011). The National Quality Strategy aims to provide better and affordable care to help individuals or communities achieve better health outcomes. The current study focuses on "timeliness" and "patient centeredness" characteristics of "quality of care".

Timeliness: IOM suggests that any high-quality process should flow smoothly with minimum delays and barriers to using and/or delivering health care services. Delays in diagnosis may result in preventable complications, thus underlining the need of timely attention to children with 
special health care needs. The indicator of "timeliness" was included in the study by utilizing a measure for "Routine screening" of children with special health care needs.

Patient Centeredness: (Gerteis, Susan, Jennifer, \& Thomas, 1993) identified several dimensions of patient-centered care: (1) respect for patients' values, preferences, and expressed needs; (2) coordination and integration of care; (3) information, communication, and education; (4) physical comfort; (5) emotional support—relieving fear and anxiety; and (6) involvement of family and friends. This indicator of quality performance was covered via two measures: a) Shared decision making; b) Coordinated care within medical home.

Safety, Efficiency, Equity and Effectiveness are equally important concepts for measuring quality of care. However, for the current study, problems with quality of care are reported by the caregivers and concepts like safety, effectiveness etc. were difficult to assess in such a survey questionnaire. Also, this national survey (NS-CSHCN 2009-2010 survey) focuses on aspects of care that have been found to pose significant issues in care related to children with special health care needs and encompass all the current issues.

\section{Impact of the condition on the family (family impact)}

The outcome measure of family impact was addressed via three domains/constructs: Financial burden, Time-related burden, and Employment burden on the families. 


\section{STUDY 1}

To examine disparities in perceived "access to services", "quality of care" and "family impact" for children with ASD as compared to children with other developmental disabilities (DD) and other mental health conditions (MHC).

Study Population: All the children between the age group of 3-17 years, with a caregiver reported current diagnosis of either ASD, or any other developmental disability only (without ASD or MHC), or any other mental health condition only (without ASD or DD).

ASD: Autism Spectrum Disorders, DD: Developmental Disability (Down syndrome, mental retardation, or developmental delay, and cerebral palsy), and MHC: Mental Health Condition (Attention deficit hyperactivity disorder, depression, anxiety and behavioral/conduct problems).

\section{SIGNIFICANCE AND IMPACT OF THE STUDY 1}

Caring for a child with ASD involves mental and physical commitment from parents, caregivers, and families. Children with ASD have to typically go through a very long evaluation period involving multiple professionals to get an accurate diagnosis (Seltzer, Krauss, Osmond, \& Vestal, 2000). Once diagnosed, the child with ASD is prescribed medical and therapeutic interventions such as antipsychotics use, behavioral interventions such as Applied Behavior Analysis, speech/language and occupational therapies, alternative health care treatment and other such services (Warren et al., April 2011). Researchers have observed that parents/caregivers of children with ASD have consistently expressed dissatisfaction with the provision, quantity, as well as quality of services provided by different health care organizations. 
Children with ASD are inherently different from children with other developmental disabilities or mental health conditions: The burden of comorbidities in children with ASD is extensive and can range from physical conditions like colitis, ulcerations, inflammatory bowel disease and other bowel disorders, muscular dystrophy, epilepsy (as high as 19\% prevalence) (Kohane et al., 2012; Levy et al., 2010), to neurological/developmental conditions like cranial/CNS anomalies, sleep dysfunction (Maski, Jeste, \& Spence, 2011), developmental delay, ADHD and down syndrome and other psychiatric disorders (Joshi et al., 2010). A study showed that co-occurrence of another DD exceeded ninety percent for children with ASDs as compared to eighty two percent for children with mental retardation, seventy six percent for children with developmental delay, and fifty one percent for children with cerebral palsy (Boulet, Boyle, \& Schieve, 2009). Due to this burden, caregivers of children with ASD may have needs that extend beyond the services provided to children with developmental disabilities or mental health conditions. It has also been noted that children with ASD require services from a wide range of professionals like pediatricians, gastroenterologists, psychiatrists, psychologists and most commonly from certified trainers like speech language therapists, occupational therapists, and applied behavior analysis (ABA) therapists (Volkmar, Cook, Pomeroy, Realmuto, \& Tanguay, 1999). The costs associated with using multiple numbers of services, many that are provided on one-to-one basis are exorbitant, especially for therapies like ABA which may be as frequent as $40 \mathrm{hrs} /$ week (Centers for Disease Control and Prevention (CDC), 2012b). Such significant differences in health care needs and costs between children with ASD and other developmental disabilities/mental health conditions have been reported by many other researchers as well (Kogan et al., 2008a; Kohane et al., 2012; Krauss, Gulley, Sciegaj, \& Wells, 2003; Wang \& Leslie, 2010) 
The current study aims to examine the disparities related to access to care, quality of care, and impact of the condition on the family as reported by caregivers of children with ASD as compared to caregivers of children with other developmental disabilities (DD) and mental health conditions (MHC). Some studies have found that caregivers of children with ASD have greater problems with access to care (Krauss, Gulley, Sciegaj, \& Wells, 2003; Ming et al., 2011), are less satisfied with the quality of services provided (Liptak, Orlando, Yingling, TheurerKaufman et al., 2006b) and show greater unmet needs and burden (Cadman et al., 2012) as compared to caregivers of children with disabilities like mental retardation and ADHD. However, our study will examine the issues with access to services, quality of care and family impact reported by caregivers of children with ASD as compared to those reported by caregivers of children with DD which includes down syndrome, mental retardation or developmental delay, and cerebral palsy and MHC which includes attention deficit hyperactivity disorder, depression, anxiety and behavioral/conduct problems. It is understood that due to multiple extensive comorbidities (Boulet, Boyle, \& Schieve, 2009; Joshi et al., 2010; Kohane et al., 2012), greater health care needs and costs, caregivers of children with ASD use more health care services as compared to caregivers of children in the other two groups. In addition, availability of wide array of treatment choices in absence of an absolute pharmacological approach to treat, caregivers of children with ASD may use more services. It is possible that the care which is currently provided to children with ASD under the umbrella of developmental disabilities may not be enough to serve this population and such children may need a more comprehensive and coordinated care with better access to health care professionals and trained therapists. In additions, factors like disproportionately higher costs for the ASD group as compared to the other two groups bring along greater financial, time, and employment burden on the family as 
well. It is hypothesized that caregivers of children with ASD will report greater access problems, greater quality of care problems, and greater impact on the family as compared to caregivers of children with other DD and MHC. This study is needed to underline the disparities existing within the care offered by developmental disability clinics to children with ASD. Such disparities should be addressed by health policy makers, organizations and various providers and serve the unfulfilled needs of children with ASD with optimum allocation of funds within the group of developmental disabilities. 


\section{STUDY 2}

To examine and compare disparities in perceived "access to care" and "family impact for children with ASD across the 50 states and Washington D.C. (United States).

Study Population: All the children between the age group of 3-17 years, with a caregiver reported current diagnosis of ASD.

\section{SIGNIFICANCE AND IMPACT OF THE STUDY 2}

State factors such state legislations and health policies such as insurance reform bills or Medicaid/SCHIP income eligibility and provider workforce are significant factors that determine access to services and financial burden on families of children with special health care needs ( $\mathrm{S}$. L. Parish, Shattuck, \& Rose, 2009; S. L. Parish, Rose, Yoo, \& Swaine, 2012) as well as children with ASD (Mandell \& Palmer, 2005). Many studies have focused on examining differences in caregiver reported access to care problems and family impact/burden for children with special health care needs across the 50 states and their association with state structural factors (S. L. Parish, Shattuck, \& Rose, 2009; S. L. Parish, Rose, Yoo, \& Swaine, 2012) . However, very few studies have examined such state-to-state disparities in access to care and family impact/burden among caregivers of children with ASD. Parish et al. (2012a) examined the effect of autism parity legislation in states on burden on families of children with ASD and found that states with legislation were significantly different from those without legislation in terms of family burden. It was observed that out of pocket costs were higher in states without autism parity legislation as compared to states with legislation. Another study (K. C. Thomas, Parish, Rose, \& Kilany, 2012) found that state Medicaid reimbursement rates to providers have an independent effect on 
access to care for children with ASD. Families living in states with higher reimbursement rates had lower problems with accessing care.

The current study aims to examine nation-wide disparities in caregiver reported problems accessing services and family impact for children with ASD. The study will also assess the association of state health policy and health care workforce with problems accessing services and family impact. Unlike other studies conducted till now, this study includes specific health policy and usual source of care variables relevant to care of children with ASD. Health policies like autism insurance reform bill, Medicaid generosity, and state fiscal effort for intellectual disabilities/developmental disabilities were included as state independent variables. Other state independent variables included are source of care factors like number of pediatricians per child, number of ABA therapists per each child with ASD, special education expenditures and studentpersonnel ratio, and number of ASD specific organizations in the state. It is hypothesized that the better the state structural factors, the lesser the access problems and family impact/burden for caregivers of children with ASD. It is critical to examine access and family impact/burden related disparities across the states for caregivers of children with ASD because: 1) There has been a significant increase in prevalence of children with ASD, their needs and utilization of services in all the sectors of health care and education, 2) Unmet needs and dissatisfaction with quantity and quality of services have been consistently reported by caregivers of children with ASD. Such reports of unmet needs and financial burden for caregivers of children with ASD have been found to be significantly different across the 50 states and Washington D.C. (US), 3) Previous studies have also well-established that there is an association of access to care problems and caregiver burden/family impact with state structural factors. This study aims to focus on the state structural factors that are specific to care for children with ASD. Since, majority of these 
factors are modifiable depending on state legislations and funds allocation, it is expected that care for children with ASD can be enhanced, if the appropriate areas for improvement are recognized.

\section{CONCEPTUAL FRAMEWORK}

The theoretical design for both the studies was based on the Donabedian model (1966) for assessment of quality of care which has widely been applied to health care. The current model has three main components: Structural indicators, Process indicators, Outcome indicators

Structural Indicators: Individual level- includes the characteristics of the population at risk and has been mentioned as a measure of potential access. These indicators may be divided into manipulable and non-manipulable characteristics as well. Predisposing characteristics encompasses measures of demographics (child age, race, gender), social structure (education, occupation), and health beliefs (attitudes, values, and beliefs about health services). Enabling resources include personal/family characteristics (marital status, income, insurance, available transportation).

Measures of need include the individual's perceived need for services as well as evaluated health status (severity of child's condition, number of CSHCN in the household, Child's use of services funded by the IDEA which include early intervention or special education services). 


\section{Study 1}

\section{Process}

Structure: Individual level

\section{Population Characteristics}

1. Predisposing-Child Age, Sex, Race/Ethnicity, Caregiver Education, MSA status, Type of Condition

2. Enabling- Marital Status, Caregiver Income, Health Insurance

3. Need-Severity of child's condition, Functional ability, number of children with SHCN in the household

\section{Access to Services}

Problems

1. Difficulty using services

2. No usual source of care

3. Difficulty getting referrals

4. Adequacy of health insurance coverage

\section{Quality of Care} Problems

1. Shared decision making

2. Coordinated care

3. Early and continuous screening

Figure 1. Conceptual Framework based on modified Donabedian Model for quality of care 


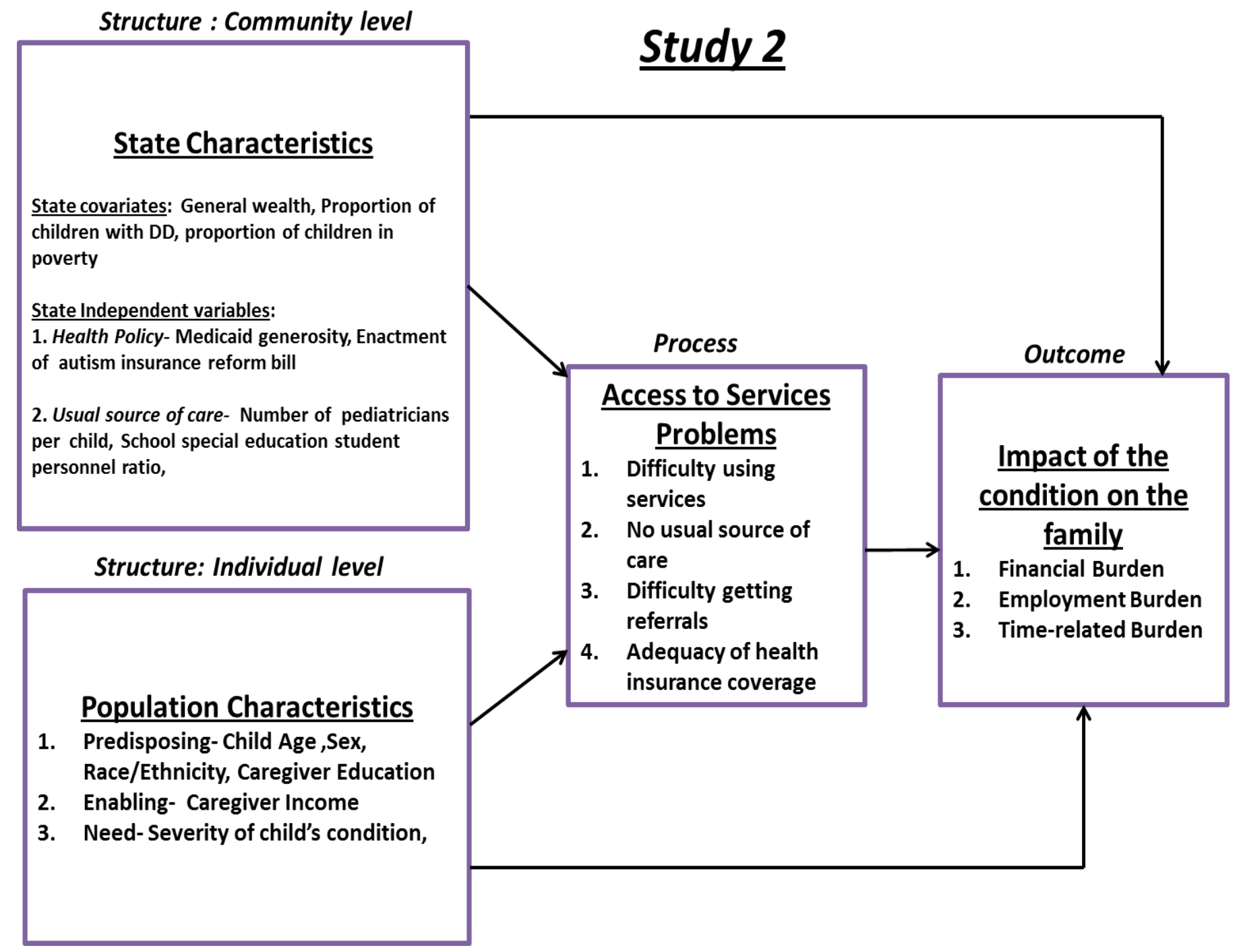

Figure 2. Conceptual Framework based on modified Donabedian Model for quality of care including state contextual characteristics 


\section{ANALYTICAL APPROACH}

\section{Study 1}

Aim 1- To examine association of child's diagnosis (ASD, DD without ASD, MHC without ASD, or DD \& MHC without ASD) with caregiver reported population characteristics.

Aim 1, Objective 1.1- Differences in child age, sex, race/ethnicity, caregiver education, and MSA status for children, caregiver marital status, annual income, and health insurance status, functional ability, and number of children with special health care needs in the household between children with ASD as compared to children with other developmental disabilities, and other mental health conditions will be assessed. Mean differences will be tested for using a twosample independent t-test for continuous variables and a Pearson Chi Square test for categorical variables.

Aim 2- To examine the association of population characteristics and child's diagnosis with “access to care" problems, "quality of care" problems, and "family impact" reported by caregivers of children with either ASD or other developmental disabilities or other mental health conditions.

Aim 2, Objective 2.1-2.3- A Pearson Chi Square test for categorical variables will be conducted to assess the association of the child's diagnosis (ASD, DD without ASD, MHC without ASD, and DD \& MHC without ASD) with all the constructs of "access to care" problems, "quality of care" problems, and "family impact". Significant differences will be determined using a 95\% confidence interval. Separate binary logistic regressions per each outcome measure will be used to assess the impact of child age, sex, race/ethnicity, caregiver education, and MSA status for children, caregiver marital status, annual income, and health insurance status, severity of child's 
condition, number of functional limitations, and number of children with special health care needs in the household, and type of condition (ASD, DD without ASD, and MHC without ASD) on all constructs of "access to care" problems (Difficulty using services, no usual source of care, difficulty getting referrals, and adequacy of health insurance coverage), "quality of care" problems (Shared decision making, care coordination, and routine screening), and "family impact" measures (Financial burden, time-related burden, and employment burden) reported by caregivers. Adjusted odds ratios with $95 \%$ confidence intervals were reported.

\section{Study 2}

Aim 1- The national estimates for state covariates and independent variables were collected from different sources and embedded into the NS-CSHCN data file.

Aim 2- To examine the disparities in "access to care" and "family impact" for caregivers of children with ASD across the 50 states and Washington D.C. (US).

Aim 2, Objective 2.1-2.2 - To determine differences across 50 states and Washington D.C. (US) in "access to care", and "family impact" reported by caregivers of children with ASD. Unadjusted percentages of the caregivers of children with ASD having access to care" problems and "family impact/burden" will be reported for each state.

Aim 3- To examine the association of the state covariates and independent variables with "access to care" problems reported by caregivers of children with ASD.

Aim 4- To examine the association of the state covariates and independent variables with "family impact" reported by caregivers of children with ASD. 
Aim 3\&4- With multilevel data and binary outcomes, hierarchical generalized linear modeling which accommodates logistic regression will be used (Raudenbush and Bryk, 2002). Multilevel models of families nested within states are used because they concurrently partition the variance in the outcome into individual-level and state-level components in the same single model. These models ensure that state-level variables explain between-state variation only. Further, they correctly estimate inflated standard errors for state policy characteristics. These models will be used to estimate the effect of "health policy", and "usual source of care" on "access to care" problems and "family impact" reported by caregivers of children with ASD. All the models will be adjusted for population characteristics and state covariates. Adjusted odds ratios and $95 \%$ confidence intervals will be reported.

Missing values: If the missing values in the dependent variables are conditionally missing (i.e. missingness corresponds to respondents who were ineligible to respond to the question), then no action will be taken. In cases where missing values are greater than 5\%, multiple imputation procedures will be used.

NOTE: For performing all statistical procedures SAS version 9.3 will be used. Multilevel regressions will be performed using STATA version 11 package. 


\section{STRENGTHS \& LIMITATIONS}

This is the first nationally representative study on children with ASD to assess caregiver reported "access to care" and "quality of care" problems together. In addition, this study focuses on outcomes in children with ASD as compared to children with other developmental disabilities, and other mental health conditions, which has not been included in any studies pertaining to "access to care" problems, "quality of care" problems, and "family impact". The second study focuses on examining disparities across states with respect to access to care and family impact for children with ASD. According to the literature, most studies have either focused on all children with special health care needs or on less number of state characteristics which are not very specific to children with ASD.

However, one of the limitations of both the studies is that it is assumed that caregivers in the sample population are willing to use the services. No behavioral attitudes are assessed in the study or the survey itself. Also, multiple measures are utilized to form a composite concept of "access to care", "quality of care" and "family impact". This is a limitation, since definitions of such concepts are not fixed and may include several other measures which were not part of the survey. Also, these outcome measures were neither validated, nor their reliability was measured during the study period. To address this limitation, specific definitions of all the three outcome measures have been adopted from core measures defined by Maternal Child and Health Bureau. However, results may vary on replication depending on the items included to develop a measure and the study population. Finally, NS-CSHCN is a secondary data collection and may have an inherent recall or response bias. 


\section{REFERENCES}

Autism and Developmental Disabilities Monitoring Network Surveillance Year 2008 Principal Investigators, \& Centers for Disease Control and Prevention. (2012). Prevalence of autism spectrum disorders--autism and developmental disabilities monitoring network, 14 sites, united states, 2008. Morbidity and Mortality Weekly Report.Surveillance Summaries (Washington, D.C.: 2002), 61(3), 1-19.

Boulet, S. L., Boyle, C. A., \& Schieve, L. A. (2009). Health care use and health and functional impact of developmental disabilities among US children, 1997-2005. Archives of Pediatrics \& Adolescent Medicine, 163(1), 19-26. doi: 10.1001/archpediatrics.2008.506

Brown, H. K., Ouellette-Kuntz, H., Hunter, D., Kelley, E., Cobigo, V., \& Lam, M. (2011). Beyond an autism diagnosis: Children's functional independence and parents' unmet needs. Journal of Autism and Developmental Disorders, 41(10), 1291-1302. doi: 10.1007/s10803010-1148-y

Cadman, T., Eklund, H., Howley, D., Hayward, H., Clarke, H., Findon, J., . . Glaser, K. (2012). Caregiver burden as people with autism spectrum disorder and attentiondeficit/hyperactivity disorder transition into adolescence and adulthood in the united kingdom. Journal of the American Academy of Child and Adolescent Psychiatry, 51(9), 879-888. doi: 10.1016/j.jaac.2012.06.017; 10.1016/j.jaac.2012.06.017

Centers for Disease Control and Prevention (CDC). (2012a). Data \& statistics. Retrieved 3/25, 2013, from http://www.cdc.gov/ncbddd/autism/data.html

Centers for Disease Control and Prevention (CDC). (2012b). National center on birth defects and developmental disabilities. Retrieved 3/25, 2013, from http://www.cdc.gov/ncbddd/features/counting-autism.html

Gerteis, M., Susan, E., Jennifer, D., \& Thomas, L. D. (1993). Through the patient's eyes. understanding and promoting patient-centered care. San Francisco, CA: Jossey-Bass.

Harris, S. L., \& Handleman, J. S. (1990). In Harris S. L., Handleman J. S. (Eds.), Aversive and nonaversive interventions: Controlling life-threatening behavior by the developmentally disabled. New York, NY US: Springer Publishing Co.

Jang, J., Dixon, D. R., Tarbox, J., \& Granpeesheh, D. (2011). Symptom severity and challenging behavior in children with ASD. Research in Autism Spectrum Disorders, 5(3), 1028-1032.

Johnson, N., Frenn, M., Feetham, S., \& Simpson, P. (2011). Autism spectrum disorder: Parenting stress, family functioning and health-related quality of life. Families, Systems, \& Health, 29(3), 232-252. doi: 10.1037/a0025341

Joshi, G., Petty, C., Wozniak, J., Henin, A., Fried, R., Galdo, M., . . Biederman, J. (2010). The heavy burden of psychiatric comorbidity in youth with autism spectrum disorders: A large 
comparative study of a psychiatrically referred population. Journal of Autism and Developmental Disorders, 40(11), 1361-1370. doi: 10.1007/s10803-010-0996-9; 10.1007/s10803-010-0996-9

Kanner, L. (1943). Autistic disturbances of affective contact. Nervous Child, 2, 217-250. Khanna, R., Madhavan, S. S., Smith, M. J., Patrick, J. H., Tworek, C., \& Becker-Cottrill, B. (2011). Assessment of health-related quality of life among primary caregivers of children with autism spectrum disorders. Journal of Autism and Developmental Disorders, 41(9), 1214-1227.

Kogan, M. D., Strickland, B. B., Blumberg, S. J., Singh, G. K., Perrin, J. M., \& van Dyck, P. C. (2008). A national profile of the health care experiences and family impact of autism spectrum disorder among children in the united states, 2005-2006. Pediatrics, 122(6), e1149-58. doi: 10.1542/peds.2008-1057; 10.1542/peds.2008-1057

Kohane, I. S., McMurry, A., Weber, G., MacFadden, D., Rappaport, L., Kunkel, L., .. . Churchill, S. (2012). The co-morbidity burden of children and young adults with autism spectrum disorders. PloS One, 7(4), e33224. doi: 10.1371/journal.pone.0033224; 10.1371/journal.pone.0033224

Kraijer, D. (1999). Autism and autistic-like conditions in mental retardation. Journal of Intellectual Disability Research, 43(4), 341.

Krauss, M. W., Gulley, S., Sciegaj, M., \& Wells, N. (2003). Access to specialty medical care for children with mental retardation, autism, and other special health care needs. Mental Retardation, 41(5), 329-339. doi: 2

Lazoff, T., Zhong, L., Piperni, T., \& Fombonne, E. (2010). Prevalence of pervasive developmental disorders among children at the english montreal school board. Canadian Journal of Psychiatry.Revue Canadienne De Psychiatrie, 55(11), 715-720.

Levy, S. E., Giarelli, E., Lee, L. C., Schieve, L. A., Kirby, R. S., Cunniff, C., . . Rice, C. E. (2010). Autism spectrum disorder and co-occurring developmental, psychiatric, and medical conditions among children in multiple populations of the united states. Journal of Developmental and Behavioral Pediatrics : JDBP, 31(4), 267-275. doi: 10.1097/DBP.0b013e3181d5d03b; 10.1097/DBP.0b013e3181d5d03b

Liptak, G. S., Orlando, M., Yingling, J. T., Theurer-Kaufman, K., Malay, D. P., Tompkins, L. A., \& Flynn, J. R. (2006a). Satisfaction with primary health care received by families of children with developmental disabilities. Journal of Pediatric Healthcare, 20(4), 245-252.

Liptak, G. S., Orlando, M., Yingling, J. T., Theurer-Kaufman, K. L., Malay, D. P., Tompkins, L. A., \& Flynn, J. R. (2006b). Satisfaction with primary health care received by families of children with developmental disabilities. Journal of Pediatric Health Care : Official Publication of National Association of Pediatric Nurse Associates \& Practitioners, 20(4), 245-252. doi: 10.1016/j.pedhc.2005.12.008 
Liptak, G. S., Stuart, T., \& Auinger, P. (2006). Health care utilization and expenditures for children with autism: Data from U.S. national samples. Journal of Autism and Developmental Disorders, 36(7), 871-879. doi: 10.1007/s10803-006-0119-9

Mandell, D. S., \& Palmer, R. (2005). Differences among states in the identification of autistic spectrum disorders. Archives of Pediatrics \& Adolescent Medicine, 159(3), 266-269. doi: 10.1001/archpedi.159.3.266

Maski, K. P., Jeste, S. S., \& Spence, S. J. (2011). Common neurological co-morbidities in autism spectrum disorders. Current Opinion in Pediatrics, 23(6), 609-615. doi: 10.1097/MOP.0b013e32834c9282; 10.1097/MOP.0b013e32834c9282

Matson, J. L., Wilkins, J., \& Macken, J. (2009). The relationship of challenging behaviors to severity and symptoms of autism spectrum disorders. Journal of Mental Health Research in Intellectual Disabilities, 2(1), 29-44.

Ming, X., Hashim, A., Fleishman, S., West, T., Kang, N., Chen, X., \& Zimmerman-Bier, B. (2011). Access to specialty care in autism spectrum disorders-a pilot study of referral source. BMC Health Services Research, 11, 99-6963-11-99. doi: 10.1186/1472-6963-11-99; 10.1186/1472-6963-11-99

Montes, G., Halterman, J. S., \& Magyar, C. I. (2009). Access to and satisfaction with school and community health services for US children with ASD. Pediatrics, 124, S407-S413. doi: 10.1542/peds.2009-1255L

Morgan, C. N., Roy, M., Nasr, A., Chance, P., Hand, M., Mlele, T., \& Roy, A. (2002). A community survey establishing the prevalence rate of autistic disorder in adults with learning disability. Psychiatric Bulletin, 26(4), 127-130. doi: 10.1192/pb.26.4.127

Murphy, G. H., Beadle-Brown, J., Wing, L., Gould, J., Shah, A., \& Holmes, N. (2005). Chronicity of challenging behaviours in people with severe intellectual disabilities and/or autism: A total population sample. Journal of Autism \& Developmental Disorders, 35(4), 405-418. doi: 10.1007/s10803-005-5030-2

Parish, S. L., Rose, R. A., Yoo, J., \& Swaine, J. G. (2012). State medicaid policies and the health care access of low-income children with special health care needs living in the american south. North Carolina Medical Journal, 73(1), 15-23.

Parish, S. L., Shattuck, P. T., \& Rose, R. A. (2009). Financial burden of raising CSHCN: Association with state policy choices. Pediatrics, 124 Suppl 4, S435-42. doi: 10.1542/peds.2009-1255P; 10.1542/peds.2009-1255P

Ruble, L. A., Heflinger, C. A., Renfrew, J. W., \& Saunders, R. C. (2005). Access and service use by children with autism spectrum disorders in medicaid managed care. Journal of Autism and Developmental Disorders, 35(1), 3-13. 
Siklos, S., \& Kerns, K. A. (2006). Assessing need for social support in parents of children with autism and down syndrome. Journal of Autism and Developmental Disorders, 36(7), 921933. doi: 10.1007/s10803-006-0129-7

Spann, S. J., Kohler, F. W., \& Soenksen, D. (2003). Examining parents' involvement in and perceptions of special education services: An interview with families in a parent support group. Focus on Autism \& Other Developmental Disabilities, 18(4), 228-237.

Thomas, K. C., Parish, S. L., Rose, R. A., \& Kilany, M. (2012). Access to care for children with autism in the context of state medicaid reimbursement. Maternal and Child Health Journal, 16(8), 1636-1644. doi: 10.1007/s10995-011-0862-1; 10.1007/s10995-011-0862-1

Tonge, B., \& Brereton, A. (2011). Autism spectrum disorders. Australian Family Physician, 40(9), 672-677. Volkmar, F., Cook, E. H.,Jr, Pomeroy, J., Realmuto, G., \& Tanguay, P. (1999). Practice parameters for the assessment and treatment of children, adolescents, and adults with autism and other pervasive developmental disorders. american academy of child and adolescent psychiatry working group on quality issues. Journal of the American Academy of Child and Adolescent Psychiatry, 38(12 Suppl), 32S-54S.

Wang, L., \& Leslie, D. L. (2010). Health care expenditures for children with autism spectrum disorders in medicaid. Journal of the American Academy of Child and Adolescent Psychiatry, 49(11), 1165-1171. doi: 10.1016/j.jaac.2010.08.003; 10.1016/j.jaac.2010.08.003

Warren, Z., Veenstra-VanderWeele, J., Stone, W., Bruzek, J. L., Nahmias, A. S., Foss-Feig, J. H., . . . McPheeters, M. L. (April 2011). Therapies for children with autism spectrum disorders.. (Comparative Effectiveness Reviews no. 26 No. 11-EHC029-EF). Rockville (MD): Agency for Healthcare Research and Quality. doi:

http://effectivehealthcare.ahrq.gov/ehc/products/106/651/Autism_Disorder_exec-summ.pdf 


\title{
CHAPTER TWO
}

\section{Access to Services, Quality of care, and Family Impact for Children with Autism, Other Developmental Disabilities, and Other Mental Health Conditions}

\begin{abstract}
Aim: To examine perceived access to services, quality of care, and family impact reported by caregivers of children aged 3-17 years with Autism Spectrum Disorders (ASD), as compared to caregivers of children with other developmental disabilities (DD) and mental health conditions (MHC).
\end{abstract}

Methods: A cross sectional study was conducted using the 2009-2010 National Survey of Children with Special Health Care Needs $(\mathrm{N}=18,702)$. Access to care was measured as: difficulty using services, difficulty getting referrals, lack of usual source of care, and inadequate insurance coverage. Quality of care was assessed as problems reported with: care coordination, lack of shared decision making, and no routine screening. Family impact was measured via: financial, employment, and time related burden. Chi-square analyses and logistic regressions were performed to examine the likelihood of reporting problems with access to services, quality of care, and family impact and compared across ASD, DD (cerebral palsy, down syndrome, developmental delay, or mental retardation), MHC (attention deficit hyperactivity disorder, anxiety, behavioral/conduct problems, or depression) and DD \& MHC (those who had both DD and MHC) group, after adjusting for socio-demographics, number of special children in the household, child's functional ability, and presence of a physical condition. All analyses were adjusted for complex survey design. 
Results: Access to Services: ASD caregivers were significantly more likely to have difficulty using services as compared to DD, MHC, and DD \& MHC caregivers. ASD caregivers were more likely to report inadequate insurance coverage as compared to MHC, and DD but not DD \& MHC caregivers. Quality of care: ASD caregivers were more likely to report lack of shared decision making, as compared to DD, MHC, and DD \& MHC caregivers. ASD caregivers were also more dissatisfied with care coordination as compared to DD, MHC and DD \& MHC caregivers. Family Impact: ASD caregivers were more likely to have financial burden as compared to DD and MHC, but not DD \& MHC caregivers. ASD caregivers were also found to be more likely to have employment burden, as compared to DD, MHC, and DD \& MHC caregivers. Time-related burden was also significantly different between the four groups, where ASD caregivers were more likely to have time-related burden as compared to MHC, and DD \& MHC caregivers.

Conclusion: ASD caregivers differ significantly in their report of difficulty using services, adequacy of insurance coverage, shared decision making, care coordination, and family impact as compared to DD and MHC caregivers.

Keywords: autism, access to services, quality of care, family impact, developmental disability, mental health conditions 


\section{INTRODUCTION}

Prevalence of Autism Spectrum Disorders (ASD) has risen in the past decade by $78 \%$ (Centers for Disease Control and Prevention (CDC), 2012e), where every 1 in 88 children aged 8 years is affected by this condition. The disorder is associated with stereotyped patterns of behavior and social impairments (American Psychiatric Association, 2000), along with an extensive diagnoses of physical and neurological comorbidities (Kohane et al., 2012; Levy et al., 2010). Diagnosis of ASDs pose challenges to clinicians due to their close resemblance with symptoms of and/or co-ocurrence of other developmental disabilities (DD) (Li et al., 2011; Murray, 2010; O'Brien \& Pearson, 2004; Volkmar, Cook, Pomeroy, Realmuto, \& Tanguay, 1999) and mental health conditions (MHC) (Murray, 2010). In such cases, it is difficult to differentiate between the core ASD symptoms and symptoms associated with the comorbidity such as mental retardation (Volkmar, Cook, Pomeroy, Realmuto, \& Tanguay, 1999). Despite similarities of some features such as cognitive delay and socio-behavioral issues among children with ASDs, DDs, and MHCs, the ASD group has been highlighted as distinctive in terms of developmental course, treatment, and management by the clinicians (Volkmar, Cook, Pomeroy, Realmuto, \& Tanguay, 1999).

Extensive health care needs of children with ASDs have been indicated in studies where the ASD group was reported to have greater mental health (Hassiotis \& Turk, 2012) and special education services' use (Boulet, Boyle, \& Schieve, 2009) as compared to children with other DDs such as mental retardation and cerebral palsy. Liptak, Stuart, \& Auinger (2006) used Medical Expenditure Panel Survey (MEPS) and National Hospital Ambulatory Care Survey (NHAMCS) to assess the health care needs and services' utilization of children with ASD. On an average, children with ASD were found to have significantly greater number of outpatient 
visits, non-physician visits, and prescription medicines with refills, as compared to children with mental retardation and depression. Also, significantly greater percentages of children with ASD $(98 \%)$ were in need of special school program such as special education, as compared to children with mental retardation (73\%) and depression (51\%). In addition, the costs associated with total health care, outpatient visits, physician visits, prescription medications, and out of pocket expenditures were significantly greater for children with ASD, as compared to children with mental retardation and depression. Boulet et al. also highlighted the differences across ASDs, other DDs, and MHCs, where ASD group was associated with most extensive co-occurrence of another DD (95\%) as compared to other neurologic and behavioral condition groups. The authors also found that children with ASD demonstrated significantly greater likelihood of visiting a mental health care professional, a therapist, and greater special education use, as compared to other developmental conditions such as cerebral palsy and mental retardation.

Service utilization may be a greater challenge for families of children with ASD as compared to families of children with other DD and MHC due to a number of reasons: 1) the complexity of the disorder itself (Volkmar, Cook, Pomeroy, Realmuto, \& Tanguay, 1999), which encompasses a wide set of symptoms and features that may qualify for diagnosis of other developmental conditions; 2) multiple and extensive comorbidities (Boulet, Boyle, \& Schieve, 2009; Kohane et al., 2012; Levy et al., 2010) such as epilepsy, schizophrenia, cranial anomalies, inflammatory bowel disease, sleep disorders, and muscular dystrophy (Kohane et al., 2012; Maski, Jeste, \& Spence, 2011). A study showed that co-occurence of another developmental disability exceeded $90 \%$ for children with ASDs as compared to $82 \%$ for children with mental retardation, $76 \%$ percent for children with developmental delay, and $51 \%$ for children with cerebral palsy (Boulet, Boyle, \& Schieve, 2009); 3) Management of such heterogeneous set of 
conditions in children with ASD requires provision of services by multiple professionals which may extend those provided by routine developmental disability centers or clinics, a fact supported by many observational studies (Bitsko et al., 2009; Boulet, Boyle, \& Schieve, 2009; Krauss, Gulley, Sciegaj, \& Wells, 2003); and 4) availability of a wide array of pharmacological and behavioral treatments lacking evidence of an absolute gold standard (Warren et al., April 2011). In addition, the direct and indirect substantial medical expenditures incurred on families of children with ASDs also pose as significant barriers to accessing services and facilitators to increasing financial burden (Centers for Disease Control and Prevention (CDC), 2012a; Kogan et al., 2008; Liptak, Stuart, \& Auinger, 2006).

It has been observed in multiple studies that caregivers of children with ASD report greater unmet needs (Siklos \& Kerns, 2006), issues with access to services (Krauss, Gulley, Sciegaj, \& Wells, 2003; Ruble, Heflinger, Renfrew, \& Saunders, 2005), and dissatisfaction with quality of services provided (Montes, Halterman, \& Magyar, 2009; Spann, Kohler, \& Soenksen, 2003), when compared to children without ASD. On the other hand, some studies have observed differences among caregivers of children with ASD and other DDs, in reports of unmet needs (Cadman et al., 2012), problems with access to services (Boulet, Boyle, \& Schieve, 2009; Krauss, Gulley, Sciegaj, \& Wells, 2003), and quality of care provided (Liptak et al., 2006). Krauss et al. (2003) found that caregivers of children with ASD report significantly greater issues with access to care as compared to children with mental retardation and other children with special health care needs. Ming et al. (2011) found that lesser number of children with ASD received referrals for specialists from their primary care physicians as compared to children with other neurologic disorders. Liptak et al. (2006) examined perceptions of parents of children with a DD including ASD about satisfaction with primary health care. They found that families 
of children with ASD were more likely to be report dissatisfaction with communication and care coordination among primary care physicians, unmet needs, and express more negative comments, as compared to families of children with other DD.

The current study aims to examine caregiver perceived issues with access to services, quality of care, and impact of the condition on the family for children with ASD, as compared to children with other DD and MHC. Children with DDs are impaired in physical, learning, language, or behavioral aspect which affects their typical development and some of these conditions include cerebral palsy, down syndrome, developmental delay, or mental retardation (Centers for Disease Control and Prevention (CDC), 2012b). Children with MHCs include those who have conditions such as attention deficit hyperactivity disorder (Furman, 2008), anxiety, behavioral/conduct problems, or depression. To the best of our knowledge, no single study has assessed and compared these three outcomes together across children with ASD, DD, and MHC. Identifying differences in reports of issues with access to services, quality of care, and family impact, can serve as an indication of the differences in health care needs of ASD and DD or MHC groups which can be used to inform policy makers, insurance programs, and health care providers about the complexity and variations in needs of the ASD group, who are usually provided services within the umbrella of developmental disability networks. Due to intensive health care needs, care received from multiple professionals, need of extensive care coordination, and costs involved in taking care of a child with ASD (Centers for Disease Control and Prevention (CDC), 2012a), their caregivers are expected to be more likely to report issues with access to services, quality of care, and greater family impact, as compared to DD and MHC caregivers. 


\section{METHODS}

\section{Data source}

The 2009-2010 National Survey of Children with Special Health Care Needs (NS-CSHCN) provides child- and household- level data along with state of residence for the analyses (Maternal and Child Health Bureau, Data Resource Center for Child and Adolescent Health, 2011). The National Survey of Children with Special Health Care Needs is a computer assisted random digit dial telephone survey with a complex multistage design representative of the US civilian noninstitutionalized population with children aged 0 to 17 years with and without special health care needs. A total of 372,698 children were screened for special health care needs in the 50 states and DC from 196,159 households. The analyses reported here is based on sample of children who were identified as CSHCN through survey's CSHCN screener $(\mathrm{N}=40,242)$.

\section{Study population}

All the children in the age group of 3-17 years with a caregiver reported current diagnosis of ASD, DD without ASD, MHC without ASD, or DD \& MHC without ASD were identified $(\mathrm{N}=$ 18,702).

\section{Measures}

Child's Special Condition. ASD was identified as caregiver reported confirmation to the question, "Does the child currently have autism, Asperger's disorder, pervasive developmental disorder, or other autism spectrum disorder". Similarly, caregiver reports were used to identify children with a DD (cerebral palsy, down syndrome, developmental delay, or mental retardation, No ASD), or an MHC (attention deficit hyperactivity disorder, anxiety, behavioral/conduct 
problems, or depression, No ASD). The final sample was divided into four special condition groups: ASD, DD without ASD, MHC without ASD, and DD \& MHC without ASD.

Access to Services. According to Aday and Andersen access is defined as not only by the availability of resources or the ability to obtain it but also actual utilization of services (Aday \& Andersen, 1981; Aday \& Andersen, 1984). For the current study, the services include those offered by primary care providers, schools, hospital systems, other clinics/health centers, and any other relevant institution. Access to services was assessed using four binary measures of problems accessing health care from the NS-CHSCN: difficulty using services, difficulty getting referrals, lack of source of care, and adequacy of health insurance coverage. Difficulty using services is based on a yes/no question, "During the past year, have you had any difficulties using or delay in services?". Difficulty getting referrals was derived from the question, "Was getting referrals a big problem, a small problem, or not a problem?", and categorized into big/small problem and no problem. Lack of source of care is a yes/no question, "Does the child have a personal doctor and received all routine/specialty care, when needed?". Adequacy of health insurance was derived from the question, "Did the health insurance provide benefits that meet child's needs and allowed to see a provider?", categorized into never/sometimes and usually/always.

Quality of care. The quality of screening, communication and coordination with the health care providers and the health care system was assessed via three binary measures: shared decision making, lack of care coordination, and no routine screening of the child. Shared decision making was measured was derived from the question, "Did the health care provider discussed, encouraged to ask questions, and respected your treatment choices", which was categorized into usually/always and never/sometimes. Lack of care coordination was reported via question, "Did 
you receive help from the health care providers or any other individual and how satisfied were you with the help provided?", categorized into received help/satisfied/somewhat satisfied and did not receive help/some what dissatisfied/very dissatisfied. No routine screening was derived from the question, "Number of times the child received a well child check up, when he was not sick or injured?" categorized into none and one/more than one.

Impact of the condition on the family or family impact. This outcome was assessed using three binary measures of family burden due to child's condition: financial burden, employment burden, and time-related burden. Financial burden was derived from question, " Whether family paid $\$ 5,000, \$ 1,000$ to $\$ 5,000$, or less than $\$ 1,000$ for child's medical care in the past year, excluding health insurance premiums and costs reimbursed by insurance or other payment sources?", which was categorized into $\geq \$ 1,000$ and $<\$ 1000$ spending. Employment burden was a yes/no question, "Did the caregiver stop working because of child's condition?". Time related burden was assessed via question "Number of hours the caregiver spends in providing, arranging, and coordinating care for the child with the condition?" where the variable was categorized into $\geq 10$ hours and $<10$ hours per week, a cut off which has been used previously by Kogan et al. (2008).

Other covariates. Socio-demographic variables included in all the analysis were child's age (3-5 years, 6-11 years, and 12-17 years), child gender (male, female), race and ethnicity (nonHispanic Whites, Blacks, other races, and any Hispanic race) caregiver income level $(<100 \%$ FPL, 100-200\% FPL, 200-400\% FPL, and >400 \% FPL), caregiver education level (Less than high school, high school, and greater than high school), metropolitan statistical area (MSA) status (Metro, non-metro, and less than 500,000 population), geographic region (Northeast, Midwest, South, and West), and type of health insurance (Public, Private, Public/Private, Other). 
Other relevant covariates included number of special needs children (One, more than one) in the household, child's functional ability (Never affected, some times and very little affected, always usually affected), and presence of a physical comorbidity (Yes/No).

\section{Statistical Analyses}

Two sets of Chi-square tests were conducted to determine bivariate associations. The first test was performed to assess the association between child's special condition and sociodemographic variables, number of special children in the household, child's functional ability, and presence of a physical comorbidity. The second test was performed to assess the association between child's special condition and each of the access to services (difficulty using services, difficulty getting referrals, lack of usual source of care, and adequacy of health insurance coverage), quality of care (lack of shared decision making, no routine screening, and lack of care coordination), and family impact (financial, employment, and time-related burden) outcomes. Unadjusted and multivariate adjusted logistic regressions were conducted to test the association between measures of access to services, quality of care, and family impact with the child's special condition (ASD, DD without ASD, MHC without ASD, and DD \& MHC without ASD). The adjusted logistic regressions controlled for socio-demographic variables, number of special needs children in the household, child's functional ability, and presence of a physical comorbidity. All analyses were adjusted for the complex survey design of 2009- 2010 NSCSHCN using sampling weights. Analyses were conducted using SAS 9.3 (SAS Inc.). 


\section{RESULTS}

Overall, the study sample was primarily male (65\%), $6-17$ years old $(90.5 \%)$, and nonHispanic White (62.7\%) children. Caregivers were primarily mothers (76\%), married (62.2\%), with greater than high school education (66.2\%), and above 200\% FPL income level (51.7\%). Demographic information of the study sample by child's special condition is summarized in Table 1. Sixteen percent of the study sample were children with ASD $(n=3,025,15.9 \%)$. Majority of those with ASD were males (80.4\%), older (6-17 years; 83.4\%), had private health insurance (44\%), and were functionally always affected (68.3\%). Children with a DD were primarily in the age group of 6-11 years (43.5\%), had public health insurance (43.0\%), and were functionally always affected (59.9\%). Children with an MHC were primarily much older as compared to ASD and DD groups (12-17 years; 55.7\%), had private health insurance (48.0\%), and were functionally sometimes affected (42.6\%). Children with both a DD and MHC were older (6-17 years; 91\%), had public health insurance (52.9\%), and were functionally always affected $(58.8 \%)$.

\section{Child's Special Condition and Outcomes}

Chi-square Analysis

Table 2 demonstrates the association of child's special condition with measures of access to services, quality of care, and family impact. Numbers and weighted percentages correspond to caregivers who reported problems with measures of all three outcomes. Caregiver reported difficulty using services, inadequacy of insurance coverage, lack of shared decision making, lack of coordination, financial burden, employment burden, and time-related burden differed by the type of special condition. Greater number of ASD caregivers reported difficulty using services 
(55.2\%), as compared to DD (43.5\%) and MHC (36.5\%) caregivers. Caregiver report of difficulty using services for children with DD \& MHC both was similar to ASD caregivers (51.5\%). Around thirty-two percent of ASD caregivers (32.1\%) reported insurance coverage as inadequate, whereas lesser proportions of MHC (18.6\%), DD (21.4\%), and DD \& MHC (26.4\%) caregivers reported this issue. More number of ASD caregivers also reported lack of shared decision making (43.5\%), as compared to DD (36.3\%), MHC (31.3\%), and DD \& MHC (38.9\%) caregivers. Lack of coordination was a problem for $86.7 \%$ of ASD caregivers, as compared to $61.3 \%$ of MHC caregivers. Financial burden was observed in greater number of ASD caregivers (53.2\%) than DD (41.2\%), MHC (35.8\%), and DD \& MHC (42.6\%) caregivers. Employment burden was observed in greater ASD caregivers (38.3\%), as compared to DD (30.9\%), DD \& MHC (26.9\%), and MHC (11.6\%) caregivers. Time-related burden was observed to affect a similar number of ASD (45.6\%) and DD (44.7\%) caregivers. Proportions of DD \& MHC (35.5\%) and MHC (19.2\%) caregivers reporting time-related burden, were lesser as compared to ASD and DD caregivers.

Logistic Regression Analyses

Table 3 and 4 show the odds ratios (OR's), adjusted odds ratios (AOR's), and 95\% confidence intervals (CI) for unadjusted and adjusted models respectively, for each measure of the three outcomes: access to services, quality of care, and family impact. Adjusting for sociodemographic variables, number of special children in the household, child's functional ability, and presence of a physical comorbidity had very little effect on the odds ratios for child's special condition and all the measures of access to services, quality of care, and family impact. 
Access to Services. ASD caregivers were significantly different from DD and MHC caregivers in their report of difficulty using services and adequacy of health insurance coverage. ASD caregivers were significantly more likely to have difficulty using services as compared to DD $(\mathrm{AOR}=1.74,95 \% \mathrm{CI}=1.31-2.32)$ and $\mathrm{MHC}(\mathrm{AOR}=1.56,95 \% \mathrm{CI}=1.30-1.89)$ caregivers ASD caregivers were also more likely to have difficulty using services, when compared to DD \& MHC caregivers $(\mathrm{AOR}=1.29,95 \% \mathrm{CI}=1.02-1.61)$. ASD caregivers were significantly more likely to report inadequate insurance coverage as compared to $\mathrm{MHC}(\mathrm{AOR}=1.71,95 \% \mathrm{CI}=$ 1.37-2.14 $)$ and $\mathrm{DD}(\mathrm{AOR}=1.60,95 \% \mathrm{CI}=1.10-2.33)$. ASD caregivers were not different from DD \& MHC caregivers in their report of adequacy of insurance coverage. A sub-analysis (not shown here) assessed problems or difficulty using services due to issues with services' eligibility, availability, getting appointments, service cost, and obtaining information. It was found that, as compared to caregivers of children with MHC, caregivers of children with ASD were significantly more likely to report issues with availability $(\mathrm{AOR}=2.16,95 \% \mathrm{CI}=1.66$ 2.82), information $(\mathrm{AOR}=1.89,95 \% \mathrm{CI}=1.46-2.45)$, eligibility $(\mathrm{AOR}=1.80,95 \% \mathrm{CI}=1.38$ 2.37), $\operatorname{cost}(\mathrm{AOR}=1.67,95 \% \mathrm{CI}=1.31-2.14)$, and appointments $(\mathrm{AOR}=1.35,95 \% \mathrm{CI}=1.09$ 1.68). When compared to the DD \& MHC group, the ASD group was found to be significantly more likely to report issues with availability $(\mathrm{AOR}=1.44,95 \% \mathrm{CI}=1.10-1.90)$, obtaining information $(\mathrm{AOR}=1.35,95 \% \mathrm{CI}=1.01-1.80)$, and cost of services $(\mathrm{AOR}=1.43,95 \% \mathrm{CI}=$ 1.09-1.88).

Quality of Care. ASD caregivers were more likely to report lack of shared decision making, as compared to both $\mathrm{DD}(\mathrm{AOR}=1.41,95 \% \mathrm{CI}=1.07-1.85), \mathrm{MHC}(\mathrm{AOR}=1.53,95 \% \mathrm{CI}=1.26-$ $1.85)$, and $\mathrm{DD} \& \mathrm{MHC}(\mathrm{AOR}=1.29,95 \% \mathrm{CI}=1.03-1.62)$ caregivers. Lack of care coordination was also reported by ASD caregivers, who were more likely to report this issue as 
compared to $\mathrm{DD}(\mathrm{AOR}=1.46,95 \% \mathrm{CI}=1.07-2.01), \mathrm{MHC}(\mathrm{AOR}=3.37,95 \% \mathrm{CI}=2.73-4.16)$, and DD \& MHC caregivers $(\mathrm{AOR}=1.90,95 \% \mathrm{CI}=1.46-2.49)$.

Family Impact. ASD caregivers were more likely to have financial burden as compared to DD $(\mathrm{AOR}=1.47,95 \% \mathrm{CI}=1.08-2.00)$ and $\mathrm{MHC}(\mathrm{AOR}=1.51,95 \% \mathrm{CI}=1.20-1.84)$ caregivers. There were no significant differences in financial burden between ASD caregivers and DD \& MHC caregivers. ASD caregivers were also found to be more likely to have employment burden, as compared to $\mathrm{DD}(\mathrm{AOR}=1.71,95 \% \mathrm{CI}=1.32-2.21), \mathrm{MHC}(\mathrm{AOR}=2.91,95 \% \mathrm{CI}=$ 2.35-3.61), and DD \& MHC ( $\mathrm{AOR}=1.75,95 \% \mathrm{CI}=1.35-2.27)$ caregivers. Time-related burden was also significantly different for ASD, DD, and MHC groups, where ASD caregivers were more likely to have time-related burden as compared to $\mathrm{MHC}(\mathrm{AOR}=2.81,95 \% \mathrm{CI}=2.08$ 3.81 $)$ and $\mathrm{DD} \& \mathrm{MHC}(\mathrm{AOR}=1.60,95 \% \mathrm{CI}=1.14-2.27)$ caregivers. 


\section{DISCUSSION}

Many significant differences were observed between caregivers of children with ASD and caregivers of children with DD and MHC. ASD caregivers were generally more likely to report issues with difficulty using services, adequacy of insurance coverage, shared decision making, and coordination of care, as compared to caregivers of children with DD and MHC. ASD caregivers also have greater financial, employment, and time-related burden, as compared to DD and MHC caregivers. Getting referrals, usual source of care, and routine screening did not seem to be problematic for ASD caregivers, as compared to DD and MHC caregivers.

Children with ASD formed around sixteen percent of the study sample as compared to those with MHC, who constituted more than half of the sample (58.2\%). Greater proportions of older children in 12 -17 years age group were associated with MHC as compared to either ASD or DD or DD \& MHC groups. Majority of the ASD children were functionally always affected (68.3\%), as compared to MHC children who were functionally affected never/some times (42.5\%). However, a similar proportion of children with DD alone (59.9\%) or DD \& MHC (58.8\%) showed similar extent of functional disability as ASD children.

Access to services has been an issue for ASD caregivers, with reports of difficulty using services, getting referrals, and lack of access to specialty care being some of the consistently reported problems (Bitsko et al., 2009; Krauss, Gulley, Sciegaj, \& Wells, 2003; Liptak et al., 2006). This study was conducted to examine whether ASD caregiver reports of access problems differ from other DD or MHC caregivers. Difficulties or delays using services such as school services, hospital and other health care systems were found to be a problem for ASD caregivers. Difficulties using services can be attributed to reasons like availability, eligibility, cost, and 
problems in obtaining information. The sub-analysis showed that ASD caregivers were more likely to report issues with availability, obtaining information, and cost of the services, when compared to MHC and DD \&MHC caregivers. Inadequacy of insurance coverage was also another factor which was significantly different between ASD, DD, and MHC caregivers. In general, ASD caregivers were more likely to report inadequate insurance coverage as compared to DD and MHC caregivers, but not when compared to DD \& MHC caregivers. It is possible that children who have a DD \& MHC are similar to children with ASD, in terms of their condition profile and subsequent services' use due to presence of more than one condition. Studies have shown that multiple co-occurring conditions are associated with greater health care needs, health care utilization, and use of wide array of services (Bitsko et al., 2009; Boulet, Boyle, \& Schieve, 2009; Gurney, McPheeters, \& Davis, 2006). Bitsko et al. (2009) found that children with multiple neurologic conditions are more likely to have unmet needs and problems accessing and using services, as compared to those with a single neurologic condition. Bitsko et al. also commented on how the unmet needs of children with neurologic conditions are a direct consequence of either having more needs or the severity of the condition. However, more studies are required to understand the patterns of health care services use by ASD children and its association with needs, and severity of the conditions. Such patterns should also be compared to those with other DD and MHC disorders, so that disparities in provision of health care to ASD groups are identified and addressed.

Quality of care reported by caregivers of children with ASD is significantly different from caregivers of children with MHC, DD, and those who have children with DD \& MHC. ASD caregivers were more likely to report issues with shared decision making among their providers, and coordination within the health care system. Family or patient centered care is a 
critical component for an efficient health care system (IOM 1990) and is associated with better perceptions of access and availability of care (Rhoades Smucker, 2001). Studies have observed that caregivers of children with developmental disabilities and specifically ASD have reported inability of pediatricians and other primary care providers to understand their concerns, and provide information about their child's condition as well as putting parents in touch with other parents of children with similar conditions (Liptak et al., 2006). Along with these issues, the authors also reported that parents of children with ASD were more negative in their ratings of primary care physicians as compared to caregivers of children with other DD (Liptak et al., 2006). Findings from our study show that ASD caregivers are dissatisfied with their primary care providers' extent of sharing and encouragement with asking questions. ASD caregivers were $29 \%$ more likely to be dissatisfied with shared decision making, as compared to DD \& MHC caregivers. Lack of coordination was also a huge discrepancy in the quality of care provided to caregivers of children with ASD. When compared to caregivers of children with DD, MHC, or DD \& MHC, caregivers of children with ASD reported greater likelihood of being dissatisfied with the communication and coordination among the health care providers. As compared to DD \& MHC caregivers, ASD caregivers were $90 \%$ more likely to report lack of coordination among health care providers. Such consistent reports of dissatisfaction with quality of care for ASD caregivers can be attributed to their feeling of helplessness, despite multiple services' use (Liptak, Stuart, \& Auinger, 2006). In absence of an evidence based single treatment approach (Warren et al., April 2011), ASD caregivers may be more doubtful about care provided, a fact that should be addressed by primary care physicians.

Studies have established that ASD caregivers suffer from greater burden and poorer health outcomes when compared to the general population (Cidav, Marcus, \& Mandell, 2012; 
Kogan et al., 2008; Wang \& Leslie, 2010). Kogan et al. (2008) demonstrated that ASD caregivers have a greater family impact as compared to children with other special health care needs. The findings from this study show that ASD caregivers were more likely to report financial and employment burden as compared to DD and MHC caregivers. However, ASD and DD \& MHC group did not differ significantly on financial burden, supporting a previous finding where both the groups did not differ on their report of inadequacy of insurance coverage as well. Our study also showed that ASD caregivers were more likely to leave a job because of the child's condition, as compared to all other special condition groups. Time burden was also an issue, where caregivers of children with ASD were more likely to spend 10 hours or more per week in coordinating or arranging care for the child, as compared to MHC and DD \& MHC caregivers. On the other hand, the DD caregivers were as likely to report time burden as ASD caregivers, indicating some similarities for both groups of children, in terms of health care needs.

In short, caregivers of children with MHC as well as DD reported the least likelihood of difficulty using services, inadequacy of health insurance coverage, lack of shared decision making, lack of care coordination, financial burden, and employment burden, as compared to ASD caregivers. Time burden did not differ across ASD and DD caregivers. Interestingly, ASD caregivers were also more likely to report difficulty using services, lack of shared decision making and care coordination, time and employment burden, as compared to caregivers of children who had both a DD \& MHC. This finding is contrary to the fact that those with multiple neurologic conditions may have greater needs, use more health care services and show greater unmet needs as compared to single condition (Bitsko et al. 2009). It should also be noted that ASD itself is a spectrum of conditions, where majority (some times a prevalence of 95\%) of children have more than a single comorbidity (Joshi et al., 2010; Kohane et al., 2012) and 
evidently encompasses symptoms that require greater provider and caregiver attention, as compared to DD and MHC caregivers.

The current study has several strengths. Our study used a nationally representative population of children with special health care needs with the most recent estimates of 20092010 NS-CSHCN. According to the literature review, the current study is the first one to examine perceived health care disparities across caregivers of children with ASD, DD, and MHC. Most studies have focused on assessing these outcomes across children with and without ASD. Our study highlights two major points: 1) Barriers to accessing quality care still exist for caregivers of children with ASD, and specific core deficits such as care coordination should be addressed by development of better patient-provider networks or better patient centered medical homes; 2) Extensive financial, employment and time related burden reported by ASD caregivers highlights that the needs of this group are complex and challenging for the caregivers/families.

Even though the recent state mandates of behavioral therapies' coverage (National Conference of State Legislatures, 2012; S. Parish, Thomas, Rose, Kilany, \& McConville, 2012) have shown to provide financial relief to families of children with ASD, the workforce required to serve the increasing number of children with ASD is still a significant issue.

\section{Limitations}

The current study was limited by the type of DD and MHC available in the survey and may not have accounted for other neurologic conditions. Also, the DD and MHC groups formed may have conditions that may not exactly fall into a single group. Such categorization has been used in a previous study by Nageswaran et al. (2010) using the 2005 NS-CSHCN in assessment of difficulty using services across different types of special conditions. However, clinical 
relevance of such categorization could not be established in this study. Outcomes measures in the study were adopted from the core outcomes designed by of the Maternal Child and Health Bureau and have been utilized in some other studies as well (Kogan et al., 2008; Nageswaran, Parish, Rose, \& Grady, 2011). However, the present study did not establish any validity or reliability of these measures. Therefore, replication of the study results may vary depending on the items used to define the outcome measures. This is a cross-sectional study which does not establish causality of association of type of special condition and outcome measures.

\section{CONCLUSION}

ASD caregivers have significant barriers in accessing services, receiving quality care, and report adverse family impact. Children with ASD form a vulnerable population within the group of developmental disabilities and may require services and care that extend beyond that provided by the current health care system. Public policies and state level programs should assess the deficits and discrepancies in care provided to the ASD group and aim to address such disparities. 


\section{REFERENCES}

Aday, L. A., \& Andersen, R. M. (1981). Equity of access to medical care: A conceptual and empirical overview. Medical Care, 19(12), 4-27.

Aday, L. A., \& Andersen, R. M. (1984). The national profile of access to medical care: Where do we stand? American Journal of Public Health, 74(12), 1331-1339.

American Psychiatric Association (Ed.). (2000). Diagnostic and statistical manual of mental disorders (4th ed.). Washington D.C.: American Psychiatric Publishing, Inc.

Bitsko, R. H., Visser, S. N., Schieve, L. A., Ross, D. S., Thurman, D. J., \& Perou, R. (2009). Unmet health care needs among CSHCN with neurologic conditions. Pediatrics, 124 Suppl 4, S343-51. doi: 10.1542/peds.2009-1255D; 10.1542/peds.2009-1255D

Boulet, S. L., Boyle, C. A., \& Schieve, L. A. (2009). Health care use and health and functional impact of developmental disabilities among US children, 1997-2005. Archives of Pediatrics \& Adolescent Medicine, 163(1), 19-26. doi: 10.1001/archpediatrics.2008.506

Cadman, T., Eklund, H., Howley, D., Hayward, H., Clarke, H., Findon, J., . . Glaser, K. (2012). Caregiver burden as people with autism spectrum disorder and attentiondeficit/hyperactivity disorder transition into adolescence and adulthood in the united kingdom. Journal of the American Academy of Child and Adolescent Psychiatry, 51(9), 879-888. doi: 10.1016/j.jaac.2012.06.017; 10.1016/j.jaac.2012.06.017

Centers for Disease Control and Prevention (CDC). (2012a). Data \& statistics. Retrieved 3/25, 2013, from http://www.cdc.gov/ncbddd/autism/data.html

Centers for Disease Control and Prevention (CDC). (2012b). Developmental disabilities. Retrieved 3/25, 2013, from http://www.cdc.gov/ncbddd/developmentaldisabilities/index.html

Centers for Disease Control and Prevention (CDC). (2012c). New data on autism spectrum disorders. Retrieved 3/6, 2013, from http://www.cdc.gov/features/countingautism/

Cidav, Z., Marcus, S. C., \& Mandell, D. S. (2012). Implications of childhood autism for parental employment and earnings. Pediatrics, 129(4), 617-623. doi: 10.1542/peds.2011-2700; 10.1542/peds.2011-2700

Furman, L. M. (2008). Attention-deficit hyperactivity disorder (ADHD): Does new research support old concepts? Journal of Child Neurology, 23(7), 775-784. doi:

10.1177/0883073808318059; 10.1177/0883073808318059

Gurney, J. G., McPheeters, M. L., \& Davis, M. M. (2006). Parental report of health conditions and health care use among children with and without autism: National survey of children's 
health. Archives of Pediatrics \& Adolescent Medicine, 160(8), 825-830. doi:

10.1001/archpedi.160.8.825

Hassiotis, A., \& Turk, J. (2012). Mental health needs in adolescents with intellectual disabilities: Cross-sectional survey of a service sample. Journal of Applied Research in Intellectual Disabilities : JARID, 25(3), 252-261. doi: 10.1111/j.1468-3148.2011.00662.x; 10.1111/j.1468-3148.2011.00662.x

Joshi, G., Petty, C., Wozniak, J., Henin, A., Fried, R., Galdo, M., . . Biederman, J. (2010). The heavy burden of psychiatric comorbidity in youth with autism spectrum disorders: A large comparative study of a psychiatrically referred population. Journal of Autism and Developmental Disorders, 40(11), 1361-1370. doi: 10.1007/s10803-010-0996-9; 10.1007/s10803-010-0996-9

Kogan, M. D., Strickland, B. B., Blumberg, S. J., Singh, G. K., Perrin, J. M., \& van Dyck, P. C. (2008). A national profile of the health care experiences and family impact of autism spectrum disorder among children in the United States, 2005-2006. Pediatrics, 122(6), e1149-58. doi: 10.1542/peds.2008-1057; 10.1542/peds.2008-1057

Kohane, I. S., McMurry, A., Weber, G., MacFadden, D., Rappaport, L., Kunkel, L., . . . Churchill, S. (2012). The co-morbidity burden of children and young adults with autism spectrum disorders. PloS One, 7(4), e33224. doi: 10.1371/journal.pone.0033224; 10.1371/journal.pone.0033224

Krauss, M. W., Gulley, S., Sciegaj, M., \& Wells, N. (2003). Access to specialty medical care for children with mental retardation, autism, and other special health care needs. Mental Retardation, 41(5), 329-339. doi: 2

Levy, S. E., Giarelli, E., Lee, L. C., Schieve, L. A., Kirby, R. S., Cunniff, C., . . Rice, C. E. (2010). Autism spectrum disorder and co-occurring developmental, psychiatric, and medical conditions among children in multiple populations of the united states. Journal of Developmental and Behavioral Pediatrics : JDBP, 31(4), 267-275. doi: 10.1097/DBP.0b013e3181d5d03b; 10.1097/DBP.0b013e3181d5d03b

Li, B. M., Liu, X. R., Yi, Y. H., Deng, Y. H., Su, T., Zou, X., \& Liao, W. P. (2011). Autism in dravet syndrome: Prevalence, features, and relationship to the clinical characteristics of epilepsy and mental retardation. Epilepsy \& Behavior : E\&B, 21(3), 291-295. doi: 10.1016/j.yebeh.2011.04.060; 10.1016/j.yebeh.2011.04.060

Liptak, G. S., Orlando, M., Yingling, J. T., Theurer-Kaufman, K. L., Malay, D. P., Tompkins, L. A., \& Flynn, J. R. (2006). Satisfaction with primary health care received by families of children with developmental disabilities. Journal of Pediatric Health Care : Official Publication of National Association of Pediatric Nurse Associates \& Practitioners, 20(4), 245-252. doi: 10.1016/j.pedhc.2005.12.008 
Liptak, G. S., Stuart, T., \& Auinger, P. (2006). Health care utilization and expenditures for children with autism: Data from U.S. national samples. Journal of Autism and Developmental Disorders, 36(7), 871-879. doi: 10.1007/s10803-006-0119-9

Logan, S. L., Nicholas, J. S., Carpenter, L. A., King, L. B., Garrett-Mayer, E., \& Charles, J. M. (2012). High prescription drug use and associated costs among medicaid-eligible children with autism spectrum disorders identified by a population-based surveillance network. Annals of Epidemiology, 22(1), 1-8. doi: 10.1016/j.annepidem.2011.10.007; 10.1016/j.annepidem.2011.10.007

Maski, K. P., Jeste, S. S., \& Spence, S. J. (2011). Common neurological co-morbidities in autism spectrum disorders. Current Opinion in Pediatrics, 23(6), 609-615. doi: 10.1097/MOP.0b013e32834c9282; 10.1097/MOP.0b013e32834c9282

Maternal and Child Health Bureau, Data Resource Center for Child and Adolescent Health. (2011). National survey of children with special health care needs: Fast facts about the survey. Retrieved 3/25, 2013, from http://www.childhealthdata.org/docs/default-documentlibrary/ns-cshcn-fast-facts-2009.pdf

Montes, G., Halterman, J. S., \& Magyar, C. I. (2009). Access to and satisfaction with school and community health services for US children with ASD. Pediatrics, 124, S407-S413. doi: 10.1542/peds.2009-1255L

Murray, M. J. (2010). Attention-deficit/hyperactivity disorder in the context of autism spectrum disorders. Current Psychiatry Reports, 12(5), 382-388. doi: 10.1007/s11920-010-0145-3; 10.1007/s11920-010-0145-3

Nageswaran, S., Parish, S. L., Rose, R. A., \& Grady, M. D. (2011). Do children with developmental disabilities and mental health conditions have greater difficulty using health services than children with physical disorders? Maternal and Child Health Journal, 15(5), 634-641. doi: 10.1007/s10995-010-0597-4; 10.1007/s10995-010-0597-4

National Conference of State Legislatures. (2012). Insurance coverage for autism. Retrieved 4/3, 2013, from http://www.ncsl.org/issues-research/health/autism-and-insurance-coverage-statelaws.aspx

O'Brien, G., \& Pearson, J. (2004). Autism and learning disability. Autism : The International Journal of Research and Practice, 8(2), 125-140. doi: 10.1177/1362361304042718

Parish, S., Thomas, K., Rose, R., Kilany, M., \& McConville, R. (2012). State insurance parity legislation for autism services and family financial burden. Intellectual and Developmental Disabilities, 50(3), 190-198. doi: 10.1352/1934-9556-50.3.190; 10.1352/1934-955650.3.190 
Rhoades Smucker, J. M. (2001). Managed care and children with special health care needs. Journal of Pediatric Health Care : Official Publication of National Association of Pediatric Nurse Associates \& Practitioners, 15(1), 3-9. doi: 10.1067/mph.2001.107883

Ruble, L. A., Heflinger, C. A., Renfrew, J. W., \& Saunders, R. C. (2005). Access and service use by children with autism spectrum disorders in medicaid managed care. Journal of Autism and Developmental Disorders, 35(1), 3-13.

Siklos, S., \& Kerns, K. A. (2006). Assessing need for social support in parents of children with autism and down syndrome. Journal of Autism and Developmental Disorders, 36(7), 921933. doi: 10.1007/s10803-006-0129-7

Spann, S. J., Kohler, F. W., \& Soenksen, D. (2003). Examining parents' involvement in and perceptions of special education services: An interview with families in a parent support group. Focus on Autism \& Other Developmental Disabilities, 18(4), 228-237.

Volkmar, F., Cook, E. H.,Jr, Pomeroy, J., Realmuto, G., \& Tanguay, P. (1999). Practice parameters for the assessment and treatment of children, adolescents, and adults with autism and other pervasive developmental disorders. american academy of child and adolescent psychiatry working group on quality issues. Journal of the American Academy of Child and Adolescent Psychiatry, 38(12 Suppl), 32S-54S.

Wang, L., \& Leslie, D. L. (2010). Health care expenditures for children with autism spectrum disorders in medicaid. Journal of the American Academy of Child and Adolescent Psychiatry, 49(11), 1165-1171. doi: 10.1016/j.jaac.2010.08.003; 10.1016/j.jaac.2010.08.003

Warren, Z., Veenstra-VanderWeele, J., Stone, W., Bruzek, J. L., Nahmias, A. S., Foss-Feig, J. H., . . McPheeters, M. L. (April 2011). Therapies for children with autism spectrum disorders.. (Comparative Effectiveness Reviews no. 26 No. 11-EHC029-EF). Rockville (MD): Agency for Healthcare Research and Quality. doi: http://effectivehealthcare.ahrq.gov/ehc/products/106/651/Autism_Disorder_exec-summ.pdf 
Table 1. Description of Study Sample $(\mathbf{N}=18,702)$ by Type of Special Condition

\begin{tabular}{|c|c|c|c|c|c|c|c|c|}
\hline & \multicolumn{2}{|c|}{ ASD } & \multicolumn{2}{|c|}{$\begin{array}{l}\text { DD without } \\
\text { ASD } \\
\end{array}$} & \multicolumn{2}{|c|}{$\begin{array}{c}\text { MHC without } \\
\text { ASD }\end{array}$} & \multicolumn{2}{|c|}{$\begin{array}{l}\text { DD \& MHC } \\
\text { without ASD }\end{array}$} \\
\hline & $\mathbf{N}$ & Wt. \% & $\mathbf{N}$ & Wt. \% & $\mathbf{N}$ & Wt. \% & $\mathbf{N}$ & Wt. \% \\
\hline ALL & 3,025 & 15.9 & 2116 & $\mathbf{1 1 . 5}$ & 11,018 & 58.2 & 2,543 & 14.4 \\
\hline \multicolumn{9}{|l|}{ Gender*** } \\
\hline Male & 2,437 & 80.4 & 1217 & 59.3 & 7,071 & 62.6 & 1,664 & 63.5 \\
\hline Female & 585 & 19.6 & 896 & 40.7 & 3,929 & 37.4 & 877 & 36.5 \\
\hline \multicolumn{9}{|l|}{$\operatorname{Age}^{* * *}$} \\
\hline 3-5 years & 430 & 16.7 & 558 & 28.2 & 353 & 3.9 & 188 & 9.0 \\
\hline 6-11 years & 1,416 & 47.3 & 889 & 43.5 & 4,519 & 40.3 & 1,145 & 45.8 \\
\hline 12-17 years & 1,179 & 36.1 & 669 & 28.3 & 6,146 & 55.7 & 1,210 & 45.2 \\
\hline \multicolumn{9}{|l|}{ Race/Ethnicity*** } \\
\hline Hispanic, Any Race & 327 & 15.7 & 285 & 22.3 & 1,076 & 14.1 & 293 & 15.1 \\
\hline Non- Hispanic Whites & 2,195 & 63.1 & 1402 & 52.8 & 8,056 & 65.9 & 1,673 & 57.1 \\
\hline Non-Hispanic Blacks & 207 & 10.6 & 214 & 16.4 & 961 & 13.4 & 311 & 19.8 \\
\hline Non- Hispanic, Other & 296 & 10.6 & 215 & 8.5 & 925 & 6.6 & 266 & 8.0 \\
\hline \multicolumn{9}{|l|}{ Caregiver Education**** } \\
\hline LT HS & 125 & 7.9 & 147 & 13.0 & 633 & 12.3 & 229 & 16.5 \\
\hline HS & 376 & 15.9 & 374 & 25.1 & 1,851 & 21.1 & 522 & 26.3 \\
\hline GT HS & 2,524 & 76.2 & 1595 & 61.8 & 8,534 & 66.6 & 1,792 & 57.2 \\
\hline \multicolumn{9}{|l|}{ Poverty Level ${ }^{* * *}$} \\
\hline$<100 \%$ FPL & 481 & 18.7 & 462 & 27.0 & 2,085 & 24.2 & 706 & 35.3 \\
\hline $100-200 \%$ FPL & 622 & 21.5 & 451 & 25.6 & 2,209 & 22.1 & 609 & 26.0 \\
\hline 200 - $400 \%$ FPL & 982 & 31.8 & 685 & 27.2 & 3,304 & 27.7 & 732 & 23.9 \\
\hline$>400 \% \mathrm{FPL}$ & 940 & 28.0 & 518 & 20.2 & 3,420 & 25.9 & 496 & 14.7 \\
\hline \multicolumn{9}{|l|}{ MSA status* } \\
\hline Non- Metro & 366 & 14.3 & 340 & 15.6 & 1,654 & 15.9 & 450 & 18.7 \\
\hline Metro & 1,667 & 75.0 & 1109 & 75.8 & 5,995 & 73.9 & 1,273 & 71.1 \\
\hline$<500,000$ state population & 984 & 10.7 & 662 & 8.6 & 3,355 & 10.2 & 814 & 10.3 \\
\hline \multicolumn{9}{|l|}{ Region*** } \\
\hline West & 847 & 24.7 & 594 & 24.3 & 2,441 & 19.0 & 634 & 19.8 \\
\hline Mid-west & 636 & 19.3 & 483 & 23.0 & 2,634 & 23.1 & 549 & 22.4 \\
\hline South & 834 & 33.0 & 596 & 34.4 & 3,752 & 40.5 & 859 & 39.2 \\
\hline Northeast & 658 & 23.0 & 395 & 18.4 & 1,950 & 17.3 & 448 & 18.6 \\
\hline \multicolumn{9}{|l|}{ Marital Status $* * *$} \\
\hline Single & 251 & 9.5 & 228 & 16.1 & 1,125 & 15.4 & 315 & 18.9 \\
\hline Married & 2,107 & 69.5 & 1480 & 67.5 & 6,705 & 60.5 & 1,447 & 56.1 \\
\hline Separated/Widowed/Divorced & 451 & 21.0 & 249 & 16.5 & 1,918 & 24.0 & 465 & 25.0 \\
\hline \multicolumn{9}{|c|}{ Number of Special children in the $\mathrm{HH}^{* * *}$} \\
\hline One & 2,449 & 67.0 & 1723 & 67.4 & 8,629 & 62.1 & 1,911 & 57.3 \\
\hline Two or more & 576 & 33.0 & 393 & 32.6 & 2,389 & 37.9 & 632 & 42.7 \\
\hline
\end{tabular}


Table 1. Description of Study Sample $(\mathrm{N}=18,702)$ by Type of Special Condition

\begin{tabular}{|c|c|c|c|c|c|c|c|c|}
\hline & \multicolumn{2}{|c|}{ ASD } & \multicolumn{2}{|c|}{$\begin{array}{l}\text { DD without } \\
\text { ASD }\end{array}$} & \multicolumn{2}{|c|}{$\begin{array}{c}\text { MHC without } \\
\text { ASD }\end{array}$} & \multicolumn{2}{|c|}{$\begin{array}{l}\text { DD \& MHC } \\
\text { without ASD }\end{array}$} \\
\hline & $\mathbf{N}$ & Wt. \% & $\mathbf{N}$ & Wt. \% & $\mathbf{N}$ & Wt. \% & $\mathbf{N}$ & Wt. \% \\
\hline ALL & 3,025 & 15.9 & 2116 & 11.5 & 11,018 & 58.2 & 2,543 & 14.4 \\
\hline \multicolumn{9}{|l|}{ Health Insurance Status } \\
\hline Yes & 2,936 & 97.3 & 2041 & 96.6 & 10,680 & 96.4 & 2,464 & 96.6 \\
\hline No & 86 & 2.7 & 73 & 3.4 & 319 & 3.6 & 77 & 3.4 \\
\hline \multicolumn{9}{|l|}{ Health Insurance Type ${ }^{* * *}$} \\
\hline Private & 1,509 & 44.4 & 875 & 33.5 & 6,102 & 48.0 & 902 & 30.1 \\
\hline Public & 862 & 32.4 & 742 & 43.0 & 3,490 & 38.1 & 1,177 & 52.9 \\
\hline Both & 468 & 17.4 & 375 & 18.7 & 683 & 6.8 & 302 & 10.7 \\
\hline Other & 97 & 3.1 & 47 & 1.4 & 404 & 3.4 & 83 & 3.0 \\
\hline None & 86 & 2.7 & 73 & 3.4 & 319 & 3.6 & 77 & 3.4 \\
\hline \multicolumn{9}{|c|}{ Child's Functional Ability**** } \\
\hline Never Affected & 192 & 6.2 & 182 & 9.9 & 3,604 & 30.2 & 211 & 7.8 \\
\hline Sometimes/Very Little & 810 & 25.6 & 660 & 30.2 & 4,817 & 42.6 & 863 & 33.4 \\
\hline Always/Usually & 2,015 & 68.3 & 1269 & 59.9 & 2,565 & 27.2 & 1,465 & 58.8 \\
\hline \multicolumn{9}{|l|}{ Physical Comorbidity*** } \\
\hline Yes & 1,519 & 55.0 & 1359 & 69.3 & 5,613 & 57.0 & 1,519 & 67.0 \\
\hline No & 1,245 & 45.0 & 603 & 30.7 & 4,316 & 43.0 & 755 & 33.0 \\
\hline
\end{tabular}

Note: Based on self-reported data from caregivers $(\mathrm{N}=18,702)$ of children aged 3-17 years who had either Autism Spectrum Disorder, a Developmental Disorder, or a Mental Health condition. ASD: Autism Spectrum Disorder. DD: Developmental Disorder (Cerebral palsy, down syndrome, developmental delay, or mental retardation). MHC: Mental Health Condition (Attention Deficit Hyperactivity Disorder, anxiety, behavioral/conduct problems, or depression).LT: Less than. GT: Greater than. HS: High School. FPL: Federal Poverty Line. HH: Household. Wt.: Weighted. Asterisks represent significant differences in groups based on chi-square tests. Estimates reported correspond to column percentages. All analyses accounted for the complex survey design of 2009-2010 National Survey of Children with Special Health Care Needs (NS-CSHCN). $* * * \mathrm{P}<0.001 ; * * 0.001 \leq \mathrm{P}<0.01 ; * 01 \leq \mathrm{P}<$ 0.05 . 
Table 2. Access to Services, Quality of Care, \& Family Impact measures by type of Special Condition

\begin{tabular}{|c|c|c|c|c|c|c|c|c|}
\hline & \multicolumn{2}{|c|}{ ASD } & \multicolumn{2}{|c|}{$\begin{array}{c}\text { DD without } \\
\text { ASD } \\
\end{array}$} & \multicolumn{2}{|c|}{$\begin{array}{c}\text { MHC without } \\
\text { ASD }\end{array}$} & \multicolumn{2}{|c|}{$\begin{array}{l}\text { DD \& MHC } \\
\text { without ASD }\end{array}$} \\
\hline & $\mathbf{N}$ & $\begin{array}{c}\mathrm{Wt} . \\
\%\end{array}$ & $\mathbf{N}$ & $\begin{array}{l}\text { Wt. } \\
\%\end{array}$ & $\mathbf{N}$ & $\begin{array}{c}\text { Wt. } \\
\%\end{array}$ & $\mathbf{N}$ & $\begin{array}{c}\text { Wt. } \\
\%\end{array}$ \\
\hline $\mathbf{A L L}$ & 3,025 & 15.9 & 2,116 & 11.5 & 11,018 & 58.2 & 2,543 & 14.4 \\
\hline \multicolumn{9}{|l|}{ Access to Services } \\
\hline Difficulty Using Services*** & 1,647 & 55.2 & 918 & 43.5 & 3,724 & 36.5 & 1,253 & 51.5 \\
\hline Difficulty Getting Referrals & 340 & 29.1 & 198 & 28.1 & 675 & 23.9 & 311 & 30.0 \\
\hline Lack of Usual Source of Care & 373 & 14.0 & 254 & 13.4 & 1,469 & 14.9 & 317 & 13.6 \\
\hline Inadequate Insurance Coverage ${ }^{* * *}$ & 914 & 32.1 & 365 & 21.4 & 1,757 & 18.6 & 563 & 26.9 \\
\hline \multicolumn{9}{|l|}{ Quality of Care } \\
\hline Lack of Shared Decision Making*** & 1,205 & 43.5 & 642 & 36.3 & 3,024 & 31.3 & 941 & 38.9 \\
\hline Lack of Care Coordination*** & 2,545 & 86.7 & 1,706 & 81.5 & 6,453 & 61.3 & 2,023 & 80.6 \\
\hline No Routine Screening & 342 & 9.7 & 206 & 8.7 & 1,162 & 10.3 & 228 & 7.9 \\
\hline \multicolumn{9}{|l|}{ Family Impact } \\
\hline Financial Burden $* * *$ & 1,625 & 53.2 & 915 & 41.2 & 4,021 & 35.8 & 1,096 & 42.6 \\
\hline Employment Burden*** & 1,051 & 38.3 & 595 & 30.9 & 1,046 & 11.6 & 610 & 26.9 \\
\hline Time Burden $* * *$ & 598 & 45.6 & 504 & 44.7 & 680 & 19.2 & 430 & 35.5 \\
\hline
\end{tabular}

Note: Based on self-reported data from caregivers $(\mathrm{N}=18,702)$ of children aged 3-17 years who had either Autism Spectrum Disorder, a Developmental Disorder, or a Mental Health condition. ASD: Autism Spectrum Disorder. DD: Developmental Disorder (Cerebral palsy, down syndrome, developmental delay, or mental retardation). MHC: Mental Health Condition (Attention Deficit Hyperactivity Disorder, anxiety, behavioral/conduct problems, or depression). Wt.: Weighted. Asterisks represent significant differences in groups based on chi-square tests. Estimates reported correspond to column percentages. All analyses accounted for the complex survey design of 2009- 2010 National Survey of Children with Special Health Care Needs (NS-CSHCN). ***P $<0.001 ; * * 0.001 \leq \mathrm{P}$ $<0.01 ; * 01 \leq \mathrm{P}<0.05$. 
Table 3. Unadjusted Odds Ratios and 95\% Confidence Intervals from Logistic Regressions on Measures of Access to Services, Quality of Care, and Family Impact.

\begin{tabular}{|c|c|c|c|c|c|c|}
\hline & \multicolumn{6}{|c|}{ Unadjusted } \\
\hline & \multicolumn{2}{|c|}{ ASD vs. MHC } & \multicolumn{2}{|c|}{ ASD vs. DD } & \multicolumn{2}{|c|}{ ASD vs. DD \& MHC } \\
\hline & OR & $95 \% \mathrm{CI}$ & OR & $95 \% \mathrm{CI}$ & OR & $95 \% \mathrm{CI}$ \\
\hline \multicolumn{7}{|l|}{ Access to Services } \\
\hline Difficulty Using Services & $2.14 * * *$ & $(1.82,2.52)$ & $1.63 * * *$ & $(1.27,2.10)$ & $1.25^{*}$ & $(1.01,1.55)$ \\
\hline Difficulty Getting Referrals & $1.34 *$ & $(1.01,1.79)$ & 1.09 & $(0.75,1.58)$ & 0.98 & $(0.70,1.36)$ \\
\hline Lack of Usual Source of Care & 0.90 & $(0.72,1.14)$ & 0.90 & $(0.72,1.14)$ & 0.98 & $(0.70,1.37)$ \\
\hline Inadequate Insurance Coverage & $1.98 * * *$ & $(1.65,2.39)$ & $1.68 * *$ & $(1.16,2.45)$ & 1.22 & $(0.96,1.56)$ \\
\hline \multicolumn{7}{|l|}{ Quality of Care } \\
\hline Lack of Shared Decision Making & $1.66 * * *$ & $(1.40,1.97)$ & $1.34^{*}$ & $(1.02,1.77)$ & 1.15 & $(0.92,1.43)$ \\
\hline Lack of Care Coordination & $4.15^{* * *}$ & $(3.43,5.02)$ & $1.36^{*}$ & $(1.01,1.83)$ & $1.68 * * *$ & $(1.30,2.18)$ \\
\hline No Routine Screening & 0.88 & $(0.69,1.13)$ & 1.02 & $(0.71,1.46)$ & 1.19 & $(0.86,1.65)$ \\
\hline \multicolumn{7}{|l|}{ Family Impact } \\
\hline Financial Burden & $1.92 * * *$ & $(1.63,2.25)$ & $1.65 * * *$ & $(1.27,2.13)$ & $1.49 * * *$ & $(1.20,1.84)$ \\
\hline Employment Burden & $4.38 * * *$ & $(3.59,5.34)$ & $1.40 * *$ & $(1.08,1.81)$ & $1.63 * * *$ & $(1.29,2.05)$ \\
\hline Time Burden & $3.48 * * *$ & $(2.62,4.63)$ & 1.05 & $(0.73,1.52)$ & $1.46^{*}$ & $(1.06,2.00)$ \\
\hline \multicolumn{7}{|c|}{$\begin{array}{l}\text { Note: Based on self-reported data from caregivers (N=18,702) of children aged 3-17 years who had either Autism } \\
\text { Spectrum Disorder, a Developmental Disorder, or a Mental Health condition. ASD: Autism Spectrum Disorder. DD: } \\
\text { Developmental Disorder. MHC: Mental Health Condition (Attention Deficit Hyperactivity Disorder, anxiety, } \\
\text { behavioral/conduct problems, or depression). The reference groups for the dependent variables in the order of } \\
\text { appearance are: "No Difficulty Using Services", "No Difficulty Getting Referrals", "Presence of a Usual Source of } \\
\text { Care", and "Adequate Insurance Coverage", "Presence of Shared Decision Making", "Satisfactory Coordination } \\
\text { among Health Care Providers \& Services", "Routine Screening", "No Financial Burden", "No Employment } \\
\text { Burden", and "No Time Burden". OR: Odds Ratio. CI: Confidence Intervals. All analyses accounted for the } \\
\text { complex survey design of } 2009 \text { National Survey of Children with Special Health Care Needs (NS-CSHCN). ***P < } \\
0.001 ; * * 0.001 \leq \mathrm{P}<0.01 ; * 01 \leq \mathrm{P}<0.05 \text {. }\end{array}$} \\
\hline
\end{tabular}


Adjusted Odds Ratios and 95\% Confidence Intervals from Logistic Regressions on Measures of Access to Services, Quality of Care, and Family Impact

\begin{tabular}{|c|c|c|c|c|c|c|}
\hline & \multicolumn{6}{|c|}{ Adjusted } \\
\hline & \multicolumn{2}{|c|}{ ASD vs. MHC } & \multicolumn{2}{|c|}{ ASD vs. DD } & \multicolumn{2}{|c|}{ ASD vs. DD \& MHC } \\
\hline & AOR & $95 \% \mathrm{CI}$ & AOR & $95 \% \mathrm{CI}$ & AOR & $95 \% \mathrm{CI}$ \\
\hline \multicolumn{7}{|l|}{ Access to Services } \\
\hline Difficulty Using Services & $1.56^{* * *}$ & $(1.30,1.89)$ & $1.74 * * *$ & $(1.31,2.32)$ & $1.29 *$ & $(1.02,1.61)$ \\
\hline Difficulty Getting Referrals & 1.29 & $(0.94,1.77)$ & 1.13 & $(0.77,1.65)$ & 1.10 & $(0.77,1.57)$ \\
\hline Lack of Usual Source of Care & 1.02 & $(0.80,1.31)$ & 1.28 & $(0.88,1.86)$ & 1.18 & $(0.83,1.67)$ \\
\hline Inadequate Insurance Coverage & $1.71 * * *$ & $(1.37,2.14)$ & $1.60 *$ & $(1.10,2.33)$ & 1.21 & $(0.95,1.54)$ \\
\hline \multicolumn{7}{|l|}{ Quality of Care } \\
\hline Lack of Shared Decision Making & $1.53^{* * * *}$ & $(1.26,1.85)$ & $1.41 *$ & $(1.07,1.85)$ & $1.29 *$ & $(1.03,1.62)$ \\
\hline Lack of Care Coordination & $3.37 * * *$ & $(2.73,4.16)$ & $1.46^{*}$ & $(1.07,2.01)$ & $1.90 * * *$ & $(1.46,2.49)$ \\
\hline No Routine Screening & 0.97 & $(0.72,1.30)$ & 1.03 & $(0.71,1.50)$ & 1.34 & $(0.95,1.91)$ \\
\hline \multicolumn{7}{|l|}{ Family Impact } \\
\hline Financial Burden & $1.51 * * *$ & $(1.24,1.84)$ & $1.47 *$ & $(1.08,2.00)$ & 1.24 & $(0.99,1.56)$ \\
\hline Employment Burden & $2.91 * * *$ & $(2.35,3.61)$ & $1.71 * * *$ & $(1.32,2.21)$ & $1.75^{* * *}$ & $(1.35,2.27)$ \\
\hline Time Burden & $2.81 * * *$ & $(2.08,3.81)$ & 1.27 & $(0.89,1.83)$ & $1.60 * *$ & $(1.14,2.27)$ \\
\hline \multicolumn{7}{|c|}{$\begin{array}{l}\text { Note: Based on self-reported data from caregivers (N=18,702) of children aged 3-17 years who had either Autism } \\
\text { Spectrum Disorder, a Developmental Disorder, or a Mental Health condition. ASD: Autism Spectrum Disorder. DD: } \\
\text { Developmental Disorder (Cerebral palsy, down syndrome, developmental delay, or mental retardation). MHC: } \\
\text { Mental Health Condition (Attention Deficit Hyperactivity Disorder, anxiety, behavioral/conduct problems, or } \\
\text { depression). The reference groups for the dependent variables in the order of appearance are: "No Difficulty Using } \\
\text { Services", "No Difficulty Getting Referrals", "Presence of a Usual Source of Care", and "Adequate Insurance } \\
\text { Coverage", "Presence of Shared Decision Making", "Satisfactory Coordination among Health Care Providers \& } \\
\text { Services", "Routine Screening", "No Financial Burden", "No Employment Burden", and "No Time Burden". Each } \\
\text { model was adjusted for child's age child gender (male, female), race and ethnicity, caregiver income level, } \\
\text { metropolitan statistical area (MSA) status, geographic region, type of health insurance, number of special children in } \\
\text { the household, child's functional ability, and a physical comorbidity. AOR: Adjusted Odds Ratio. CI: Confidence } \\
\text { Intervals. All analyses accounted for the complex survey design of } 2009 \text { National Survey of Children with Special } \\
\text { Health Care Needs (NS-CSHCN). ***P }<0.001 ; * * 0.001 \leq \mathrm{P}<0.01 ; * 01 \leq \mathrm{P}<0.05 \text {. }\end{array}$} \\
\hline
\end{tabular}




\title{
Chapter Three
}

\section{Role of State Policies and Healthcare Workforce in Improving Access to Services and Family Impact for Caregivers of Children with Autism Spectrum Disorders (ASD)}

\begin{abstract}
Aim: To report the variations across 50 states and DC and examine the impact of state health policies and workforce on caregiver reported access to services and family impact for children with ASD.
\end{abstract}

Methods: Data on caregivers of children with ASD was drawn from 2009-2010 National Survey for Children with Special Health Care Needs $(\mathrm{N}=3,025)$ with a representative sample from each state. Two state health policy (Medicaid Income Eligibility \& autism mandate as a proxy measure of states' autism health care initiative) and two state health care workforce' (Child to Pediatrician Ratio \& Special Education Teachers per 1,000 Special Education Students) estimates were taken from publicly available sources. Binary dependent outcome measures included caregiver reported: 1) Access to services (Difficulty using services, difficulty getting referrals, lack of source of care, and inadequate insurance coverage); 2) Impact of the condition on the family (Financial, Time-related, and Employment burden). Multilevel regressions were used to model the associations between state contextual characteristics and dependent outcome measures, controlling for state median household income, percentage of children in poverty, percentage of children with developmental disorders, child, and caregiver level characteristics.

Results: The caregivers of children with ASD reported difficulty using services $(54.5 \%)$, difficulty getting referrals $(27.7 \%)$, lack of source of care $(18.2 \%)$, inadequate insurance coverage $(31.2 \%)$, financial burden $(54 \%)$, time-related burden $(39.5 \%)$, and employment burden (35\%). The study had mixed findings from multilevel regression: In general, Medicaid income 
eligibility threshold of $\leq 100 \%$ FPL was associated with lower likelihood of difficulty getting referrals, reporting lack of source of care, and inadequate insurance coverage. Having an autism mandate in the state was associated with greater odds of reporting difficulty using services, lack of source of care, inadequate insurance coverage, but lower likelihood of reporting financial burden. For the state health care workforce, increase in child to pediatrician ratio was associated with increased likelihood of reporting problems with all measures of access. Increase in special education teachers per 1,000 special education students was associated with lower odds of reporting difficulty using services, time -related and employment burden.

Conclusion: State contextual characteristics play a significant role in determining the caregiver reported access to services and family impact for children with ASD, above and beyond the child and caregiver characteristics. State Medicaid income eligibility, autism mandate, and state health care workforce are significant predictors of caregiver reported problems with access and impact of the condition on the family. In general, lower Medicaid income eligibility, no autism mandate, greater proportion of pediatricians and special education teachers in a state was associated with lower likelihood of reporting problems with accessing services and adverse family impact. However, due to the mixed nature of the results from this study, caution is warranted in the interpretation and extrapolation of these findings and further studies are required to establish a robust relationship between state contextual characteristics and outcome measures used in the study.

Keywords: autism, state health policy, Medicaid, workforce, autism mandate. 


\section{INTRODUCTION}

Families of children with Autism Spectrum Disorders (ASD) have consistently reported problems accessing quality services (Kogan et al., 2008b; Krauss, Gulley, Sciegaj, \& Wells, 2003; Liptak et al., 2006; Liptak et al., 2008; Montes, Halterman, \& Magyar, 2009; Nageswaran, Parish, Rose, \& Grady, 2011). Families of children with ASD have also reported greater health related, financial and time burden as compared to typically growing as well as other children with special health care needs (Johnson, Frenn, Feetham, \& Simpson, 2011; Khanna et al., 2011; Kogan et al., 2008a). Many studies suggest the role of state policies and health care practices in improving access to and quality of services, but very few have analyzed their link with the caregiver perceived access to services and impact on the families of children with ASD. A study by Thomas et al. studied the role of state residence and Medicaid reimbursement rates on identification of ASD, and problems with accessing services using the 2005 National Survey of Children with Special Health Care Needs (NS-CSHCN) for families of children with and without ASD (Thomas, Parish, Rose, \& Kilany, 2012). The authors observed significant variation in identification of ASD among states and an independent effect of Medicaid reimbursement rate on problems accessing services for families of children with and without ASD. The findings showed that families raising children with autism and living in states with higher reimbursement rates reported lower odds of experiencing problems accessing care. Another study examined the impact of state Medicaid policy choices on problems accessing health care services (S. L. Parish, Rose, Yoo, \& Swaine, 2012). Study findings indicated that families of low income southern CSHCN who resided in states with less frequent Medicaid eligibility renewal requirements and higher Medicaid reimbursements reported better health care access as compared to their southern counterparts in states with more frequent eligibility renewals and lower reimbursement rates. 
The current study aims to examine the association of state Medicaid income eligibility threshold level and autism coverage mandate (National Conference of State Legislatures, 2012) with problems accessing services and family impact reported by caregivers of children with ASD. This study will also assess the impact of state health care workforce such as the strength of pediatrician and special education teachers' workforce on access to services and family impact reported by caregivers of children with ASD.

State Policy Characteristics: Problems in accessing services and consequent burden on a family of a child with a disability such as ASD can vary depending on the extent of support from state infrastructural and health care systems. Provision of services for children with ASD under such systems may be determined by state health policies such as state Medicaid program and autism coverage mandate to a certain extent (National Conference of State Legislatures, 2012).

Medicaid, a jointly funded state and federal health program plays a critical role in providing access to services for children, especially those from low income families (Vivier, 2005) and with developmental disabilities such as ASD (Braddock, Hemp, Rizzolo, Parish, \& Pomeranz, 2002). A recent study showed that Medicaid delivered services to almost $45 \%$ of children with ASD aged 3-17 years through special education. In addition, the treated prevalence of ASD in Medicaid system rose significantly from 2.26 to 3.39 per 1000 from the year 2001-2005 (Semansky, Xie, \& Mandell, 2011). Being one of the major funding sources for children with ASD, it is possible that families that live in states with greater generosity (higher income eligibility level) are less likely to report problems accessing services and eventually the financial burden associated with the child's health care needs. This may also be attributed to two reasons : 1) State Medicaid programs determine the type and extent of services provided, which may range from screening, diagnosis, functional assessment to behavioral therapies, respite care, and other 
home and community based services for children with ASD and their caregivers, where insurance coverage acts as a facilitator to accessing such services; and 2) Medicaid services are offered depending on the income eligibility threshold level per state, where greater income eligibility threshold is associated with greater number of children with ASD covered. A study (S. L. Parish, Shattuck, \& Rose, 2009) examined the association of financial burden in families of low income CSHCN with variability in state's Medicaid and Children's Health Insurance Program (SCHIP) generosity. Families living in states with higher Medicaid and SCHIP income eligibility guidelines were less likely to have high financial burden. However, no other study has been conducted to assess the association of state Medicaid income eligibility level with problems accessing services and family impact for caregivers of children with ASD. The current study aims to examine the association of state Medicaid income eligibility threshold level with caregiver reported problems accessing services and impact of the condition on the family. Another state health policy that has risen of importance to children with ASD is the autism coverage mandate (sec. 1501) (Patient protection and affordable care act, 2010) which requires state health insurance programs to cover diagnosis, screening, medical, psychiatric, and behavioral treatments deemed necessary for the child with ASD by a licensed professional. Even though, some state mandates may limit coverage of services such as ABA to certain amount per annum, but a passed bill indicates state's inclination towards taking autism specific health care initiatives (National Conference of State Legislatures, 2012). The autism mandates are adopted by some states to reduce the financial burden on families of children with ASD by covering exorbitantly costly treatments such as Applied Behavior Analysis (as high as $\$ 150,000$ per year).

The states that passed mandate before or during the survey period (2009) including some type of coverage were: Arizona, Connecticut, Colorado, Florida, Illinois, Indiana, Louisiana, 
Montana, New Jersey, New Mexico, Pennsylvania, South Carolina, Texas, Wisconsin (National Conference of State Legislatures, 2012). States that provided very limited or no coverage at all were assigned as less active states in terms of autism health care initiatives. This study hypothesizes that states with autism coverage mandate and higher Medicaid income eligibility threshold will report better access to services and lower family impact as compared to states with no mandates and lower Medicaid income eligibility threshold.

Healthcare Workforce: Among some of the issues with health care reported by caregivers of children with ASD, one is the lack of usual source of care (Lin, Yu, \& Harwood, 2012) and unmet specialty and usual services' needs (Chiri \& Warfield, 2012; Kogan et al., 2008a). Lack of qualified/skilled primary care and specialty providers has been reported to be a major concern by advocates of autism health care as well as families of children with ASD (Krauss, Gulley, Sciegaj, \& Wells, 2003; Mauch, Pfefferle, Booker, Pustell, \& Levin, 2011; Warfield \& Gulley, 2006). Children with ASD receive services at two points: School district and health care workforce. Provision of school special education under the federal legislation of Individuals with Disabilities Education Act (IDEA; Public Law 101-157; U.S. Department of Education, 1997) is a primary source of health related services for children with ASD. Special education includes services designed to improve development of the child with ASD based on an individualized education program (IEP: a legal document that includes provision of services like special education classes and related services like physical, behavioral, occupational, and speech/language therapies and number/hours per week of special education teachers and/or other paraprofessionals assigned to the child with the disability, depending on his/her needs). In the year 2009-2010, children with ASD formed 5.8\% of the special education population in the US, as compared to only $1.5 \%$ in the year 2000-2001 (Scull \& Winkler M., 2011). The role of school 
provided special education has been described as critical in development of the child with a disability (Rodriguez, Saldana, \& Moreno, 2012), where teacher training has led to positive outcomes for the child with ASD (Probst \& Leppert, 2008). There is a reported shortage of special education teachers/paraprofessionals in the United States and a need of more trained professionals has been underlined in the literature (Smith, Tyler, Montrosse, \& Young, C., \& Robb, S.M., 2011).

Health care providers like pediatricians or child physicians are generally the primary contact for caregivers of children with a developmental disability such as ASD (Tchaconas \& Adesman, 2013). It is generally the pediatricians who are approached by parents of the child with ASD for screening, diagnosis, and assessment of their child's development. According to the American Academy of Pediatrics, the role of pediatricians is very critical in early or timely identification and evaluation of the child with ASD (Committee on Children With Disabilities, 2001; Johnson, Myers, \& American Academy of Pediatrics Council on Children With Disabilities, 2007). However, it has been observed that geographic maldistribution of pediatricians and greater proportion of them working part-time now, has had a potential impact on workforce shortage, especially in rural areas (Althouse \& Stockman, 2011). In such circumstances, caregivers of children with ASD may face delays in diagnosis, screening, and early interventions due to lack of easy availability of pediatricians as well as other subspecialists for their child with ASD.

Some studies have shown that state pediatrician and special education teachers' workforce is associated with identification/screening of children with ASD and consequent reports of unmet needs by their caregivers/families. Mandell and Palmer (2005) found that prevalence and identification of ASD in a state is associated with availability of pediatrician 
supply and school based health centers in the state. Another study by Mayer et al (Mayer, Skinner, Slifkin, \& National Survey of Children With Special Health Care Needs, 2004) showed that greater general pediatricians and subspecialists supply was directly associated with lower likelihood of reporting unmet needs with routine and specialty care for CSHCN. However, none of the above studies examined the association of pediatrician and special education teachers' supply with caregiver perceived access to services and family impact. Considering the increasing prevalence of ASD (Autism and Developmental Disabilities Monitoring Network Surveillance Year 2008 Principal Investigators \& Centers for Disease Control and Prevention, 2012), a considerable strength of pediatricians and special education professionals will be needed to ensure easy access for timely screening, assessment and development of children with ASD. This study will assess the association of healthcare workforce such as the strength of pediatrician and school special education teacher workforce with caregiver reported problems accessing services and impact of the condition on the family. It is hypothesized that greater strength of health care workforce will be associated with better access and lower family impact.

The current study is the first one to examine the impact of both state health policies and health care workforce on the caregiver reported problems in accessing services and family impact. Other studies have either focused on assessing the impact of state policies on access to care for children with special health care needs, especially those from low income families (S. L. Parish, Shattuck, \& Rose, 2009; S. L. Parish, Rose, Yoo, \& Swaine, 2012) or on identification of children with ASD (Mandell \& Palmer, 2005). Our study will use a hierarchical generalized linear modeling technique to account for clustering of observations within a state and use the 2009-2010 National Survey of Children with Special Health Care Needs (NS-CSHCN). 


\section{METHODS}

\section{Data}

The 2009-2010 National Survey of Children with Special Health Care Needs (NS-CSHCN) provides child- and household- level data along with state of residence for the analyses (Maternal and Child Health Bureau, Data Resource Center for Child and Adolescent Health, 2011). The National Survey of Children with Special Health Care Needs is a computer assisted random digit dial telephone survey with a complex multistage design representative of the US civilian noninstitutionalized population with children aged 0 to 17 years with and without special health care needs. The analyses reported here is based on sample of children from 49 states and DC in the United States who were identified as CSHCN through survey's CSHCN screener $(\mathrm{N}=40,242)$. Study population included children aged 3-17 years age with a parent reported current diagnosis of autism/Asperger's disorder/ Pervasive developmental disorder/Other autism spectrum disorder and available state level data within the survey $(\mathrm{N}=3,025)$.

State-level data were compiled from multiple sources. Estimates on proportion of state children in poverty were taken from American Community Survey (Macartney, 2011). Proportion of children with developmental/behavioral/emotional disorders were provided by Annie E. Casey foundation (The Annie E. Casey Foundation, 2011). State median household annual income 2009 estimates were collected from American Community Survey (Noss, 2011). Data on Medicaid income eligibility as percentage of federal poverty level were drawn from Kaiser Commission on Medicaid and the Uninsured (Donna Cohen, Marian, Samantha, \& Caryn, 2009). Autism coverage mandate passed by the state legislature before 2009 was drawn from

National Conference of State Legislatures (National Conference of State Legislatures, 2012). 
The number of children per pediatrician in a state was provided by American Board of Pediatrics (American Board of Pediatrics, 2012). The data on number of school special education personnel per thousand special education students in a state was provided by Thomas B. Fordham Institute (Scull \& Winkler M., 2011). These special education employees included those who might provide one-on-one tutoring, assist with classroom management, conduct parental-involvement activities, or provide instructional support under the supervision of a teacher. Use of this state level data was exempt from Office of Human Research Ethics oversight because the data were already available for public access and use.

Individual covariates. Covariates included an indicator of child's age (3-5 years, 6-11 years, and 12-17 years), child gender (male, female), race and ethnicity (non- Hispanic Whites, Blacks, other races, and any Hispanic race), caregiver education level (Less than high school, high school, and greater than high school), caregiver household income relative to the FPL ( $<100 \%$ FPL, 100-200\% FPL, 200-400\% FPL, and >400 \% FPL).

State covariate. Three state level covariates were modeled: percentage of children in poverty which was an indicator of state's general wealth (one unit difference $=1$ percentage point). Percentage of children with developmental/emotional/behavioral disorders was used as an indicator of state developmental disability burden (one unit difference $=1$ percentage point). State median household income for the year 2009 was included as a measure of state relative wealth (in thousands of dollars).

State- independent variables. Two types of state measures were used: State health policy and health care workforce. State health policy indicator were Medicaid income eligibility standard as percent of FPL for children aged 6 - 19 years of age and an effective State autism insurance 
coverage mandate (Yes/No). Health care workforce indicators were: 1) Number of children per pediatrician (Child to Pediatrician ratio), where an increase in the ratio indicates lesser number of pediatricians per child available in the state; 2) Number of special education personnel (Teacher to special education student ratio) per thousand special education students in the state, where an increase in the ratio indicates more number of personnel available in state schools.

\section{Dependent variables}

Access to Services. According to Aday and Andersen access is defined as not only by the availability of resources or the ability to obtain it but also actual utilization of services (Aday \& Andersen, 1981; Aday \& Andersen, 1984). For the current study, the services include those offered by primary care providers, schools, hospital systems, other clinics/health centers, and any other relevant institution. Access to services was assessed using four binary measures of problems accessing health care from the NS-CHSCN: difficulty using services, difficulty getting referrals, lack of source of care, and adequacy of health insurance coverage. Difficulty using services is based on a yes/no question, "During the past year, have you had any difficulties using or delay in services?" Difficulty getting referrals was derived from the question, "Was getting referrals a big problem, a small problem, or not a problem?", and categorized into big/small problem and no problem. Lack of source of care is a yes/no question, "Does the child have a personal doctor and received all routine/specialty care, when needed?" Adequacy of health insurance was derived from the question, "Did the health insurance provide benefits that meet child's needs and allowed to see a provider?", categorized into never/sometimes and usually/always. 
Impact of the condition on the family or family impact. This outcome was assessed using three binary measures of family burden due to child's condition: financial burden, employment burden, and time-related burden. Financial burden was derived from question, " Whether family paid $\$ 5,000, \$ 1,000$ to $\$ 5,000$, or less than $\$ 1,000$ for child's medical care, excluding health insurance premiums and costs reimbursed by insurance or other payment sources?", which was categorized into $\geq \$ 1,000$ and $<\$ 1000$ spending. Employment burden was a yes/no question, "Did the caregiver stop working because of child's condition?" Time related burden was assessed via question "Number of hours the caregiver spends in providing, arranging, and coordinating care for the child with the condition?" where the variable was categorized into $\geq 10$ hours and $<10$ hours per week, a cut off which has been used previously by Kogan et al. (2008).

\section{Analysis}

The study used hierarchical generalized linear modeling which accommodates binary logistic regression with multilevel data. Multilevel models of caregivers nested within states were used because they concurrently partition the variance in the outcome into individual-level and state-level components in the same single model. These models ensure that state-level variables explain between-state variation only. Further, they correctly estimate inflated standard errors for state structural factors such as health policy and health care workforce. Two separate models for each outcome measures were run: Health Policy and Healthcare Workforce model. All basic analysis was performed using SAS 9.3 and multilevel regression analysis was performed using STATA version 11 package. 


\section{RESULTS}

Table 1 represents the child, caregiver and state characteristics for children with ASD. The sample $(n=3,025)$ was primarily male children $(80 \%)$ who were always affected functionally $(66 \%)$, non-Hispanic Whites $(72 \%)$, caregivers with greater than high school education (83\%) and above 200\% FPL (63\%). In terms of caregiver reported problems with access, around 54\% reported difficulties using services, $27 \%$ reported difficulty getting referrals, $31 \%$ reported inadequate insurance coverage, and $18 \%$ reported lack of source of care. More than half of the sample reported financial burden (54\%), followed by $39 \%$ reporting time related burden and $35 \%$ reporting employment burden. On an average, $18 \%$ of state children lived in poverty and $16 \%$ of state population had a developmental disorder. Mean median annual household income was $\$ 52,300$ for all states. Mean Medicaid income eligibility threshold level was $155 \%$ FPL. In terms of workforce, on an average there were 1,600 children per pediatrician in a state and 137 special education teachers per 1,000 special education students in a state. Table 2 demonstrates the variations in proportion of caregivers reporting problems in accessing services and family impact. Proportion of caregivers reporting: difficulty using services ranged from $34 \%$ in District of Columbia to $76 \%$ in Arizona, difficulty getting referrals ranged from $3.4 \%$ in North Carolina to $71 \%$ in South Carolina, lack of source of care ranged from $7.4 \%$ in Tennessee to $39 \%$ in Nevada, and inadequate insurance coverage ranged from $15 \%$ in Rhode Island to $62 \%$ in Illinois. Financial burden was lowest at $23.9 \%$ in District of Columbia and highest at $73.5 \%$ in Massachusetts; employment burden ranged from $12.7 \%$ in Arkansas to $52 \%$ in South Carolina; and time burden ranged from 3.7\% in Wyoming to $74 \%$ in Ohio.

Table 3 and 4 show multilevel regression results for impact of state health policy and healthcare workforce on caregiver reported problems accessing services and family impact. 
Autism mandate coverage was significantly associated with caregiver reported difficulty using services, lack of source of care, and inadequate insurance coverage. Having an autism coverage mandate was associated with higher odds of reporting problems accessing services, where the increase in likelihood of reporting problems ranged from $25 \%$ (difficulty using services) to $53 \%$ (inadequate insurance coverage). Medicaid income eligibility threshold was also significantly associated with problems accessing services, where $\leq 100 \%$ FPL threshold was associated with lower likelihood of difficulties getting referrals $(\mathrm{AOR}=0.71)$, reporting lack of source of care $(\mathrm{AOR}=0.53)$, and inadequate insurance coverage $(\mathrm{AOR}=0.70)$. For measures of family impact, states with autism insurance mandate were associated with lower likelihood of reporting financial burden $(A O R=0.99)$, but higher likelihood of time- related burden $(A O R=1.39)$. Medicaid income eligibility threshold level of $\leq 100 \%$ FPL was associated with lower likelihood of employment and time related burden.

Table 5 and 6 summarize the results from multilevel regression for association of health care workforce with problems accessing services and family impact. An increase in child to pediatrician ratio by 100 was associated with higher likelihood of reporting difficulty using services $(A O R=1.03)$, difficulty getting referrals $(A O R=1.11)$, lack of source of care $(A O R=$ $1.03)$, and inadequate insurance coverage $(A O R=1.03)$. An increase in number of special education teachers by 10 in a state was associated with lower likelihood of difficulty using services $(A O R=0.99)$. An increase in special education teachers by 10 was also associated with a lower likelihood of caregivers reporting employment $(\mathrm{AOR}=0.99)$ and time-related burden $(\mathrm{AOR}=0.96)$

The impact of state covariates on problems accessing services and family impact was also observed. An increasing proportion of children in poverty were associated with higher 
likelihood of problems accessing services. An increasing proportion of children with a developmental disorder in the state was associated with greater likelihood of having difficulties using services $(\mathrm{AOR}=1.05)$, but lower likelihood of reporting inadequate insurance coverage $(\mathrm{AOR}=0.97)$. An increase in median household income by $\$ 1000$ was associated with greater likelihood of reporting problems with accessing services, financial, and employment burden. However, median household income was not associated with any measure of family impact in the healthcare workforce model (Table 6). 


\section{DISCUSSION}

The current study results are based on hierarchical generalized linear model, where we measured the impact of state health policy choices and healthcare workforce on caregiver reported problems accessing services and family impact. Findings indicate that there is a significant variation explained by state covariates and independent variables $(8-22 \%)$ for problems accessing services and family impact. The current study yielded mixed findings about the impact of state health policies and workforce on caregiver reported problems accessing services and family impact for children with ASD. Among the state health policy choices, both Medicaid income eligibility threshold and autism coverage mandate was significantly associated with the problems accessing care and family impact measures. Medicaid income eligibility threshold level below and equal to $100 \%$ FPL was associated with lower likelihood of difficulties getting referrals, lack of usual source of care, and inadequate insurance coverage. These findings differ from findings by Parish et al. (S. L. Parish, Shattuck, \& Rose, 2009) who found that increasing threshold of Medicaid income eligibility level is associated with lower likelihood of financial burden. In this study, the Medicaid income eligibility level threshold was not associated with caregiver reported financial burden. Another significant finding was the association of autism coverage mandate, where having a mandate in the state was associated with greater problems accessing services but lower financial burden. This was an unexpected finding; autism coverage mandate (National Conference of State Legislatures, 2012) was developed to allow the families of children with ASD to access services that they couldn't earlier due to exorbitant costs incurred by services such as Applied Behavior Analysis. There could be two reasons for this finding: 1) the current study did not account for diffusion of policy effects in the state. The autism coverage mandate was used as a proxy measure for state's active role in autism 
health care initiatives and cannot be directly associated with the impact of the policy itself; and 2) It is possible that the states which offer insurance coverage for the services may be affected by other issues such as lack of workforce and trained professionals across all geographical regions evenly in the state, giving rise to caregiver dissatisfaction with availability of services.

Health care workforce was also found to be important determinants of access problems and family impact reported by caregivers of children with ASD. Higher child to pediatrician ratio in a state was associated with higher likelihood of difficulty using services, reporting lack of source of care, and inadequate insurance coverage. This means that lesser number of pediatricians per state is associated with greater access issues, which has been suggested by other studies as well (Mandell \& Palmer, 2005). We also examined the impact of school special education teacher student ratio on problems with access and family impact. Increasing number of special education teachers per 1000 special education students in a state school was associated with lower likelihood of difficulty using services and reporting lack of source of care. Knowing that special education is one of the major health care workforce for children with ASD and there is a paucity of special education professionals in the US (Mauch, Pfefferle, Booker, Pustell, \& Levin, 2011; Scull \& Winkler M., 2011), it is imperative to have more trained workforces for providing developmental services to children with ASD. Another significant finding was the association of special education teacher student ratio with employment and time-related burden, where greater number of special education teachers per 1000 special education students was associated with lower likelihood of reporting employment and time-related burden. It has been observed that caregivers of children with ASD demand better quality, and more number of hours of special education interventions in schools and feel the needs of their child are not fulfilled by the time spent with the paraprofessionals as compared to caregivers of other children with 
disabilities in schools (Etscheidt, 2003; Spann, Kohler, \& Soenksen, 2003). Since the strength of the schools' special education professionals is a direct contributor to the amount of time a special education teacher can spend with the child with the disability, the low workforce can have a direct/indirect impact on caregiver burden. The current findings indicate that greater special education teacher workforce in a state is associated with lower burden on caregivers of children with ASD. It has been mentioned by the Centers for Medicaid and Medicare, that lack of trained workforce for children with ASD is one the deficit areas for states to improve on to provide better access and quality of care (Mauch, Pfefferle, Booker, Pustell, \& Levin, 2011). Also, with the changes in screening and diagnostic criteria in $D S M-V$, changes in epidemiology of ASD is also expected (American Psychiatric Association, 2012). With such changes, the role of pediatricians and other trained professionals is expected to expand significantly.

The current study has limitations. The analyses we conducted are cross-sectional and correlational and causality between the state independent variables and outcome measures of our study cannot be inferred. Even though most of the state level covariates and independent variables were drawn from established sources, establishing the validity of such measures was not possible in the study. Inferences from this study should be derived with caution, keeping in mind the multiple sources of data used. The current study assessed the variations between states, but estimated a population average effect of state covariates and independent variables on the outcome measures. Therefore, a state-specific effect on the outcome measures cannot be drawn. However, the variation accounted by state variables when the model was fit ranged between 8 to $22 \%$, which is still significant. Some of study findings showed unexpected results, where higher state Medicaid income eligibility threshold, median annual household income was associated with greater likelihood of experiencing problems accessing services and family impact. Even 
though similar results have been observed in Parish et al (S. L. Parish, Shattuck, \& Rose, 2009), where greater income was associated with report of greater absolute and relative financial burden, further detailed studies are required to assess a robust relationship between median household income and caregiver perceptions about availability of and access to services. Outcomes measures in the study were adopted from the core outcomes designed by the Maternal Child and Health Bureau and have been utilized in some other studies as well (Kogan et al., 2008b; Nageswaran, Parish, Rose, \& Grady, 2011). However, the present study did not establish any validity or reliability of these measures. Therefore, replication of the study results may vary depending on the items used to define the outcome measures.

The current study has several strengths as well. To the best of our knowledge, this is the first study to examine the impact of state health policy and health care workforce on caregiver reported problems accessing services and family impact. The study used 2009-2010 NSCSHCN, where sampling design allowed for representative sample of children with ASD from each state. Also, the clustering of caregivers of children within states was accounted for in the multilevel modeling, where the relationships between state health policy and health care workforce with outcome measures were observed.

\section{CONCLUSION}

Significant variation exists among states for problems accessing services and impact of the condition on the family for caregivers of children with ASD. State health policy and workforce have an independent effect on problems accessing services and family impact. Higher state Medicaid income eligibility threshold and autism mandate coverage in a state was associated with greater access problems. However, having autism mandate coverage was 
associated with lower financial burden. Greater strength of health care workforce such as pediatrician to children ratio was associated with lower likelihood of reporting difficulties using services, getting referrals, lack of source of care, and inadequate insurance coverage. Increase in special education teacher to student ratio was associated with lower likelihood of difficulties using services, and experiencing employment and time-related burden. Further studies are required to assess a robust relationship between the state contextual variables and caregiver reported access and family impact for children with ASD. 


\section{REFERENCES}

Aday, L. A., \& Andersen, R. M. (1981). Equity of access to medical care: A conceptual and empirical overview. Medical Care, 19(12), 4-27.

Aday, L. A., \& Andersen, R. M. (1984). The national profile of access to medical care: Where do we stand? American Journal of Public Health, 74(12), 1331-1339.

Althouse, L. A., \& Stockman, J. A. (2011). The pediatric workforce: An update on general pediatrics and pediatric subspecialties workforce data from the american board of pediatrics. The Journal of Pediatrics, 159(6), 1036-40.e3. doi:10.1016/j.jpeds.2011.07.043; 10.1016/j.jpeds.2011.07.043

American Board of Pediatrics. (2012). Workforce data: 2011-2012. American Board of Pediatrics.

American Psychiatric Association. (2012). DSM-5 proposed criteria for autism spectrum disorder designed to provide more accurate diagnosis and treatment. (News Release No. 12-03). Arlington,VA: American Psychiatric Association.

Autism and Developmental Disabilities Monitoring Network Surveillance Year 2008 Principal Investigators, \& Centers for Disease Control and Prevention. (2012). Prevalence of autism spectrum disorders--autism and developmental disabilities monitoring network, 14 sites, united states, 2008. Morbidity and Mortality Weekly Report.Surveillance Summaries (Washington, D.C.: 2002), 61(3), 1-19.

Braddock, D., Hemp, R., Rizzolo, M. C., Parish, S., \& Pomeranz, A. (2002). The state of the states in developmental disabilities: 2002 study summary. (Brief Report). Boulder, CO: University of Colorado: Coleman Institute for Cognitive Disabilities and the Department of Psychiatry.

Chiri, G., \& Warfield, M. E. (2012). Unmet need and problems accessing core health care services for children with autism spectrum disorder. Maternal and Child Health Journal, 16(5), 1081-1091. doi:10.1007/s10995-011-0833-6; 10.1007/s10995-011-0833-6

Committee on Children With Disabilities. (2001). American academy of pediatrics: The pediatrician's role in the diagnosis and management of autistic spectrum disorder in children. Pediatrics, 107(5), 1221-1226.

Donna Cohen, R., Marian, J., Samantha, A., \& Caryn, M. (2009). A foundation for health reform: Findings of a 50 state survey of eligibility rules, enrollment and renewal procedures, and cost- sharing practices in medicaid and CHIP for children and parents during 2009. kaiser commission on medicaid and the uninsured. 〈br / > ( No. 8028). The Henry J. Kaiser Family Foundation. 
Etscheidt, S. (2003). An analysis of legal hearings and cases related to individualized education programs for children with autism. Research \& Practice for Persons with Severe

Disabilities, 28(2), 51-69.

Johnson, C. P., Myers, S. M., \& American Academy of Pediatrics Council on Children With Disabilities. (2007). Identification and evaluation of children with autism spectrum disorders. Pediatrics, 120(5), 1183-1215. doi:10.1542/peds.2007-2361

Kogan, M. D., Strickland, B. B., Blumberg, S. J., Singh, G. K., Perrin, J. M., \& van Dyck, P. C. (2008a). A national profile of the health care experiences and family impact of autism spectrum disorder among children in the United States, 2005-2006. Pediatrics, 122(6), e1149-58. doi:10.1542/peds.2008-1057; 10.1542/peds.2008-1057

Kogan, M. D., Strickland, B. B., Blumberg, S. J., Singh, G. K., Perrin, J. M., \& van Dyck, P.,C. (2008b). A national profile of the health care experiences and family impact of autism spectrum disorder among children in the United States, 2005-2006. Pediatrics, 122(6), e1149-e1158.

Krauss, M. W., Gulley, S., Sciegaj, M., \& Wells, N. (2003). Access to specialty medical care for children with mental retardation, autism, and other special health care needs. Mental Retardation, 41(5), 329-339. doi:2

Lin, S. C., Yu, S. M., \& Harwood, R. L. (2012). Autism spectrum disorders and developmental disabilities in children from immigrant families in the united states. Pediatrics, 130 Suppl 2, S191-7. doi:10.1542/peds.2012-0900R; 10.1542/peds.2012-0900R

Liptak, G. S., Benzoni, L. B., Mruzek, D. W., Nolan, K. W., Thingvoll, M. A., Wade, C. M., \& Fryer, G. E. (2008). Disparities in diagnosis and access to health services for children with autism: Data from the national survey of children's health. Journal of Developmental and Behavioral Pediatrics : JDBP, 29(3), 152-160. doi:10.1097/DBP.0b013e318165c7a0; 10.1097/DBP.0b013e318165c7a0

Liptak, G. S., Orlando, M., Yingling, J. T., Theurer-Kaufman, K., Malay, D. P., Tompkins, L. A., \& Flynn, J. R. (2006). Satisfaction with primary health care received by families of children with developmental disabilities. Journal of Pediatric Healthcare, 20(4), 245-252.

Macartney, S. (2011). Child poverty in the united states 2009 and 2010: Selected race groups and hispanic origin. (American Community Survey Briefs No. ACSBR/10-05).American Community Survey.

Mandell, D. S., \& Palmer, R. (2005). Differences among states in the identification of autistic spectrum disorders. Archives of Pediatrics \& Adolescent Medicine, 159(3), 266-269. doi:10.1001/archpedi.159.3.266

Maternal and Child Health Bureau, Data Resource Center for Child and Adolescent Health. (2011). National survey of children with special health care needs: Fast facts about the 
survey. Retrieved 3/25, 2013, from http://www.childhealthdata.org/docs/default-documentlibrary/ns-cshcn-fast-facts-2009.pdf

Mauch, D., Pfefferle, S., Booker, C., Pustell, M., \& Levin, J. (2011). Report on state services to individuals with autism spectrum disorders (ASD). ( No. S-10 CMS-33 No. 2). Centers for Medicare \& Medicaid Services (CMS) ASD Services Project: Centers for Medicare \& Medicaid Services (CMS).

Mayer, M. L., Skinner, A. C., Slifkin, R. T., \& National Survey of Children With Special Health Care Needs. (2004). Unmet need for routine and specialty care: Data from the national survey of children with special health care needs. Pediatrics, 113(2), e109-15.

Montes, G., Halterman, J. S., \& Magyar, C. I. (2009). Access to and satisfaction with school and community health services for US children with ASD. Pediatrics, 124, S407-S413. doi:10.1542/peds.2009-1255L

Nageswaran, S., Parish, S. L., Rose, R. A., \& Grady, M. D. (2011). Do children with developmental disabilities and mental health conditions have greater difficulty using health services than children with physical disorders? Maternal and Child Health Journal, 15(5), 634-641. doi:10.1007/s10995-010-0597-4; 10.1007/s10995-010-0597-4

National Conference of State Legislatures. (2012). Insurance coverage for autism. Retrieved 4/3, 2013, from http://www.ncsl.org/issues-research/health/autism-and-insurance-coverage-statelaws.aspx

Noss, A. (2011). Household income for states: 2009 and 2010. american community survey briefs. . ( No. ACSBR/10-02).U.S. Department of Commerce, Economics and Statistics Administration U.S. Census Bureau.

Parish, S. L., Rose, R. A., Yoo, J., \& Swaine, J. G. (2012). State medicaid policies and the health care access of low-income children with special health care needs living in the american south. North Carolina Medical Journal, 73(1), 15-23.

Parish, S. L., Shattuck, P. T., \& Rose, R. A. (2009). Financial burden of raising CSHCN: Association with state policy choices. Pediatrics, 124 Suppl 4, S435-42. doi:10.1542/peds.2009-1255P; 10.1542/peds.2009-1255P

Patient protection and affordable care act, Pub L. 111-148 (2010).

Probst, P., \& Leppert, T. (2008). Brief report: Outcomes of a teacher training program for autism spectrum disorders. Journal of Autism and Developmental Disorders, 38(9), 1791-1796. doi:10.1007/s10803-008-0561-y; 10.1007/s10803-008-0561-y

Rodriguez, I. R., Saldana, D., \& Moreno, F. J. (2012). Support, inclusion, and special education teachers' attitudes toward the education of students with autism spectrum disorders. Autism Research and Treatment, 2012, 259468. doi:10.1155/2012/259468; 10.1155/2012/259468 
Scull, J., \& Winkler M., A. (2011). Shifting trends in special education. ().Thomas B. Fordham Institute, Advancing Educational Excellence.

Semansky, R. M., Xie, M., \& Mandell, D. S. (2011). Medicaid's increasing role in treating youths with autism spectrum disorders. Psychiatric Services (Washington, D.C.), 62(6), 588. doi:10.1176/appi.ps.62.6.588; 10.1176/appi.ps.62.6.588

Smith, D. D., Tyler, N., Montrosse, B. E., \& Young, C., \& Robb, S.M. (2011). SEFNA study implications.. (). Claremont,CA: Claremont Graduate University, IRIS@CGU.

Spann, S. J., Kohler, F. W., \& Soenksen, D. (2003). Examining parents' involvement in and perceptions of special education services: An interview with families in a parent support group. Focus on Autism \& Other Developmental Disabilities, 18(4), 228-237.

Tchaconas, A., \& Adesman, A. (2013). Autism spectrum disorders: A pediatric overview and update. Current Opinion in Pediatrics, 25(1), 130-144. doi:10.1097/MOP.0b013e32835c2b70; 10.1097/MOP.0b013e32835c2b70

The Annie E. Casey Foundation. (2011). Children who have one or more emotional, behavioral, or developmental conditions (percent) - 2007. Retrieved 4/3, 2013, from http://datacenter.kidscount.org/data/acrossstates/Rankings.aspx?ind=6031

Thomas, K. C., Parish, S. L., Rose, R. A., \& Kilany, M. (2012). Access to care for children with autism in the context of state medicaid reimbursement. Maternal and Child Health Journal, 16(8), 1636-1644. doi:10.1007/s 10995-011-0862-1; 10.1007/s10995-011-0862-1

Vivier, P. M. (2005). The impact of Medicaid on children's healthcare and health. Current Opinion in Pediatrics, 17(6), 759-763.

Warfield, M. E., \& Gulley, S. (2006). Unmet need and problems accessing specialty medical and related services among children with special health care needs. Maternal and Child Health Journal, 10(2), 201-216. doi:10.1007/s10995-005-0041-3 
Table 1. Child, Family and State Characteristics for Children with ASD. Using NSCSHCN 2009 - 2010 Survey $(N=3,025)$

\begin{tabular}{|c|c|c|}
\hline & $\mathbf{N}$ & $\%$ \\
\hline \multicolumn{3}{|l|}{ Gender } \\
\hline Male & 2,437 & 80.6 \\
\hline Female & 585 & 19.4 \\
\hline \multicolumn{3}{|l|}{ Age } \\
\hline 3-5 years & 430 & 14.2 \\
\hline 6-11 years & 1,416 & 46.8 \\
\hline 12-17 years & 1,179 & 39.0 \\
\hline \multicolumn{3}{|l|}{ Race/Ethnicity } \\
\hline Hispanic, Any Race & 327 & 10.8 \\
\hline Non- Hispanic Whites & 2,195 & 72.6 \\
\hline Non-Hispanic Blacks & 207 & 6.8 \\
\hline Non- Hispanic, Other & 296 & 9.8 \\
\hline \multicolumn{3}{|l|}{ Caregiver Education } \\
\hline LT HS & 125 & 4.1 \\
\hline HS & 376 & 12.4 \\
\hline GT HS & 2,524 & 83.4 \\
\hline \multicolumn{3}{|l|}{ Poverty Level } \\
\hline$<100 \%$ FPL & 481 & 15.9 \\
\hline $100-200 \%$ FPL & 622 & 20.6 \\
\hline $200-400 \%$ FPL & 982 & 32.5 \\
\hline$>400 \%$ FPL & 940 & 31.1 \\
\hline \multicolumn{3}{|l|}{ Child's Functional Ability } \\
\hline Never Affected & 192 & 6.4 \\
\hline Sometimes/Very Little & 810 & 26.9 \\
\hline Always/Usually & 2,015 & 66.8 \\
\hline \multicolumn{3}{|l|}{ Caregiver Reported Problems } \\
\hline Difficulty Using Services & 1,647 & 54.5 \\
\hline Difficulty Getting Referrals & 340 & 27.7 \\
\hline Lack of Source of Care & 549 & 18.2 \\
\hline Inadequate Insurance Coverage & 914 & 31.2 \\
\hline Financial Burden & 1,625 & 54 \\
\hline Employment Burden & 1,051 & 35 \\
\hline Time-Related Burden & 598 & 39.5 \\
\hline & Mean & SD \\
\hline \multicolumn{3}{|l|}{ State Covariates } \\
\hline Children in Poverty, \% & 18.9 & 0.04 \\
\hline Children with a DD in State, \% & 16 & 0.02 \\
\hline Median Annual Household Income, \$1000's & 5.23 & 8.61 \\
\hline \multicolumn{3}{|l|}{ State Policy Variable } \\
\hline Medicaid Income Eligibility,\% FPL & 155 & 65.2 \\
\hline
\end{tabular}


Table 1. Child, Family and State Characteristics for Children with ASD. Using NSCSHCN 2009 - 2010 Survey $(N=3,025)$

State Healthcare Workforce Variables

Child to Pediatrician Ratio $\quad 1,598 \quad 574.9$

Special Education Teacher per 1000 students $\quad 137 \quad 49.5$

Note: Based on self-reported data from caregivers $(\mathrm{N}=3,025)$ of children aged 3-17 years who had Autism Spectrum Disorder. LT: Less than. GT: Greater than. HS: High School. FPL: Federal Poverty Line. HH: Household, DD: Developmental Disorder. 
Table 2. Unadjusted Percentages of Caregivers of Children with ASD who reported problems with Access to Services and Family Impact by State. Using NS-CSHCN 2009- 2010 Survey $(\mathbf{N}=3,025)$

\begin{tabular}{|c|c|c|c|c|c|c|c|}
\hline State & $\begin{array}{c}\text { Difficulty } \\
\text { Using } \\
\text { Services } \\
\end{array}$ & $\begin{array}{l}\text { Difficulty } \\
\text { getting } \\
\text { referrals }\end{array}$ & $\begin{array}{l}\text { Lack of } \\
\text { Source } \\
\text { of Care }\end{array}$ & $\begin{array}{l}\text { Inadequate } \\
\text { Insurance } \\
\text { Coverage }\end{array}$ & $\begin{array}{c}\text { Financial } \\
\text { Burden }\end{array}$ & $\begin{array}{c}\text { Employment } \\
\text { Burden }\end{array}$ & $\begin{array}{l}\text { Time- } \\
\text { Related } \\
\text { Burden }\end{array}$ \\
\hline Alaska & 47.5 & 16.7 & 38.2 & 26.0 & 48.6 & 35.4 & 28.3 \\
\hline Alabama & 63.0 & 21.0 & 12.5 & 47.8 & 39.8 & 29.8 & 24.5 \\
\hline Arkansas & 52.7 & 34.9 & 18.6 & 16.0 & 47.3 & 12.7 & 39.7 \\
\hline Arizona & 76.6 & 51.7 & 23.8 & 48.8 & 52.6 & 37.4 & 73.1 \\
\hline California & 61.6 & 43.0 & 17.4 & 37.1 & 58.3 & 42.5 & 54.4 \\
\hline Colorado & 74.5 & 21.0 & 18.6 & 48.4 & 67.7 & 49.9 & 47.1 \\
\hline $\begin{array}{l}\text { Connecticut } \\
\text { District of }\end{array}$ & 52.9 & 67.4 & 12.4 & 39.2 & 54.5 & 32.9 & 32.1 \\
\hline Columbia & 34.4 & 26.5 & 15.5 & 27.7 & 23.9 & 27.0 & 62.7 \\
\hline Delaware & 53.9 & 9.9 & 15.9 & 17.3 & 44.1 & 14.8 & 18.2 \\
\hline Florida & 62.8 & 34.1 & 23.1 & 45.4 & 64.2 & 48.8 & 63.9 \\
\hline Georgia & 43.1 & 18.5 & 23.8 & 33.7 & 52.3 & 28.9 & 34.5 \\
\hline Hawaii & 43.3 & 24.5 & 18.9 & 26.5 & 49.2 & 43.9 & 28.4 \\
\hline Iowa & 47.5 & 49.1 & 11.2 & 18.7 & 47.3 & 19.0 & 35.3 \\
\hline Idaho & 56.6 & 39.0 & 33.6 & 22.6 & 50.4 & 38.3 & 63.6 \\
\hline Illinois & 66.0 & 59.2 & 29.7 & 62.2 & 56.5 & 39.5 & 27.2 \\
\hline Indiana & 70.1 & 20.9 & 25.2 & 29.1 & 60.5 & 45.1 & 23.0 \\
\hline Kansas & 50.7 & 45.3 & 26.4 & 35.4 & 53.1 & 33.3 & 28.9 \\
\hline Kentucky & 50.1 & 23.1 & 21.3 & 20.3 & 56.6 & 51.0 & 63.8 \\
\hline Louisiana & 51.5 & 40.7 & 23.2 & 42.2 & 56.3 & 34.7 & 41.4 \\
\hline Massachusetts & 57.1 & 27.7 & 12.7 & 25.1 & 73.5 & 43.6 & 49.0 \\
\hline Maryland & 50.5 & 14.9 & 32.6 & 25.8 & 57.1 & 27.7 & 25.1 \\
\hline Maine & 62.9 & 23.4 & 19.9 & 27.4 & 47.4 & 28.8 & 70.7 \\
\hline Michigan & 42.9 & 14.5 & 14.1 & 30.0 & 45.4 & 34.2 & 15.2 \\
\hline Minnesota & 47.0 & 20.6 & 11.5 & 22.2 & 65.5 & 33.3 & 49.4 \\
\hline Missouri & 53.7 & 10.1 & 17.5 & 42.7 & 59.8 & 32.6 & 35.5 \\
\hline Mississippi & 59.7 & 36.4 & 23.1 & 35.1 & 39.9 & 27.3 & 37.4 \\
\hline Montana & 56.4 & 59.6 & 17.4 & 21.1 & 63.1 & 22.0 & 4.2 \\
\hline North Carolina & 58.8 & 3.4 & 18.4 & 24.9 & 64.6 & 33.3 & 48.1 \\
\hline North Dakota & 56.5 & 23.1 & 24.1 & 22.3 & 53.4 & 29.0 & 17.8 \\
\hline Nebraska & 47.5 & 25.3 & 13.7 & 16.3 & 48.1 & 23.1 & 54.2 \\
\hline New Hampshire & 68.0 & 33.2 & 8.2 & 23.1 & 57.8 & 35.7 & 32.8 \\
\hline New Jersey & 58.4 & 28.4 & 24.4 & 38.1 & 53.8 & 22.9 & 37.2 \\
\hline New Mexico & 60.4 & 30.1 & 27.1 & 30.8 & 33.5 & 44.9 & 41.2 \\
\hline Nevada & 67.5 & 49.9 & 39.7 & 53.1 & 43.9 & 38.8 & 67.1 \\
\hline New York & 47.0 & 27.6 & 16.0 & 24.2 & 49.7 & 51.2 & 44.4 \\
\hline Ohio & 58.8 & 35.4 & 26.4 & 16.7 & 38.0 & 45.5 & 74.2 \\
\hline Oklahoma & 36.3 & 19.1 & 21.7 & 24.5 & 53.0 & 36.9 & 33.2 \\
\hline
\end{tabular}


Table 2. Unadjusted Percentages of Caregivers of Children with ASD who reported problems with Access to Services and Family Impact by State. Using NS-CSHCN 2009- 2010 Survey $(\mathbf{N}=\mathbf{3 , 0 2 5})$

\begin{tabular}{|c|c|c|c|c|c|c|c|}
\hline State & $\begin{array}{l}\text { Difficulty } \\
\text { Using } \\
\text { Services } \\
\end{array}$ & $\begin{array}{l}\text { Difficulty } \\
\text { getting } \\
\text { referrals } \\
\end{array}$ & $\begin{array}{l}\text { Lack of } \\
\text { Source } \\
\text { of Care }\end{array}$ & $\begin{array}{c}\text { Inadequate } \\
\text { Insurance } \\
\text { Coverage } \\
\end{array}$ & $\begin{array}{c}\text { Financial } \\
\text { Burden }\end{array}$ & $\begin{array}{c}\text { Employment } \\
\text { Burden }\end{array}$ & $\begin{array}{c}\text { Time- } \\
\text { Related } \\
\text { Burden } \\
\end{array}$ \\
\hline Oregon & 63.2 & 20.6 & 18.7 & 30.4 & 52.4 & 30.8 & 34.5 \\
\hline Pennsylvania & 40.7 & 17.1 & 13.3 & 16.8 & 28.2 & 36.1 & 38.5 \\
\hline Rhode Island & 38.2 & 18.8 & 30.1 & 15.2 & 42.9 & 44.7 & 21.6 \\
\hline Tennessee & 46.9 & 6.3 & 7.4 & 23.9 & 72.6 & 44.2 & 45.0 \\
\hline Texas & 46.8 & 25.5 & 23.0 & 28.1 & 50.7 & 41.6 & 57.2 \\
\hline Utah & 60.3 & 48.7 & 9.8 & 34.5 & 59.3 & 35.2 & 47.7 \\
\hline Virginia & 50.4 & 37.9 & 26.2 & 35.1 & 46.2 & 29.9 & 24.3 \\
\hline West Virginia & 69.2 & 35.9 & 17.1 & 29.0 & 50.8 & 43.4 & 67.4 \\
\hline Wyoming & 42.5 & 64.5 & 16.3 & 39.2 & 54.8 & 27.1 & 3.7 \\
\hline US Mean (ALL) & 54.8 & 31.3 & 20.7 & 30.5 & 52.0 & 35.3 & 41.5 \\
\hline
\end{tabular}

Note: Based on self-reported data from caregivers $(\mathrm{N}=3,025)$ of children aged 3-17 years who had Autism Spectrum Disorder. LT: Less than. GT: Greater than. HS: High School. FPL: Federal Poverty Line. HH: Household, DD: Developmental Disorder. All analyses accounted for the complex survey design of 2009-2010 National Survey of Children with Special Health Care Needs (NS-CSHCN). 


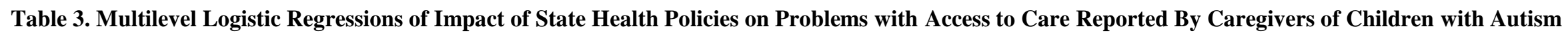
in 50 States and DC

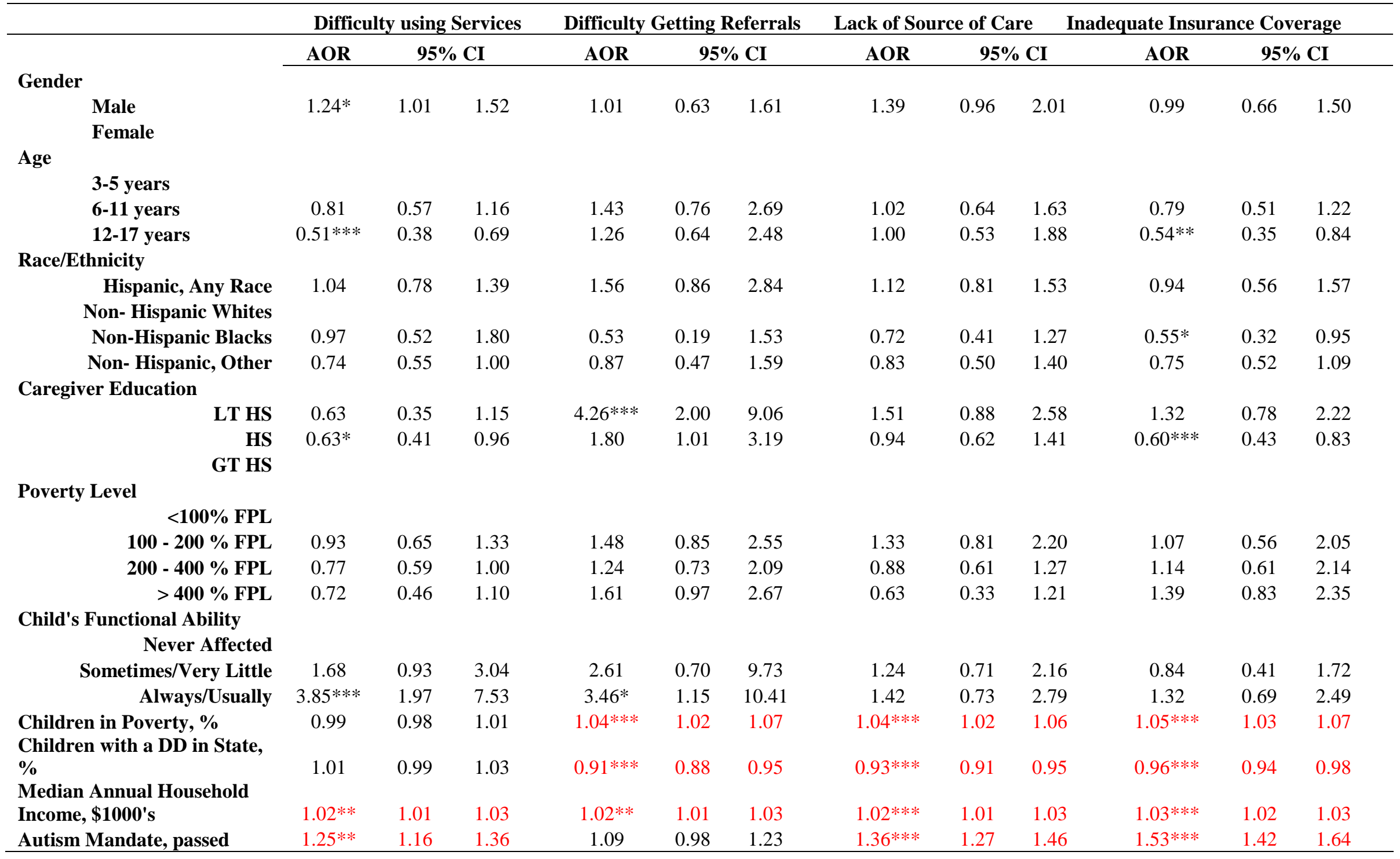




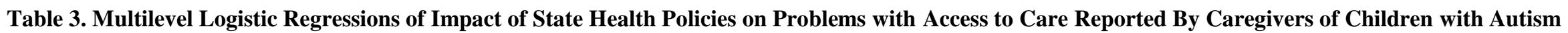
in 50 States and DC

\begin{tabular}{|c|c|c|c|c|c|c|c|c|c|c|c|c|}
\hline \multirow{4}{*}{$\begin{array}{l}\text { Medicaid Income Eligibility, } \\
\leq \mathbf{1 0 0 \%} \text { FPL } \\
\text { Variance (Error) }\end{array}$} & \multicolumn{3}{|c|}{ Difficulty using Services } & \multicolumn{3}{|c|}{ Difficulty Getting Referrals } & \multicolumn{3}{|c|}{ Lack of Source of Care } & \multicolumn{3}{|c|}{ Inadequate Insurance Coverage } \\
\hline & \multirow{3}{*}{$\begin{array}{l}\mathbf{A O R} \\
0.98\end{array}$} & \multicolumn{2}{|c|}{$95 \% \mathrm{CI}$} & \multirow{2}{*}{$\begin{array}{c}\mathbf{A O R} \\
0.71 * * *\end{array}$} & \multicolumn{2}{|c|}{$95 \% \mathrm{CI}$} & \multirow{2}{*}{$\begin{array}{c}\mathbf{A O R} \\
0.53 * * *\end{array}$} & \multicolumn{2}{|c|}{$95 \% \mathrm{CI}$} & \multirow{2}{*}{$\begin{array}{l}\text { AOR } \\
9 \\
9.70 * *\end{array}$} & \multicolumn{2}{|c|}{$95 \% \mathrm{CI}$} \\
\hline & & \multirow{2}{*}{\multicolumn{2}{|c|}{$\begin{array}{cc}0.88 & 1.07 \\
0.18(\mathbf{0 . 0 1 7}) & \end{array}$}} & & 0.65 & 0.77 & & 0.48 & 0.59 & & 0.64 & 0.77 \\
\hline & & & & & $(0.01$ & & \multicolumn{3}{|c|}{$0.14(0.016)$} & \multicolumn{3}{|c|}{$0.14(0.015)$} \\
\hline \multicolumn{13}{|c|}{$\begin{array}{l}\text { Note: Based on self-reported data from caregivers }(\mathrm{N}=3,025) \text { of children aged 3-17 years who had Autism Spectrum Disorder. LT: Less than. GT: Greater than. HS: High } \\
\text { School. FPL: Federal Poverty Line. HH: Household, DD: Developmental Disorder. All analyses accounted for the complex survey design of } 2009-2010 \text { National Survey of } \\
\text { Children with Special Health Care Needs (NS-CSHCN). AOR: Adjusted Odds Ratios. CI: Confidence Intervals. All analyses accounted for the complex survey design of } \\
2009 \text { National Survey of Children with Special Health Care Needs (NS-CSHCN). ***P }<0.001 ; * * 0.001 \leq \mathrm{P}<0.01 ; * 01 \leq \mathrm{P}<0.05 \text {. Reference group for State Medicaid } \\
\text { Income Eligihilitv }>100 \% \text { FPL }\end{array}$} \\
\hline
\end{tabular}


Table 4. Multilevel Logistic Regressions of Impact of State Health Policies on Family Impact Reported By Caregivers of Children with Autism in 50 States and DC

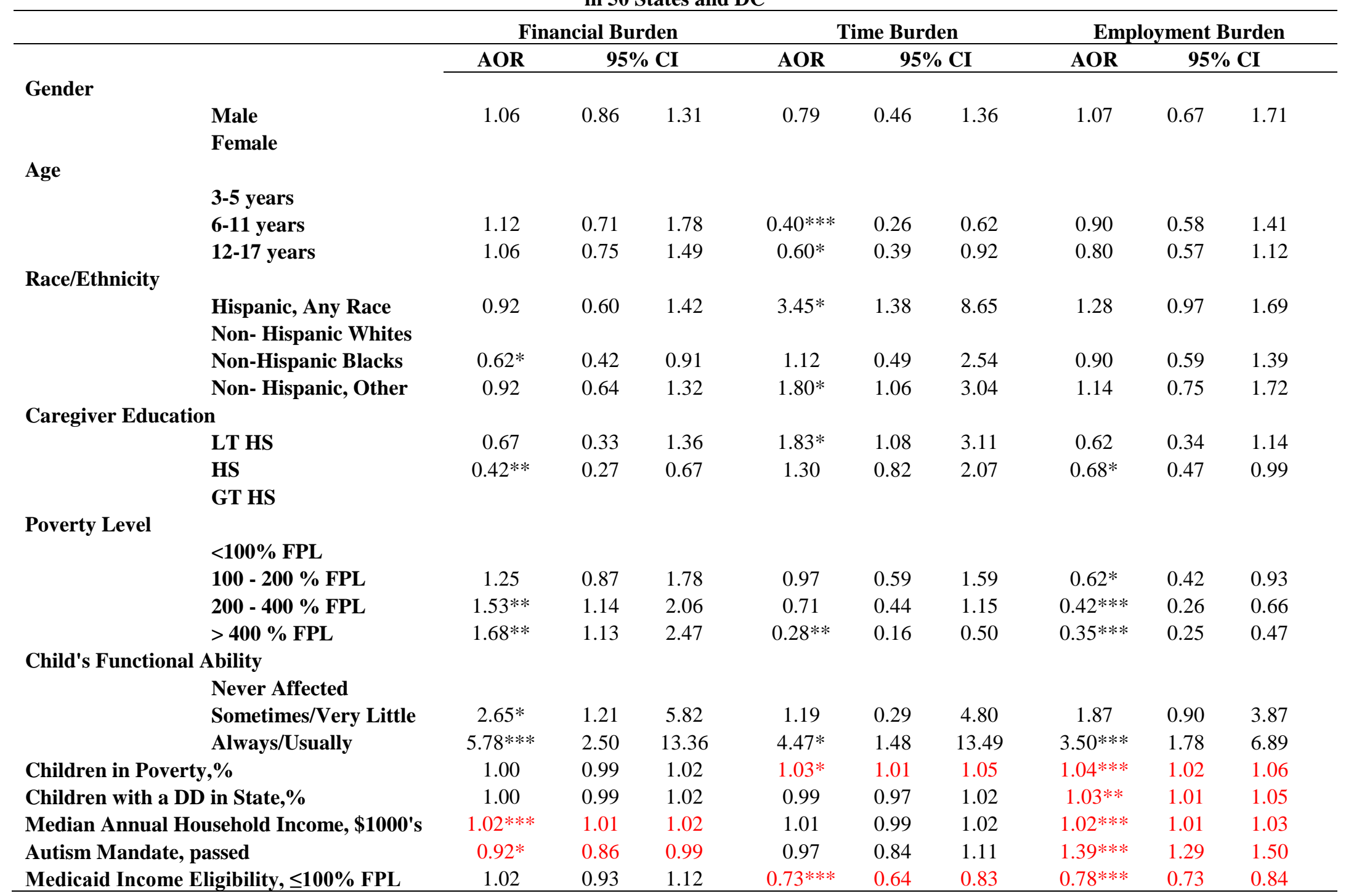


Table 4. Multilevel Logistic Regressions of Impact of State Health Policies on Family Impact Reported By Caregivers of Children with Autism in 50 States and DC

\begin{tabular}{|c|c|c|c|}
\hline & Financial Burden & Time Burden & Employment Burden \\
\hline & AOR $\quad 95 \% \mathrm{CI}$ & AOR $\quad 95 \%$ CI & AOR $\quad 95 \% \mathrm{CI}$ \\
\hline Variance (Error) & $0.10(0.007)$ & $0.21(0.020)$ & $0.13(0.014)$ \\
\hline
\end{tabular}

Note: Based on self-reported data from caregivers $(\mathrm{N}=3,025)$ of children aged 3-17 years who had Autism Spectrum Disorder. LT: Less than. GT: Greater than. HS: High School. FPL: Federal Poverty Line. HH: Household, DD: Developmental Disorder. All analyses accounted for the complex survey design of 2009-2010 National Survey of Children with Special Health Care Needs (NS-CSHCN). AOR: Adjusted Odds Ratios. CI: Confidence Intervals. All analyses accounted for the complex survey design of 2009 National Survey of Children with Special Health Care Needs (NS-CSHCN). $* * * \mathrm{P}<0.001 ; * * 0.001 \leq \mathrm{P}<0.01 ; * 01 \leq \mathrm{P}<0.05$. Reference group for State Medicaid Income Eligibility: $>100 \% \mathrm{FPL}$. 
Table 5. Multilevel Logistic Regressions of Impact of State Healthcare Workforce on Problems with Access to Services Reported By Caregivers of Children with Autism in 50 States and DC

\begin{tabular}{|c|c|c|c|c|c|c|c|c|c|c|c|c|}
\hline \multirow{2}{*}{ Gender } & \multicolumn{3}{|c|}{ Difficulty using Services } & \multicolumn{3}{|c|}{$\begin{array}{c}\text { Difficulty Getting } \\
\text { Referrals }\end{array}$} & \multicolumn{3}{|c|}{ Lack of Source of Care } & \multicolumn{3}{|c|}{$\begin{array}{c}\text { Inadequate Insurance } \\
\text { Coverage }\end{array}$} \\
\hline & AOR & 95 & CI & AOR & 95 & CI & AOR & \multicolumn{2}{|c|}{$95 \% \mathrm{CI}$} & AOR & \multicolumn{2}{|c|}{$95 \%$ CI } \\
\hline $\begin{array}{r}\text { Male } \\
\text { Female }\end{array}$ & 1.23 & 1.00 & 1.52 & 1.02 & 0.63 & 1.64 & 1.37 & 0.95 & 1.98 & 1.01 & 0.67 & 1.53 \\
\hline \multicolumn{13}{|l|}{ Age } \\
\hline $\begin{array}{r}\text { 3-5 years } \\
6-11 \text { years }\end{array}$ & 0.79 & 0.55 & 1.13 & 1.40 & 0.75 & 2.60 & 1.02 & 0.63 & 1.65 & 0.79 & 0.51 & 1.21 \\
\hline 12-17 years & $0.50 * * *$ & 0.37 & 0.67 & 1.24 & 0.64 & 2.41 & 0.99 & 0.52 & 1.88 & $0.55^{*}$ & 0.35 & 0.84 \\
\hline \multicolumn{13}{|l|}{ Race/Ethnicity } \\
\hline $\begin{array}{r}\text { Hispanic, Any Race } \\
\text { Non- Hispanic Whites }\end{array}$ & 1.03 & 0.78 & 1.37 & 1.56 & 0.86 & 2.82 & 1.11 & 0.81 & 1.53 & 0.93 & 0.56 & 1.55 \\
\hline $\begin{array}{l}\text { Non-Hispanic Blacks } \\
\text { Non- Hispanic, Other }\end{array}$ & $\begin{array}{c}0.96 \\
0.71 *\end{array}$ & $\begin{array}{l}0.52 \\
0.52\end{array}$ & $\begin{array}{l}1.77 \\
0.98\end{array}$ & $\begin{array}{l}0.50 \\
0.91\end{array}$ & $\begin{array}{l}0.17 \\
0.50\end{array}$ & $\begin{array}{l}1.47 \\
1.66\end{array}$ & $\begin{array}{l}0.73 \\
0.83\end{array}$ & $\begin{array}{l}0.41 \\
0.50\end{array}$ & $\begin{array}{l}1.28 \\
1.37\end{array}$ & $\begin{array}{c}0.54 * \\
0.76\end{array}$ & $\begin{array}{l}0.32 \\
0.52\end{array}$ & $\begin{array}{l}0.94 \\
1.10\end{array}$ \\
\hline \multicolumn{13}{|l|}{ Caregiver Education } \\
\hline $\begin{array}{r}\text { LT HS } \\
\text { HS }\end{array}$ & $\begin{array}{c}0.63 \\
0.63 *\end{array}$ & $\begin{array}{l}0.35 \\
0.41\end{array}$ & $\begin{array}{l}1.13 \\
0.97\end{array}$ & $\begin{array}{l}4.11 * * * \\
1.72\end{array}$ & $\begin{array}{l}2.00 \\
0.97\end{array}$ & $\begin{array}{l}8.45 \\
3.08\end{array}$ & $\begin{array}{l}1.54 \\
0.96\end{array}$ & $\begin{array}{l}0.90 \\
0.64\end{array}$ & $\begin{array}{l}2.64 \\
1.45\end{array}$ & $\begin{array}{c}1.29 \\
0.59 * * *\end{array}$ & $\begin{array}{l}0.77 \\
0.43\end{array}$ & $\begin{array}{l}2.16 \\
0.81\end{array}$ \\
\hline GT HS & & & & & & & & & & & & \\
\hline \multicolumn{13}{|l|}{ Poverty Level } \\
\hline $\begin{aligned} &<100 \% \text { FPL } \\
& 100-200 \% \text { FPL }\end{aligned}$ & 0.91 & 0.63 & 1.30 & 1.50 & 0.86 & 2.62 & 1.39 & 0.84 & 2.30 & 1.05 & 0.55 & 2.01 \\
\hline $200-400 \%$ FPL & $0.76^{*}$ & 0.58 & 0.99 & 1.23 & 0.73 & 2.07 & 0.90 & 0.63 & 1.30 & 1.12 & 0.60 & 2.09 \\
\hline$>400 \%$ FPL & 0.70 & 0.45 & 1.09 & 1.58 & 0.95 & 2.61 & 0.66 & 0.35 & 1.24 & 1.34 & 0.80 & 2.24 \\
\hline \multicolumn{13}{|l|}{$\begin{array}{l}\text { Child's Functional Ability } \\
\text { Never Affected }\end{array}$} \\
\hline Always/Usually & $3.91 * * *$ & 2.00 & 7.66 & $3.26^{*}$ & 1.15 & 9.29 & 1.43 & 0.73 & 2.80 & 1.31 & 0.70 & 2.47 \\
\hline $\begin{array}{l}\text { Children in Poverty, \% } \\
\text { Children with a DD in }\end{array}$ & $1.02 * * *$ & 1.01 & 1.03 & $1.11 * * *$ & 1.08 & 1.15 & $1.05 * * *$ & 1.03 & 1.07 & $1.04 * * *$ & 1.03 & 1.06 \\
\hline $\begin{array}{l}\text { State, \% } \\
\text { Median Annual Household }\end{array}$ & $1.05 * * *$ & 1.04 & 1.07 & 1.02 & 0.99 & 1.06 & 1.01 & 0.99 & 1.03 & $0.97 * * *$ & 0.95 & 0.99 \\
\hline Income, $\$ 1000 ' s$ & $1.03 * * *$ & 1.02 & 1.04 & $1.08 * * *$ & 1.05 & 1.10 & $1.03 * * *$ & 1.02 & 1.04 & $1.03 * * *$ & 1.02 & 1.04 \\
\hline Child to Pediatrician Ratio, & $1.03 * * *$ & 1.02 & 1.04 & $1.11 * * *$ & 1.09 & 1.12 & $1.03 * * *$ & 1.02 & 1.04 & $1.03 * * *$ & 1.03 & 1.04 \\
\hline
\end{tabular}


Table 5. Multilevel Logistic Regressions of Impact of State Healthcare Workforce on Problems with Access to Services Reported By Caregivers of Children with Autism in 50 States and DC

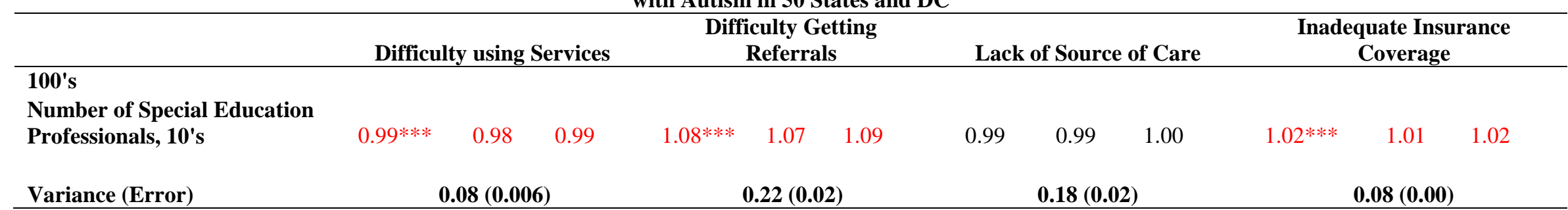

Note: Based on self-reported data from caregivers $(\mathrm{N}=3,025)$ of children aged 3-17 years who had Autism Spectrum Disorder. LT: Less than. GT: Greater than. HS: High School. FPL: Federal Poverty Line. HH: Household, DD: Developmental Disorder. All analyses accounted for the complex survey design of 2009-2010 National Survey of Children with Special Health Care Needs (NS-CSHCN). AOR: Adjusted Odds Ratios. CI: Confidence Intervals. All analyses accounted for the complex survey design of 2009 National Survey of Children with Special Health Care Needs (NS-CSHCN). ***P $<0.001 ; * * 0.001 \leq \mathrm{P}<0.01 ; * 01 \leq \mathrm{P}<0.05$. 
Table 6. Multilevel Logistic Regressions of Impact of State Healthcare Workforce on Family Impact Reported By Caregivers of Children with Autism in 50 States and DC

\begin{tabular}{|c|c|c|c|c|c|c|c|c|c|}
\hline \multirow{2}{*}{ Gender } & \multicolumn{3}{|c|}{ Financial Burden } & \multicolumn{3}{|c|}{ Time Burden } & \multicolumn{3}{|c|}{ Employment Burden } \\
\hline & AOR & \multicolumn{2}{|c|}{$95 \% \mathrm{CI}$} & AOR & \multicolumn{2}{|c|}{$95 \% \mathrm{CI}$} & AOR & \multicolumn{2}{|c|}{$95 \% \mathrm{CI}$} \\
\hline $\begin{array}{r}\text { Male } \\
\text { Female }\end{array}$ & 1.06 & 0.86 & 1.30 & 0.80 & 0.47 & 1.36 & 1.08 & 0.67 & 1.73 \\
\hline 3-5 yrs & & & & & & & & & \\
\hline $\begin{array}{r}\text { 6-11 yrs } \\
12-17 \text { yrs }\end{array}$ & $\begin{array}{l}1.12 \\
1.04\end{array}$ & $\begin{array}{l}0.70 \\
0.74\end{array}$ & $\begin{array}{l}1.79 \\
1.48\end{array}$ & $\begin{array}{c}0.40 * * * \\
0.60 *\end{array}$ & $\begin{array}{l}0.26 \\
0.39\end{array}$ & $\begin{array}{l}0.62 \\
0.93\end{array}$ & $\begin{array}{l}0.91 \\
0.80\end{array}$ & $\begin{array}{l}0.58 \\
0.57\end{array}$ & $\begin{array}{l}1.41 \\
1.11\end{array}$ \\
\hline $\begin{array}{l}\text { Race/Ethnicity } \\
\text { Hispanic, Any Race }\end{array}$ & 0.91 & 0.59 & 1.39 & $3.31^{*}$ & 1.34 & 8.16 & 1.29 & 0.98 & 1.70 \\
\hline $\begin{array}{r}\text { Non- Hispanic Whites } \\
\text { Non-Hispanic Blacks } \\
\text { Non- Hispanic, Other }\end{array}$ & $\begin{array}{l}0.62 * \\
0.90\end{array}$ & $\begin{array}{l}0.42 \\
0.65\end{array}$ & $\begin{array}{l}0.91 \\
1.26\end{array}$ & $\begin{array}{c}1.10 \\
1.89 *\end{array}$ & $\begin{array}{l}0.50 \\
1.13\end{array}$ & $\begin{array}{l}2.46 \\
3.16\end{array}$ & $\begin{array}{l}0.91 \\
1.13\end{array}$ & $\begin{array}{l}0.59 \\
0.74\end{array}$ & $\begin{array}{l}1.41 \\
1.71\end{array}$ \\
\hline $\begin{array}{r}\text { LT HS } \\
\text { HS } \\
\text { GT HS }\end{array}$ & $\begin{array}{c}0.69 \\
0.42 * * *\end{array}$ & $\begin{array}{l}0.34 \\
0.27\end{array}$ & $\begin{array}{l}1.39 \\
0.67\end{array}$ & $\begin{array}{c}1.89 * \\
1.31\end{array}$ & $\begin{array}{l}1.13 \\
0.84\end{array}$ & $\begin{array}{l}3.17 \\
2.05\end{array}$ & $\begin{array}{c}0.61 \\
0.67 *\end{array}$ & $\begin{array}{l}0.33 \\
0.47\end{array}$ & $\begin{array}{l}1.12 \\
0.97\end{array}$ \\
\hline $\begin{array}{l}\text { Poverty Level } \\
\qquad 100 \% \text { FPL }\end{array}$ & & & & & & & & & \\
\hline $\begin{array}{r}100-200 \% \text { FPL } \\
200-400 \% \text { FPL } \\
>400 \% \text { FPL }\end{array}$ & $\begin{array}{c}1.24 \\
1.54 * * * \\
1.69 *\end{array}$ & $\begin{array}{l}0.87 \\
1.15 \\
1.15\end{array}$ & $\begin{array}{l}1.79 \\
2.06 \\
2.48\end{array}$ & $\begin{array}{c}0.94 \\
0.70 \\
0.27 * * *\end{array}$ & $\begin{array}{l}0.58 \\
0.43 \\
0.16\end{array}$ & $\begin{array}{l}1.54 \\
1.12 \\
0.48\end{array}$ & $\begin{array}{c}0.61 * \\
0.42 * * * \\
0.34 * * *\end{array}$ & $\begin{array}{l}0.41 \\
0.26 \\
0.25\end{array}$ & $\begin{array}{l}0.90 \\
0.66 \\
0.47\end{array}$ \\
\hline $\begin{array}{l}\text { Child's Functional Ability } \\
\text { Never Affected }\end{array}$ & & & & & & & & & \\
\hline $\begin{array}{r}\text { Sometimes/Very Little } \\
\text { Always/Usually }\end{array}$ & $\begin{array}{c}2.67 * \\
5.79 * * *\end{array}$ & $\begin{array}{l}1.23 \\
2.52\end{array}$ & $\begin{array}{c}5.83 \\
13.35\end{array}$ & $\begin{array}{c}1.25 \\
4.69 *\end{array}$ & $\begin{array}{l}0.30 \\
1.51\end{array}$ & $\begin{array}{l}5.20 \\
14.51\end{array}$ & $\begin{array}{c}1.86 \\
3.52 * * *\end{array}$ & $\begin{array}{l}0.90 \\
1.79\end{array}$ & $\begin{array}{l}3.83 \\
6.91\end{array}$ \\
\hline $\begin{array}{l}\text { Children in Poverty, \% } \\
\text { Children with a DD in State,\% } \\
\text { Median Annual Household }\end{array}$ & $\begin{array}{c}0.99 * \\
0.98\end{array}$ & $\begin{array}{l}0.97 \\
0.96\end{array}$ & $\begin{array}{l}0.99 \\
1.00\end{array}$ & $\begin{array}{c}1.03 * * * \\
1.00\end{array}$ & $\begin{array}{l}1.01 \\
0.98\end{array}$ & $\begin{array}{l}1.06 \\
1.02\end{array}$ & $\begin{array}{c}0.99 \\
0.90 * * *\end{array}$ & $\begin{array}{l}0.98 \\
0.88\end{array}$ & $\begin{array}{l}1.01 \\
0.91\end{array}$ \\
\hline $\begin{array}{l}\text { Income, } \$ 1000 \text { 's } \\
\text { Child to Pediatrician Ratio, } \\
100 \text { 's } \\
\text { Number of Special Education }\end{array}$ & $\begin{array}{l}1.00 \\
1.00\end{array}$ & $\begin{array}{l}0.99 \\
0.99\end{array}$ & $\begin{array}{l}1.01 \\
1.01\end{array}$ & $\begin{array}{c}1.00 \\
0.96 * * *\end{array}$ & $\begin{array}{l}0.99 \\
0.96\end{array}$ & $\begin{array}{l}1.01 \\
0.97\end{array}$ & $\begin{array}{l}0.95 * * * \\
0.99 * * *\end{array}$ & $\begin{array}{l}0.95 \\
0.98\end{array}$ & $\begin{array}{l}0.96 \\
0.99\end{array}$ \\
\hline
\end{tabular}


Table 6. Multilevel Logistic Regressions of Impact of State Healthcare Workforce on Family Impact Reported By Caregivers of Children with Autism in 50 States and DC

\begin{tabular}{|c|c|c|c|c|c|c|}
\hline & \multicolumn{2}{|c|}{ Financial Burden } & \multicolumn{2}{|c|}{ Time Burden } & \multicolumn{2}{|c|}{ Employment Burden } \\
\hline & AOR & $95 \% \mathrm{CI}$ & AOR & $95 \% \mathrm{CI}$ & AOR & $95 \% \mathrm{CI}$ \\
\hline \multicolumn{7}{|l|}{ Professionals, 10's } \\
\hline Variance (Error) & & $0.22(0.02)$ & & $0.15(0.02)$ & & \\
\hline
\end{tabular}

Note: Based on self-reported data from caregivers $(\mathrm{N}=3,025)$ of children aged 3-17 years who had Autism Spectrum Disorder. LT: Less than. GT: Greater than. HS: High School. FPL: Federal Poverty Line, DD: Developmental Disorder. HH: Household. All analyses accounted for the complex survey design of 2009-2010 National Survey of Children with Special Health Care Needs (NS-CSHCN). AOR: Adjusted Odds Ratios. CI: Confidence Intervals. All analyses accounted for the complex survey design of 2009 National Survey of Children with Special Health Care Needs (NS-CSHCN). $* * * \mathrm{P}<0.001 ; * * 0.001 \leq \mathrm{P}<0.01 ; * 01 \leq \mathrm{P}<0.05$. 


\section{CHAPTER FOUR}

\section{EXECUTIVE SUMMARY}

Autism Spectrum Disorders (ASD) is a group of developmental disabilities that can cause significant social, communication and behavioral challenges. The prevalence of ASD has risen considerably in the past decade with every 1 in 88 children aged 8 years affected by this condition in the United States (Autism and Developmental Disabilities Monitoring Network Surveillance Year 2008 Principal Investigators \& Centers for Disease Control and Prevention, 2012). Recognized as the fastest growing developmental disability with a growth rate of $1,148 \%$ (Cavagnaro, 2008), the health care still lacks an evidenced based treatment approach (Warren et al., April 2011). In absence of a standard cure, health care providers focus on treatment of symptoms associated with the condition via pharmacotherapeutic, speech/language, and behavioral/developmental interventions (Centers for Disease Control and Prevention (CDC), 2012a), where the treatment regimen depends on where the child falls on the continuum of spectrum. Over the last decade, many studies have reported problems accessing services, lack

of care coordination, provision of quality care and adverse impact of the condition on the family for caregivers of children with ASD (Kogan et al., 2008; Krauss, Gulley, Sciegaj, \& Wells, 2003; Liptak et al., 2006; Liptak et al., 2008).

Our first study focused on assessing health care disparities for children with ASD as compared to children with other developmental disabilities (DD) and mental health conditions (MHC). Findings indicate significant differences among caregivers of children with ASD, DD, and $\mathrm{MHC}$ in report of problems with access to services, quality of care, and family impact. In general, caregivers of children with ASD were more likely to report difficulty using services and 
inadequacy of insurance coverage as compared to caregivers of children with a DD and MHC. Caregivers of children with ASD were also more likely to report lack of shared decision making by their providers and lack of care coordination. In addition, ASD caregivers reported greater financial, time-related and employment burden as compared to caregivers of children with DD and MHC. When compared to caregivers of children with both a DD and an MHC, ASD caregivers were still more likely to report difficulty accessing services, lack of shared decision making, care coordination, time-related and employment burden. Overall, the first study underlines two points: 1) Caregivers of ASD may feel that their child has greater health care needs which are not met with the care been provided through standard developmental disability clinics/centers and greater number of special services' centers focused solely on autism are needed for this group of children, a concern that has been raised by Centers for Medicaid and Medicare as well (Mauch, Pfefferle, Booker, Pustell, \& Levin, 2011); and 2) The impact of the condition on the family still remains significantly different for children with ASD as compared to children with other DDs and MHCs. Even though, the financial burden for ASD caregivers does not significantly differ for caregivers of children with both DD and MHC, time spent in taking care of the child and leaving a job due to child's condition are critical issues for ASD caregivers, which need to be addressed by respite care programs. Our findings have implications for health care providers who are suggested to address the concerns of ASD caregivers and try to communicate better with them. In addition, state policy makers are also needed to address problems in access and quality of care reported by caregivers of children with ASD.

Our second study examined the variation among 50 states and Washington DC for problems in accessing services and family impact reported by caregivers of children with ASD. We observed considerable variation across states due to state independent variables for problems 
accessing services and family impact (8-22\%). Our study demonstrated mixed results for the impact of state policy and availability of health care workforce in a state on caregiver report of problems with access and family impact. A state Medicaid income eligibility threshold of $\leq 100 \%$ FPL was associated with a lower likelihood of reporting difficulty getting referrals, lack of source of care, and inadequate insurance coverage. Even though, greater Medicaid coverage is expected to provide better health outcomes, quality of care and better access to low income children with special health care needs (Marks, Hoffman, \& Paradise, 2009), the impact of increasing state Medicaid eligibility level to a higher threshold in our study population was negative and did not follow the norm. In our study, lower Medicaid income eligibility threshold in a state was associated with report of better access and family impact for caregivers of children with ASD. One of the reasons of not being able to find the hypothesized effects may be due to the fact that we did not restrict our analysis to low income families, which would generally be affected more as compared to the entire population. Also, system wide shortages of pediatric specialists is also a concern and the expansion of Medicaid coverage may not directly deliver better access and ease of use of services for children with ASD. Similarly, having state autism insurance mandate coverage was associated with greater likelihood of reporting problems in accessing services. However, having a passed legislation was also associated with lower likelihood of reporting financial burden, which indicates that the coverage of behavioral therapies may have a significant role in determining the extent of financial burden. The autism mandate was passed in certain states as an attempt to reduce financial burden on families of children with ASD by providing coverage for diagnosis, screening, evaluation and behavioral interventions for children with ASD. Since, our findings indicate a decreased report of financial burden in states where the mandate was passed, suggests a possible association between state 
policy and family impact reported by caregivers of children with ASD. However, we used autism mandate as a proxy for measuring state's inclination towards health care initiatives for children with ASD and interpretation of these findings may not directly reflect the impact of the policy (rather state's active role in autism health care) on the caregiver family impact.

Our study also examined the association of health care workforce with the caregiver reported access issues and family impact. In general, greater general pediatrician and special education workforce was associated with lower likelihood of reporting difficulty using services and lack of source of care. These findings indicate that state workforce is a major concern for care of children with ASD, as mentioned in other reports and studies as well (Althouse \& Stockman, 2011; Mauch, Pfefferle, Booker, Pustell, \& Levin, 2011). Considering the increasing prevalence of ASD (Autism and Developmental Disabilities Monitoring Network Surveillance Year 2008 Principal Investigators \& Centers for Disease Control and Prevention, 2012), the need for greater number of pediatricians, sub-specialists, and special education professionals will also increase and this workforce will play a significant role in providing quality services to children with ASD.

This research intended to examine health care disparities for children with ASD. We conducted cross-sectional analyses to examine such disparities in two different aspects: 1) Examine perceived access to services, quality of care, and family impact for caregivers of children with ASD, as compared to caregivers of children with DD and MHC; and 2) Examine the variation across 50 states and Washington DC and impact of state health polices and workforce on perceived access to services and family impact for caregivers of children with ASD. According to our findings, caregivers of children with ASD experience significant problems in accessing services and adverse family impact, which is a function of both individual 
and state level characteristics. Children with ASD not only seem to have unique health care needs, but their caregivers are also at higher risk of reporting problems with accessing services and family impact, as compared to caregivers of children with other developmental/neurological conditions. These findings are also supported by some results from other studies (Krauss, Gulley, Sciegaj, \& Wells, 2003; Liptak et al., 2008).

State contextual characteristics have a significant impact on caregiver's perceptions about and actual utilization of services. Even though state may have health policies that provide coverage for specific interventions, but the lack of therapies, trained teachers, diagnosticians, health care providers, and related service professionals will still be a strong barrier for accessing services for caregivers of children with ASD. It is known that caregivers of children with ASD face an adverse family impact as compared to other children with special health care needs (Kogan et al., 2008). However, our study highlighted that ASD group stands out in caregiver reported financial, time-related as well as employment burden when compared to other DD and MHC groups. Collectively, our research highlights that accessing services and receiving quality care is still an issue for caregivers of children with ASD, which needs to be addressed by forming ASD centered specialty clinics and health care centers. Also, health care providers should not only focus on treating symptoms of the child with the condition, but also allow parents/caregivers to be equal proponents of their child's health care. State policy makers should also stress on patient centered care and consider building infrastructure such as patient centered medical homes which are designed to provide care from multiple professionals under one roof. With the overall increase in health insurance coverage and stress on health care accountability under The Affordable Care Act (Patient protection and affordable care act, 2010), it is expected 
that the access to services, quality of care, and family impact for children with ASD will improve over time.

\section{FUTURE RESEARCH}

Associations of problems accessing care and family impact for ASD caregivers with the type and extent of comorbidities of ASD can be examined to highlight the burden of another condition and increase in service needs. Further studies with causal pathways are needed to establish a robust relationship between contextual characteristics and problems with accessing services. Geographical distribution of health care providers is a very important aspect in health disparities and should be investigated further. The link between higher household income and diagnosis of a child with autism is still unclear. Further studies should try to establish whether metropolitan status and other contextual characteristics determine the diagnosis and screening rates of children with ASD.

\section{STRENGTHS}

Both the studies represented the most recent estimates from the 2009 -2010 National Survey for Children with Special Health Care Needs (NS-CSHCN). The survey provides nationally representative data on specific measures for CSHCN outcomes. To the best of our knowledge, this was the first study of its kind, where we examined the differences between children with ASD, DD, and MHC. In addition, we examined the impact of state polices and health care workforce on caregiver reported access to care issues and family impact in one study. We also adjusted for relevant covariates at all stages of the analyses. 


\section{LIMITATIONS}

All the measures used in this observational study were caregiver reported and we used no clinical data or claims to assess the relationship between our predictors and outcomes. In addition, this was a cross-sectional study design, where we cannot infer causality for associations established. The first study was limited by the type of DD and MHC available in the survey and may not have accounted for other neurologic conditions. Also, the DD and MHC groups formed may have conditions that may not exactly fall into a single group and clinical relevance may be questioned. Such categorization has been used in a previous study by Nageswaran et al. (Nageswaran, Parish, Rose, \& Grady, 2011) using the 2005 NS-CSHCN in assessment of difficulty using services across different types of special conditions. For the second study, we ran a random intercept model which assessed the variations between states, but estimated a population average effect of state covariates and independent variables on outcome measures. Therefore, we cannot draw conclusion on whether the state health policy and healthcare workforce variables that we included in the model are responsible for the variation across states for our outcome measures. However, we have reported the variance accounted for by the model that explains the extent of variation between states when the model is fit. Outcomes measures in the study were adopted from the core outcomes designed by of the Maternal Child and Health Bureau and have been utilized in some other studies as well (Kogan et al., 2008b; (Nageswaran, Parish, Rose, \& Grady, 2011). However, the present study did not establish any validity or reliability of these measures. Therefore, replication of the study results may vary depending on the items used to define the outcome measures. 


\section{REFERENCES}

Althouse, L. A., \& Stockman, J. A. (2011). The pediatric workforce: An update on general pediatrics and pediatric subspecialties workforce data from the american board of pediatrics. The Journal of Pediatrics, 159(6), 1036-40.e3. doi:10.1016/j.jpeds.2011.07.043; 10.1016/j.jpeds.2011.07.043

Autism and Developmental Disabilities Monitoring Network Surveillance Year 2008 Principal Investigators, \& Centers for Disease Control and Prevention. (2012). Prevalence of autism spectrum disorders--autism and developmental disabilities monitoring network, 14 sites, united states, 2008. Morbidity and Mortality Weekly Report.Surveillance Summaries (Washington, D.C.: 2002), 61(3), 1-19.

Cavagnaro, A. T. (2008). Autistic spectrum disorders: Changes in the california caseload, an update june 1987 june 2007. (). Sacramento, CA: California Health and Human Services Agency.

Centers for Disease Control and Prevention (CDC). (2012a). Autism spectrum disorders: Treatment. Retrieved 4/15, 2013, from http://www.cdc.gov/ncbddd/autism/treatment.html

Centers for Disease Control and Prevention (CDC). (2012b). New data on autism spectrum disorders. Retrieved 3/6, 2013, from http://www.cdc.gov/features/countingautism/

Kogan, M. D., Strickland, B. B., Blumberg, S. J., Singh, G. K., Perrin, J. M., \& van Dyck, P.,C. (2008). A national profile of the health care experiences and family impact of autism spectrum disorder among children in the united states, 2005-2006. Pediatrics, 122(6), e1149-e1158.

Krauss, M. W., Gulley, S., Sciegaj, M., \& Wells, N. (2003). Access to specialty medical care for children with mental retardation, autism, and other special health care needs. Mental Retardation, 41(5), 329-339. doi:2

Liptak, G. S., Benzoni, L. B., Mruzek, D. W., Nolan, K. W., Thingvoll, M. A., Wade, C. M., \& Fryer, G. E. (2008). Disparities in diagnosis and access to health services for children with autism: Data from the national survey of children's health. Journal of Developmental and Behavioral Pediatrics : JDBP, 29(3), 152-160. doi:10.1097/DBP.0b013e318165c7a0; 10.1097/DBP.0b013e318165c7a0

Liptak, G. S., Orlando, M., Yingling, J. T., Theurer-Kaufman, K. L., Malay, D. P., Tompkins, L. A., \& Flynn, J. R. (2006). Satisfaction with primary health care received by families of children with developmental disabilities. Journal of Pediatric Health Care : Official Publication of National Association of Pediatric Nurse Associates \& Practitioners, 20(4), 245-252. doi:10.1016/j.pedhc.2005.12.008 
Marks, C., Hoffman, C., \& Paradise, J. (2009). The impact of medicaid and SCHIP on low income children's health. (Policy Brief). Washington DC: Kaiser Commission on Medicaid and Uninsured, Henry J. Kaiser Family Foundation.

Mauch, D., Pfefferle, S., Booker, C., Pustell, M., \& Levin, J. (2011). Report on state services to individuals with autism spectrum disorders (ASD). ( No. S-10 CMS-33 No. 2). Centers for Medicare \& Medicaid Services (CMS) ASD Services Project: Centers for Medicare \& Medicaid Services (CMS).

Nageswaran, S., Parish, S. L., Rose, R. A., \& Grady, M. D. (2011). Do children with developmental disabilities and mental health conditions have greater difficulty using health services than children with physical disorders? Maternal and Child Health Journal, 15(5), 634-641. doi:10.1007/s10995-010-0597-4; 10.1007/s10995-010-0597-4

Patient protection and affordable care act , Pub L. 111-148 (2010).

Warren, Z., Veenstra-VanderWeele, J., Stone, W., Bruzek, J. L., Nahmias, A. S., Foss-Feig, J. H., . . McPheeters, M. L. (April 2011). Therapies for children with autism spectrum disorders.. (Comparative Effectiveness Reviews no. 26 No. 11-EHC029-EF). Rockville (MD): Agency for Healthcare Research and Quality. doi:http://effectivehealthcare.ahrq.gov/ehc/products/106/651/Autism_Disorder_exec$\underline{\text { summ.pdf }}$ 